\title{
Programs for Computing Properties of Coastal-Trapped Waves and Wind-Driven Motions Over the Continental Shelf and Slope
}

-Second Edition-

\author{
by
}

Kenneth H. Brink

David C. Chapman

Woods Hole Oceanographic Institution

Woods Hole, Massachusetts 02543

June 1987

\section{Technical Report}

Funding was provided by the National Science Foundation under grant Number OCE 84-08563.

Reproduction in whole or in part is permitted for any putpose of the United States Government. This report should be cited as: Woods Hole Oceanog. Inst. Tech Rept., WHOI-87-24.

Approved for publication; distribution unlimited.

\section{Approved for Distribution:}

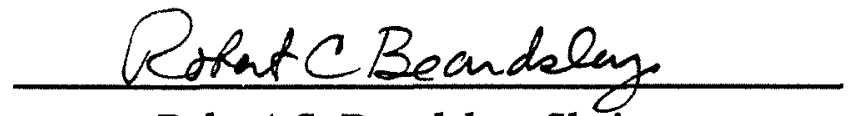

Robert C. Beardsley, Chairman Department of Physical Oceanography 
Abstract

Documentation and 1 istings are presented for a sequence of computer

programs to be used for problems in continental shelf dynamics. Three of the programs are to be used for computing properties of free and forced coastal-trapped waves. A final program may be used to compute wind-driven fluctuations over the continental shelf and slope. This second edition includes several minor revisions and corrections in the computer code and the documentation. 
In May 1987, we found that we had run out of copies of the original report. Rather than simply make more copies of the original report, we chose to create a revised version with a few improvements in the programs and in the documentation.

Only programs BTCSW and BIGLOAD2 have been modified, and most of the changes in these are either minor corrections or cosmetic improvements in the output. One set of changes in BTCSW will make a substantial difference in estimating the decay time for barotropic Kelvin waves. These corrections involve the statements

$$
\begin{aligned}
& \text { CALL LGWV --- (main program) } \\
& \text { SUBROUTINE LGWV -..- (subroutine LGWV) }
\end{aligned}
$$

and three lines following statement 220 in subroutine LGWV. In al1 cases, statements that have been changed from the original version are bracketed by $a$ line of 10 "C"s, e.g.

СCCCCCCCCC

$200 \mathrm{C}=\mathrm{WB} / \mathrm{RL}$

$\operatorname{CCCCCCCCCC~}$

in subroutine LGWV, program BTCSW.

Also, note that the line numbers for the program listings are now consecutive within each subroutine rather than for the entire 1isting.

As in the past, please feel free to contact either of us if programming bugs or inconsistencies should be detected. 
1. General Introduction 1

2. Barotropic Shelf Waves 5

3. Coasta1-Trapped Waves with Stratification and Topography

4. Near-Inertial Coasta1-Trapped Waves with Stratification and Topography

5. Wind-Driven Motions 32

Word of Caution 44

$\begin{array}{ll}\text { Acknowledgements } & 45\end{array}$

$\begin{array}{ll}\text { References } & 46\end{array}$

Program Listings

$\begin{array}{ll}\text { BTCSW } & 47\end{array}$

$\begin{array}{ll}\text { BIGLOAD2 } & 67\end{array}$

$\begin{array}{lr}\text { CROSS } & 89\end{array}$

$\begin{array}{ll}\text { BIGDRV2 } & 96\end{array}$ 


\section{CHAPTER 1}

GENERAL INTRODUCTION

In a recent sequence of papers (Brink, 1982a,b; Chapman, 1983; Clarke and Brink, 1985) a number of computer programs have been described which compute properties of linear coastal-trapped waves and wind-driven motions over the continental shelf. These programs, since they allow rather arbitrary choices of topography, stratification, etc., may be of fairly general use to the oceanographic community. For this reason, listings and documentation for these algorithms have been assembled here in an accessible form.

Some definitions are common to all of the following routines. Specifica 11y, we use the coordinate system shown in Figure 1, such that the coast (if present) lies at $x=0$ and the ocean in the region $x>0$. The alongshelf coordinate is $y$ and the vertical coordinate is $z$ (positive upwards), such that $z=0$ at the ocean surface. The $x, y$ and $z$ velocity components are then $u, v$ and $w$ respectively. Depth-integrated $u$ and $v$ velocities are defined as $U$ and $V$, respectively. Pressure and density are given as $p$ and $\rho$, respectively. A few other commonly used variables are $N^{2}, f, g, h, \omega$ and $\ell$, which represent the Brunt-Väisälä frequency squared, the Coriolis parameter, the acceleration due to gravity, the water depth, wave frequency and alongshelf wavenumber.

A few assumptions are common to all programs below. First, only linear problems are considered. Second, the water depth is always assumed to be a function of $x$ only. Third, the Brunt-Väisälä frequency may vary in $z$ only, and must be non-zero everywhere. The only exceptions are in computing barotropic continental shelf waves (program BTCSW, Chapter 2) where the problem is linearized and the Brunt-Väisälä frequency is not specified.

The general free-wave programs BTCSW and BIGLOAD2 (coastal-trapped waves with continuous stratification; Chapter 3) search for free-wave solutions using resonance iteration. The general approach is to assume that the dependent variables are sinusoidal in time and the alongshelf direction, e.g.

$$
U(x, y, t)=\hat{U}(x) \exp [i(\omega t+\ell y)],
$$



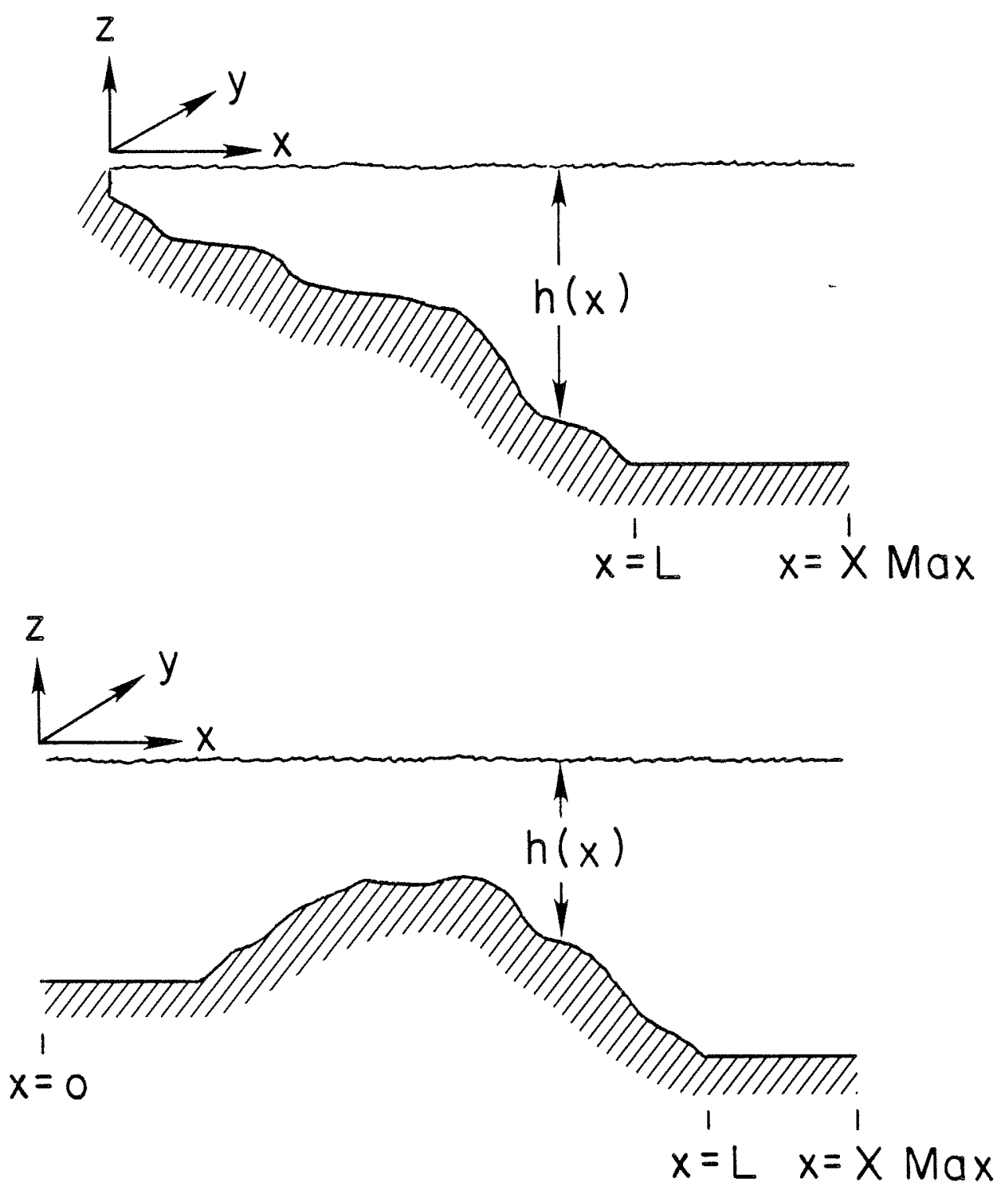

Figure 1: Topography and coordinate system definitions used in al1 programs: (upper) with a coast, (1ower) without a coast. 
reducing the problem to a two-dimensional eigenvalue problem in $(\omega, l)$ :

$$
\mathcal{Y}(\hat{U}(x ; w, \ell))=0
$$

This is solved for arbitrary forcing and a fixed $\ell$. The frequency $\omega$ is then varied until the free-mode resonance is reached. Resonance is defined as the frequency at which the integrated field variable squared,

$$
I_{v}=\int_{0}^{\infty} \hat{U}^{2} d x
$$

or

$$
I_{p}=\int_{0}^{\infty} \int_{-h}^{0} \hat{p}^{2} d z d x
$$

is at a maximum.

A few comments are in order about the workings of the programs. The units internal to a 11 programs are cgs, although input values are often in convenient units (e.g. km for $x$ ). The input file is always number 5 , and the output file number 6 . A11 programs are self-contained except for BIGLOAD2, which requires the use of IMSL subroutine LEQTIB. This subroutine is used to solve the banded matrix equation by $L-U$ decomposition.

The programs described below can be briefly summarized as follows:

1) BTCSW: barotropic continental shelf waves (e.g. Buchwald and Adams, 1968) and barotropic bank or trench waves (e.g. Brink, 1983; Mysak, LeB lond and Emery, 1979). Dispersion curves, modal structures, and wind coupling coefficients can be computed for arbitrary topography and mean alongshore flow.

2) BIGLOAD2: Coastal-trapped waves in the presence of continuous stratification (e.g. Wang and Mooers, 1976; Huthnance, 1978; Brink, 1982a,b). Dispersion curves (up to $\omega \cong 0.9 f$ ), modal structures and wind coupling coefficients can be computed for arbitrary topography and (horizontally uniform) stratification.

3) CROSS: Finding flat-bottom baroclinic modes and where $\omega=f$ for general coastal-trapped waves (Chapman, 1983). The program allows arbitrary stratification and monotonic bottom topography. 
4) BIGDRV2: Wind-driven motions over the continental margin (e.g. Clarke and Brink, 1985). The velocity, pressure and density fluctuations driven by a wind stress of the form $\hat{\tau}(x) \exp [i(\omega t+\ell y)]$ can be computed for general topography, stratification and bottom friction.

Finally, the user should be aware that programs BTCSW and CROSS require very little CPU time to complete, whereas program BIGLOAD2 uses approximately one minute of CPU time for each point on a dispersion curve and program BIGORV2 requires approximately one minute of CPU time to complete (both on a VAX 11/780). 


\section{CHAPTER 2 \\ BAROTROPIC SHELF WAVES \\ Documentation for BTCSW}

\section{A. Introduction}

This program computes modal structures and dispersion curves for free barotropic shelf waves. It can also compute bottom friction and wind coupling coefficients as in Brink and Allen (1978). Either a free surface or a rigid lid may be used, and a stable mean alongshelf flow can also be included. A variety of boundary conditions are available as options.

\section{B. Formulation}

For a linearized, inviscid barotropic ocean, the depth-integrated equations of motion are:

$$
\begin{aligned}
& \varepsilon U_{t}+\varepsilon v_{0} U_{y}-f V=-g h \zeta_{x}, \\
& v_{t}+v_{0} v_{y}+U v_{0 x}+f U=-g h \zeta_{y}, \\
& \delta \zeta_{t}+v_{0} \zeta_{y}+U_{x}+v_{y}=0,
\end{aligned}
$$

where the onshore; and alongshelf directions are $x$ and $y$, respectively, and there are no alongshe if variations in the mean flow $v_{0}(x)$ or in the depth $h$. $U$ and $V$ are the depth-integrated velocities in the $x$ and $y$ directions. The free surface elevation is $\zeta$, and subscripts $x, y$ and $t$ represent partial differentiation. The constants $g$ and $f$ are the acceleration due to gravity and the Coriolis parameter. The variables $\varepsilon$ and $\delta$ are defined as follows:

$$
\begin{aligned}
& \varepsilon=0 \text { for the long-wave approximation, } \\
& \varepsilon=1 \text { for general frequencies and wavenumbers, } \\
& \delta=0 \text { for the rigid-1id approximation, }
\end{aligned}
$$

and $\delta=1$ for a free surface.

With the assumption that $U, V$ and $\zeta$ vary as $\exp [i(\omega t+\ell y)]$, become 


$$
\begin{aligned}
& i \omega^{\prime} \varepsilon U-f V=-g h \zeta x \text {, } \\
& i \omega^{\prime} V+f^{\prime} U=-i \ell g h \zeta, \\
& i \omega^{\prime} \delta \zeta+U_{x}+i \ell V=0, \\
& \text { where } \quad \omega^{\prime}=\omega+\ell v_{0}
\end{aligned}
$$$$
\text { and } \quad f^{\prime}=f+v_{o x} \text {. }
$$

These can be reduced to either:

$$
\begin{aligned}
0= & U_{x x}\left[\delta \frac{\omega^{\prime 2}}{g}-h \ell^{2}\right] h \\
+ & U_{x}\left[h_{x} \ell^{2}-\frac{2 \omega^{\prime} \ell v_{o x^{\delta}}}{g}\right] h \\
+ & U\left[-\frac{\delta^{2} \omega^{\prime 2}}{g^{2}}\left(f f^{\prime}-\varepsilon \omega^{\prime 2}\right)+\varepsilon h^{2} \ell^{4}\right. \\
& +\frac{\delta}{g} h \ell^{2}\left(f f^{\prime}-2 \omega^{\prime 2} \varepsilon+2 f^{\prime} v_{o x}\right) \\
& \left.-\frac{h \ell^{3} f^{\prime} h_{x}}{\omega^{\prime}}-h \frac{\ell}{\omega^{\prime}} v_{o x x}\left(\delta \frac{\omega^{\prime 2}}{g}-h \ell^{2}\right)\right]
\end{aligned}
$$

or

$$
\begin{aligned}
0= & \zeta_{x x}\left[f f^{\prime}-\varepsilon \omega^{\prime 2}\right] h \\
+ & \zeta_{x}\left[\left(f f^{\prime}-\omega^{\prime 2} \varepsilon\right) h_{x}-h\left(f v_{o x x}-2 \omega^{\prime} \ell v_{o x} \varepsilon\right)\right] \\
+ & \zeta\left[-\frac{\delta}{g}\left(f f^{\prime}-\varepsilon \omega^{\prime 2}\right)^{2}+h_{x} \frac{f \ell}{\omega^{\prime}}\left(f f^{\prime}-\varepsilon \omega^{\prime 2}\right)\right. \\
& -h \frac{f \ell}{\omega^{\prime}}\left(f v_{o x x}-2 \varepsilon \omega^{\prime} \ell v_{o x}\right) \\
& \left.-h \ell^{2} \varepsilon\left(f f^{\prime}-\omega^{\prime 2} \varepsilon\right)\right] .
\end{aligned}
$$

6 
Each of these equations presents a practical difficulty. The $\zeta$ equation (2.3) possesses a spurious solution. For example, when $v_{0}=0$ this solution has $\omega=f$, and $\zeta=\zeta_{0} \exp (-\ell x)$. (See Pedlosky, 1979, pp. 79-81 for an explanation.) This spurious mode may, in turn, affect the true solutions. The $U$ equation (2.2) does not possess a spurious mode, but can lead to numerical difficulties for very shallow water (e.g. solving for a laboratory case where $\mathrm{h}<1 \mathrm{~m}$ everywhere). In general, it is preferable to use the $U$ equation, and to check it against the results of the $\zeta$ equation. The program allows the choice of the $U$ or $\zeta$ equation.

\section{Program Input}

As explained below, the user provides a bottom topographic profile, a mean flow profile (if desired), and choices for boundary conditions. The program returns modal structures for $U$ and $\zeta$, and frequencies for the prescribed wavenumbers. All outputs are in either cgs or arbitrary units, a though inputs are in convenient units. Two geometries are possible (Figure 1, p. 2). The first case (Figure 1a) contains a coastal barrier, while the second case (Figure 1b) does not. The second case is useful for bank- or trench-trapped waves. Note that $\omega>0$ is assumed, so that waves propagating in the positive $y$ direction (opposite to standard shelf waves in the northern hemisphere) must be found using $\ell<0$.

The following presentation of input parameters describes the user options. A compact list of parameters is given in section 2E. All data are read from file 5 .

line 1: IMDM NN

IMDM is the number of cases to be studied. If IMDM $\neq 1$, all of the other lines of input must be repeated for each case. This is useful if, for example, several geometries are to be studied in one run.

NN is the number of grid points in the $x$ direction. Presently, $N N \leq 100$, but this could be easily changed by the user. 
1ine 2: NITM ISD EPS DEL

These are all parameters used in the search for the resonant frequency. NITM is the maximum number of iterations allowed for finding a resonant frequency (typically 20-40).

ISD directs the frequency search.

For ISD $=0$, the program searches for the free-wave frequency closest to the initial guesses.

For ISD $=1$, the program searches only towards lower frequencies. For ISD $=-1$, the program searches only towards higher frequencies. EPS is the nominal fractional accuracy desired for $\omega$. This is always less than the true error range within which $\omega$ is known. Typically, EPS $=0.005$ ( 0.5 percent accuracy).

DEL is the fractional step size used for initially searching for w. Typically, DEL $=0.05$ (5 percent).

line 3: IUP ILLW

IUP provides the choice of searching with the $U$ or $\zeta$ equation (see section 2B).

IUP $=0$ specifies a search using $U$.

IUP $=1$ specifies a search using $\zeta$.

If some other value is given, the program defaults to IUP $=0$.

ILLW allows the option of making the long-wave approximation exactly.

ILLW $=0$ for long waves $(\varepsilon=0$ in section 28$)$.

ILLW $=1$ for the general case ( $\varepsilon=1$ in section $2 B$ ).

If some other value is given, the program defaults to ILLW $=0$.

Also, if ILLW $=0$, NCALM (see below) is set to 1 , since the waves

will be nondispersive.

line 4: IDD1 IDD3 IDD4

These parameters select the boundary conditions. IDD $1=0$ for a rigid lid $(\delta=0$ in section $2 B)$. $I D D 1=1$ for a free surface $(\delta=1$ in section $2 B)$. Other values set the default of IDDI $=0$. IDD3 = 0; the boundary condition at $x=X M A X$ is $U_{x}=0$. This is not the "real" condition, but is used for comparison with the stratified wave program (Chapter 3 ). 
IDD3 = 1; the boundary condition at $x=X M A X$ is $U=0$. This simulates

a channel problem.

IDD3 $=2$ sets up the real, exponentially decaying condition at $x=$ XMAX .

This is the preferred condition, but it is only valid if $h$ and $v_{0}$ are constant near $x=X M A X$.

If another choice is made for IDD3, the program reverts to $I D D 3=0$. IDD4 $=0$, the boundary condition at $x=0$ is $U_{x}=0$. This may be useful for bank or trench waves.

IDD4 $=1$ sets $U=0$ at $x=0$. This is the desired condition for shelf waves.

IDD4 $=2$ uses the exponential decay condition at $x=0$. This is again the preferred condition for bank or trench waves, but it is only valid for $h$ and $v_{0}$ constant at $x=0$ (geometry of Figure $1 b$ ).

Other values of IDD4 cause the program to revert to IDD4 $=1$, the shelf wave case.

1 ine 5: NCALM ILW

NCALM is the maximum number of $(w, l)$ pairs to be calculated for a given dispersion curve.

ILW provides an option on calculating parameters valid for the longwave limit. These will only be computed for the first ( $\omega, l)$ pair.

If $I L W=0$, then no long-wave parameters are computed.

If ILW $\neq 0$, then the "streamfunction" $\phi_{n}(x)$, wind-coupling coefficient $b_{n}$ and bottom drag coefficient $a_{n n}$ are computed. The definitions follow from Brink and Allen (1978).

For computation and conceptual reasons, these parameters will not be computed if either IDD4 $\neq 1$ or if $h(0)=0$, even if $I L W=1$. ILLW need not be set to 0 .

line 6: RLF DRL

These parameters define the wavenumbers for which $\omega$ is calculated. The wavenumbers used in the program will be:

$$
\ell=(R L F+(n-1) D R L) \times 10^{-8} \mathrm{~cm}^{-1}
$$

when $n$ represents the number of the $(\omega, l)$ pair on the dispersion curve. $n$ ranges from 1 to NCALM (see line 5 ). 
For example, if $R L F=0.5$ and $\mathrm{DRL}=1.0$, then the first wavenumber to be computed is $\ell=0.5 \times 10^{-8} \mathrm{~cm}^{-1}$ and the others will be $(1.5$, $2.5,3.5, \ldots) \times 10^{-8} \mathrm{~cm}^{-1}$.

line 7: IPC

If IPC $\neq 0$, then the program prints out modal structures as well as search information for each $(\omega, \ell)$ pair.

If $I P C=0$, then the modal structure is printed only for the first $(\omega, l)$ pair.

line 8: $F$ XMAX

$F$ is the Coriolis parameter, which is multiplied by $10^{-5}$ within the program. Thus, $F=7.5$ represents $f=7.5 \times 10^{-5} \mathrm{~s}^{-1}$.

XMAX is the distance (in $\mathrm{km}$ ) from $x=0$ to the offshore boundary of the grid (Figure 1). Typically, $X M A X \sim 2 L$, so that about one half of the domain has a flat bottom.

line 9: NRX

This is the number of $[x, h(x)]$ pairs to be input to define the bottom topography.

line 10 and following: $X H$

These are pairs of offshore distance $(x)$ in $\mathrm{km}$ and depth $(h)$ in $m$. These can be arbitrarily spaced, and the information is linearly interpolated to the grid points. The first pair must have $x=0$. For $x>$ (the last $x$ value read), depth is set to the last $h$ value read.

NRD

This is the number of $\left[x, v_{0}(x)\right]$ pairs to be input. If NRD $=0$, the program sets $v_{0}=0$ everywhere.

$X \quad V$

These are the NRD pairs of offshore distance $(x)$ in $\mathrm{km}$ and mean alongshelf velocity $\left(v_{0}\right)$ in $\mathrm{cm} / \mathrm{s}$. These can be arbitrarily spaced. For $x<$ (the first $x$ value read), the programs sets $v_{0}=0$. For $x>$ (the last $x$ value read), the program sets $v_{0}$ equal to the last $v_{0}$ value read. WW(1) WW(2) WW(3)

These are three initial guesses at the free-wave frequency $\omega$ for the first value of $\ell\left(=\operatorname{RLF} \times 10^{-8} \mathrm{~cm}^{-1}\right)$. The program multiplies $W W(I)$ by $10^{-5}$, so $W W(1)=0.5$ corresponds to $\omega=0.5 \times 10^{-5} \mathrm{~s}^{-1}$. 
NW

This is the number of $x$ (in $\mathrm{km}$ ) and friction weight function (WF, nondimensiona1) pairs to be input. This is useful for $x$ dependent bottom drag, i.e.

$$
E_{0}^{1 / 2}=E^{\prime} W F(x) \text {, }
$$

where $E_{0}$ is the Ekman number, $E^{\prime}$ is the Ekman number at $x=0$, and $W F(x)$ a weighting function such that $W F(0)=1$. If $N W=0$, then $W F(x)=1$ for all $x$ as in Brink and Allen (1978). If WF varies, then

$$
a_{n n}=\int_{0}^{L} W F(x)\left(\phi_{n x}(x)\right)^{2} d x,
$$

where $\phi_{n}$ is the streamfunction modal structure. $X \quad W F$

These are $[x($ in $\mathrm{km})$, WF (non-dimensional)] pairs to be input. The first pair must start at $x=0$. For $x>$ (last $x$ value read), WF is set to the last value read.

\section{General Comments}

i.) The program will work with $h=0$ at $x=0$ only in the $U$ equation mode. Thus, if $h(0)=0$, use IUP $=0$. Alternatively, $h(0)$ can be very small with either IUP $=0$ or 1 .

ii.) When the $\zeta$ equation is being used (e.g. IUP $=1$ ), there is a check for small diagonal elements in the finite-difference matrix equation. If a diagonal element is less than $10^{-36}$, a message is printed and the solution is omitted.

iii.) As a check of the $U_{x}$ boundary condition against the "real" boundary condition, calculations were run for $X M A X=2 L$, no mean flow and $n=1,2$. The worst error in $w$ was 3.6 percent for $n=1$, and the error decreased for large $l$. The $n=2$ longwave coefficients $\left(a_{22}\right.$ and $\left.b_{2}\right)$ varied substantially, however. The error in $b_{2}$ was about 50 percent. 
iv.) Identifying modes. The Kelvin wave mode will have no zero crossings of $\zeta$. The first shelf wave mode will have 1 zero crossing, the second 2, etc. The first shelf wave mode will have no sign changes in $U$, although $U=0$ at $x=0$. The second mode has one zero crossing, etc.

$v$.) When $v_{0} \neq 0$, the program checks for critical layers, and prints out the number of critical layers in the solution. Further, the program checks to see if the necessary condition for barotropic instability is satisfied. That is, if

$$
\left(\frac{f+v_{o x}}{h}\right)_{x}
$$

changes sign, a warning is given. 
E. Input Summary

The input file should include:

IMDM NN

NITM ISD EPS DEL

IUP ILLW

IDD1 IDD3 IDD4

NCALM ILW

RLF DRL

IPC

$F \quad$ XMAX

NRX

$X$

H

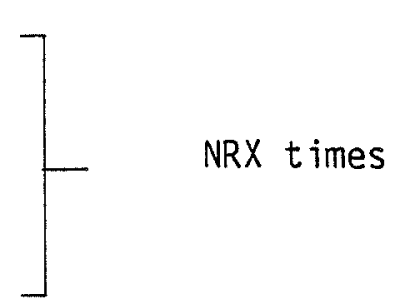

NRD

$X$

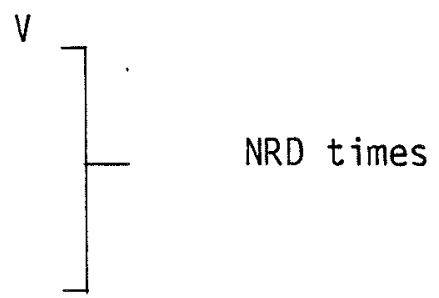

$W W(1) \quad W W(2) \quad W W(3)$

NW

$X$

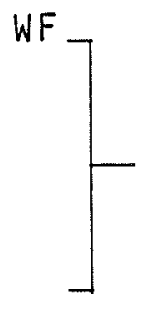

NW times

F. Program Output

The output (file 6 ) includes statements about which boundary conditions were used, and listings of $h(x), v_{0}(x), U_{n}(x), \zeta_{n}(x), W F(x)$ and $\phi_{n}(x)$. The functions of $x\left(h, v_{0}, U, \zeta, W F, \phi\right)$ are listed at $\Delta x$ increments across the 
page, beginning at $x=0$ and proceeding to $x=X M A X . \Delta x$ is given in the header information.

A11 units in the output are cgs, except for $U$ and $\zeta$ which are in arbitrary units. $\phi(x)$ is normalized as

$$
1=\int_{0}^{L} \frac{h_{x}}{h^{2}} \phi_{n}^{2} d x \text {, }
$$

so that $\phi$ has units of $\mathrm{cm}^{1 / 2}$.

The coefficients $b_{n}$ and $a_{n n}$ for $\phi_{n}$ are only strictly valid for $v_{0}=0$, and for a rigid 1id. Two different $a_{n n}, b_{n}$ pairs are given. The first (streamfunction) set is as defined in Brink and Allen (1978). The second analogous set is defined for the long-wave problem in terms of pressure. This is useful if there is a free surface, since the streamfunction is invalid. In this case

$$
p=\sum_{n} F_{n}(x) Y_{n}(y, t)
$$

where the free-wave modal structures $F_{n}(x)$ are orthogonal by

$$
\delta_{n m}=\left.\left(h F_{n m} F_{m}\right)\right|_{x=0}+\int_{0}^{\infty} h_{x} F_{n} F_{m} d x,
$$

and $Y_{n}$ obeys

$$
b_{n}^{\prime} \tau_{0}^{y}=Y_{n y}-\frac{1}{c_{n}} Y_{n t}-r_{0} \sum_{m} a_{n m}^{\prime} Y_{m}
$$

The program prints out $b_{n}{ }^{\prime}, a_{n n}{ }^{\prime}$ and the pressure normalized as above. The bottom stress is taken to have the form

$$
\tau_{B}^{y}=\operatorname{\rho r}_{O} W F(x) v
$$

where $W F$ is as above, $r_{0}$ is a bottom resistance coefficient in $\mathrm{cm} \mathrm{s} \mathrm{s}^{-1}$, and $\rho$ the fluid density. 
G. An Example Input File:

1100

$20 \quad 0$

$0.001 \quad 0.05$

$0 \quad 1$

$\begin{array}{lll}0 & 2 & 1\end{array}$

11

$1.0 \quad 1.0$

0

10.0400 .

3

0.10.

100. 150 .

200. 4000 .

3

0.0 .

50. 100 .

100. 0.

$\begin{array}{lll}0.5 & 0.52 & 0.54\end{array}$

0

The result is, after 14 iterations, $\omega=0.6867 \times 10^{-5} \mathrm{~s}^{-1}, \mathrm{a}_{11}=$ $0.19865 \times 10^{-7} \mathrm{~cm}^{-1}$ and $b_{1}=0.1428 \times 10^{-1} \mathrm{~cm}^{-1 / 2}$. This is the $n=1$ mode. 
CHAPTER 3

COASTAL-TRAPPED WAVES WITH STRATIFICATION AND TOPOGRAPHY

Documentation for BIGLOAD2

A. Introduction

This program calculates free-wave dispersion curves ( $\omega, l$ pairs) by resonance iteration, given input parameters including arbitrary bottom topography and stratification. Options include the choice of a free-surface or a rigid-lid boundary condition, and the inclusion of the component of planetary s perpendicular to the coast.

Note that this program uses an external (IMSL) subroutine in the solution procedure.

B. Formulation

The problem is formulated in the geometry of Figure 1a. Note that the depth at the coast $h(0)$ is non-zero, aithough it can be arbitrariiy smail. The governing equations are

$$
\begin{aligned}
\varepsilon u_{t}-f v & =-\frac{1}{\rho_{0}} p_{x} \\
v_{t}+f u & =-\frac{1}{\rho_{0}} p_{y} \\
0 & =-p_{z}-g \rho \\
u_{x}+v_{y}+w_{z} & =0
\end{aligned}
$$

and

$$
\rho_{t}+w \rho_{o z}=0 .
$$

The variables $u, v$ and $w$ are the velocity components in the $x, y$ and $z$ directions, respectively. The Coriolis parameter is $f$, the acceleration due to gravity is $g$, and the pressure is $p$. Density is defined by 


$$
\hat{\rho}(x, y, z, t)=\rho_{0}(z)+\rho(x, y, z, t) .
$$

The Boussinesq approximation is made throughout. Finaliy, subscripts $x, y, z$ and $t$ represent partial differentiation. The quantity $\varepsilon$ is set to either 0 (long-wave approximation) or 1 (general frequency and wavenumber).

All variables are taken to vary as $\exp [i(\omega t+\ell y)]$, so that equations (3.1) reduce to:

$$
0=p_{x x}+\frac{2 f \beta}{\left(f^{2}-\varepsilon \omega^{2}\right)} p_{x}-p\left[\varepsilon \ell^{2}+\frac{\ell \beta}{\omega}-\frac{2 f^{2} \beta \ell}{\omega\left(f^{2}-\varepsilon \omega^{2}\right)}\right]+\left(f^{2}-\varepsilon \omega^{2}\right)\left(\frac{p_{z}}{N^{2}}\right)_{z}
$$

subject to

$$
\begin{aligned}
p_{z}+\delta \frac{N^{2}}{g} p & =0 & \text { at } & z=0 \\
w+h_{x} u & =0 & \text { at } & =-h(x) \\
u & =0 & \text { at } x & =0
\end{aligned}
$$

and

$$
u_{x}=0 \quad \text { at } x=X \operatorname{MAX} .
$$

where $N$ is the Brunt-Väisälä frequency. The fourth boundary condition (Brink, 1982b) replaces the more desirable

$$
p \text { bounded as } x \rightarrow \infty \text {, }
$$

which is not very practical on a finite difference grid. The parameter $\delta$ is either 0 (rigid-1id surface) or 1 (free surface) at the user's discretion. Note that only the component of $\beta$ perpendicular to the coast has been included, so that $f=f_{0}-\beta x$. This means that if the land is north of the ocean, then $\beta>0$, while if the land is south of the ocean, then $\beta<0$. The component of $\beta$ parallel to the coast is not included because of the considerable complications involved.

The problem is solved by using the coordinate transformation

$$
\theta=\frac{z}{h(x)} \text {. }
$$


This maps the domain into a rectangle, where the problem is solved on a fixed 17 (vertical) by 25 (horizontal) point grid. Thus, vertical resolution is far better close to shore, in shallow water.

C. Program Input

The user must supply stratification, topography, the Coriolis parameter, and other information. The program then, after converging to a free wave solution, prints out frequency, wavenumber and the modal structure. A11 program outputs are either in arbitrary or cgs units.

The contents of the input file (file 5) are as follows.

line 1: EPS EST DD1.

EPS is the nominal fractional accuracy desired for the free-wave

frequency, i.e. $\Delta \omega / \omega$. The program stops searching when its next

frequency estimate agrees with the previous best estimate to this accuracy. Typically, EPS $=0.005$.

EST is the fractional initial search increment for w. Typically, EST = 0.05 .

DD1 determines whether there is a rigid 1 id $(D D 1=0$.$) or a free surface$ $(D D 1=1.0)$. This corresponds to the $\delta$ in section $3 B$.

1 ine 2: ICCM NCALM NITM ISD

ICCM is the number of dispersion curves to be calculated. If ICCM $\neq 1$, all of the remaining lines of input must be repeated for each dispersion curve.

NCALM is the number of $(\omega, \ell)$ pairs to be calculated along each dispersion curve.

NITM is the maximum number of iterations allowed for finding a single frequency on the dispersion curve. If NITM is exceeded, the program terminates.

ISD determines the direction of search for frequency.

If $I S D=0$, the program searches for the free-wave frequency closest to the initial guesses.

If $I S D=1$, the program searches only toward frequencies lower than the initial estimates.

If IDS $=-1$, the program searches only towards higher frequencies. 
line 3: $F$ XMAX

$F$ is the Coriolis parameter, which is multiplied by $10^{-5} \mathrm{~s}-1$ within the program. For example, $F=5$, represents $f_{0}=5 \times 10^{-5} \mathrm{~s}^{-1}$.

XMAX is the offshore extent of the grid in $\mathrm{km}$. Typically, XMAX $\sim 2 L$ (see Figure 1a).

line 4: BETA ILWW

BETA is the component of planetary $\beta$ perpendicular to the coast (see section 3B) entered in units of $\mathrm{s}^{-1} \mathrm{~cm}^{-1}$.

ILWW is $\varepsilon$ of section $3 B$.

If ILWW $=0$, the long-wave limit is taken exactly.

If $I L W W=1$, the program runs for general frequency and wavenumber.

If ILWW is not equal to 0 or 1 , the program terminates.

1 ine 5: NCAL, WH(1)

For a new dispersion curve, NCAL $=1$ and WH(1) is any number. When resuming an older curve which has been partially completed, NCAL = 2 and $W H(1)$ is the frequency of the last $\&$ of the previous run. This must correspond to RLF (see line 7). This information will allow better estimates at succeeding frequencies. Note that $\mathrm{WH}(1)$ is multip lied by $10^{-6} s^{-1}$, so that $W H(1)=0.5$ corresponds to $\omega=0.5 \mathrm{x}$ $10^{-6} s^{-1}$.

1 ine 6: IDIAG

If IDIAG $\neq 0$, then the $v, u$ and $\rho$ fields (as well as $p$ ) will be output for the first $(\omega, \ell)$ pair on the dispersion curve.

If IDIAG $=0$, then only $v$ (and of course $p$ ) will be output.

Regardless of IDIAG, only $p$ will be output for points after the first

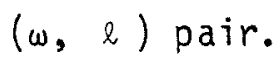

line 7: RLF DRL

These parameters determine the wavenumbers for which $\omega$ is computed. Specifically,

$$
\ell=(R L F+(n-1) D R L) \times 10^{-7} \mathrm{~cm}^{-1},
$$

for $n=1,2,3, \ldots$ NCALM.

line 8: WW(1) WW(2) WW(3)

These are three initial estimates of the free-wave frequency for the starting wavenumber. The program multiplies these values by $10^{-6} \mathrm{~s}^{-1}$, so a value of 0.5 corresponds to $\omega=0.5 \times 10^{-6} \mathrm{~s}^{-1}$. 
line 9: NRX

This is the number of $[x, h(x)]$ pairs to be input. NRX $\geq 1$ is required.

1 ine 10 and following: $X H$

These are values of offshore distance $(x)$ in $\mathrm{km}$ and water depth $(h)$ in $\mathrm{m}$.

There must be NRX pairs, and the first pair must have $x=0$. The spacing in $x$ is arbitrary, and the program fills out the topography by linear interpolation. For values of $x$ greater than the last value read, the program assigns the last depth read.

NR DZR ALPH

These are parameters used for reading the profile of $\mathrm{N}^{2}$ (the Brunt-

Väisälä frequency squared).

$N R$ is the number of $N^{2}$ values to be read.

OZR is the vertical spacing of $\mathrm{N}^{2}$ values in $\mathrm{m}$.

ALPH describes the exponential tail on the $\mathrm{N}^{2}$ profile. often $\mathrm{N}^{2}$

is not available from surface to bottom. In this case, an exponential extrapolation is used:

$$
\left.N^{2}=N_{0}^{2} \exp \left(\zeta_{0}-\zeta\right) / A L P H\right)
$$

where

$N_{0}^{2}$ is the last $N^{2}$ value read,

$\zeta_{0}$ is the depth of the last $N^{2}$ value read, and

$\zeta$ is the depth of the point, i.e. $\zeta=-z$.

ALPH is then the exponential length scale of $N^{2}$ decay, in $\mathrm{km}$.

CMLT

This is a conversion factor by which the input $N^{2}$ are multiplied in order to get units of $(\mathrm{rad} / \mathrm{s})^{2}$. Specifically,

$$
N^{2}\left(\operatorname{rad}^{2} / s^{2}\right)=C M L T \times N^{2} \text { (user units) }
$$

following lines: $N^{2}$

These are the values of $\mathrm{N}^{2}$ in user units, one per line. There must be NR regularly spaced values. The first $N^{2}$ value should be at $\mathrm{z}=0$, and $\mathrm{N}^{2}$ should never equal zero.

NRR

This is the number of $[x, r(x)]$ pairs to be input, where $r(x)$ is a bottom resistance coefficient in $\mathrm{cm} \mathrm{s}^{-1}$ defined by 


$$
\frac{1}{\rho_{0}} \underline{\tau}_{B}=r(x) \underline{v}(x,-h) \text {. }
$$

This information is used in subroutine LGWH for computing the bottom drag coefficient. $N R R \geq 1$ is required.

X R

These are the NRR pairs of offshore distance $(x)$ in $\mathrm{km}$ and bottom resistance coefficient $(r)$ in $\mathrm{cm} / \mathrm{s}$. The first $x$ value read must be zero. The $x$ spacing is arbitrary, and is filled out by linear interpolation. For values of $x$ greater than the last value read, the last value of $R$ will be used.

D. General Comments

i.) Identifying modes. Generally, the barotropic Kelvin wave $(n=0)$ wi11 have no zero crossings in pressure. The first coastal-trapped wave ( $n=1$ ) will have one zero crossing, etc. Occasionally, isolated small pockets of reversed sign in $p$ will exist, representing numerical error. These extraneous zero crossings are usually obvious when the modal structure is plotted.

ii.) The program does not generally work well when the shelf-slope width is small relative to the first internal Rossby radius of the deepocean. For such a case, the user should experiment to see if $\omega$ is stable with respect to small changes in XMAX.

iii.) Since the governing equation is formulated in terms of pressure, a spurious mode exists for $\beta=0$ and $\omega=f$. It has

$$
p=p_{0} e^{-\ell x}
$$

with $p_{z}=0$. (See Pedlosky, 1979, pp. 79-81 for more detail.) This mode makes the program's performance suspect near $\omega=f$.

iv.) For $w>f$, the inertia-gravity wave continuum is quantized by the offshore boundary condition, and the results are useless. The program will stop after three iterations if $\omega>f$ is sought. 
v.) The program has trouble finding the barotropic Kelvin wave.

vi.) The program uses a double precision external (IMSL) subroutine to solve the matrix equation.

vii.) Some users of this program may not have access to the IMSL package. In this case, subroutine BANDG from program BIGDRV2 can be modified to replace the IMSL routine LEQTIB.

Simply:

- replace

CALL LEQT1B ( AX,NM,NDD, NDD,NM, BX , 1, NM, 0, XL, IER)

in subroutine MATS with

CALL BANDG(AX,BX)

- transfer subroutine BANDG from BIGDRV2 into BIGLOAD2 and replace its fourth and fifth lines with

DOUBLE PRECISION A $(425,53), B B(425)$

DOUBLE PRECISION R. 
E. Input Summary

$\begin{array}{llll}\text { EPS } & \text { EST } & \text { DD1 } & \\ \text { ICCM } & \text { NCALM } & \text { NITM } & \text { ISD } \\ \text { F } & \text { XMAX } & & \\ \text { BETA } & \text { ILWW } & & \\ \text { NCAL } & \text { WH(1) } & & \\ \text { IDIAG } & & & \end{array}$

RLF DRL

WW(1) WW(2) WW (3)

NRX

$X$

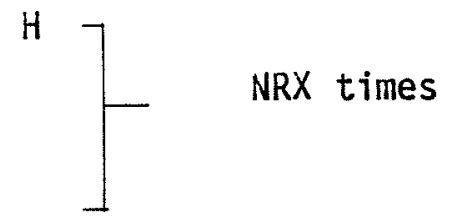

NR DZR ALPH

CMLT

$i^{2}$

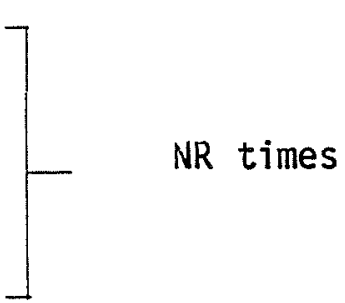

NRR

$X$

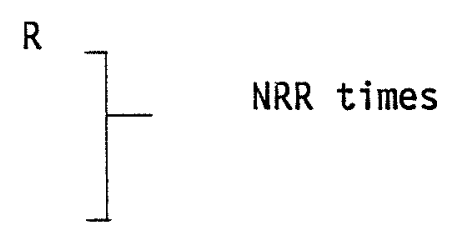

F. Program Output

The program first 1 ists the boundary conditions chosen, and a few parameters, such as $f$ and $\beta$.

Next, $N^{2}$ at $X=X M A X$ is 1 isted at grid point locations, starting at the bottom of the water column. (The first point is at $z=-h$, and the last at $z=0)$. The $\Delta z$ can be found in the pressure listing.

Then, information about the frequency search is listed. For each iteration, $\omega, \ell$ and $c=\omega / \ell$ are 1 isted, along with 


$$
R I=\int p^{2} d z d x
$$

a measure of resonance, and IER, an IMSL error code. A message announces convergence.

The $v$ (alongshelf velocity) field is listed, beginning at $x=0$. Total depth $(h)$ and depth increment (DZ) are given for each $x$. Then $v$ is listed, beginning at $z=-h$. The $v$ field is computed after $p$ has been normalized so that

$$
1=\left.\int_{-h}^{0} p^{2} d z\right|_{x=0}+\left.\int_{0}^{\infty} h_{x} p^{2} d x\right|_{z=-h} .
$$

The pressure field is also listed, and (optionally) $u$ and $\rho$. All units are consistent so that if $p$ were in dyne $/ \mathrm{cm}^{2}$, then $v$ would be in $\mathrm{cm} / \mathrm{s}$.

After the first ( $\omega, \ell)$ point on a dispersion curve, only $p$ will be listed, and in this case it is not normalized.

Immediately after the $v$ printout, $a_{n n}$ and $b_{n}$ are listed. (See Brink, 1982a.) This is an improved version due to Clarke and Van Gorder (1986). Finally, at various points in the output, the contributions of $u$ and $v$ to wave kinetic energy, and of $\rho$ and free-surface height to wave potential energy are given. These can be used to compute the diagnostic

$$
R=\frac{\text { kinetic energy }}{\text { potential energy }}
$$

This quantity approaches 1 for a baroclinic Kelvin-like wave, and becomes large (> 10) for a barotropic shelf wave. 
G. An Example

Input file:

0.0050 .050 .

$\begin{array}{llll}1 & 1 & 20 & 0\end{array}$

10.0200 .

0 . 0

10 .

0

$0.1 \quad 0.5$

$\begin{array}{lll}3.0 & 3.1 & 3.2\end{array}$

2

0.10 .

100.4000 .

25000 . 5.

1.0E-06

1.25

1.25

1

$0.0 \quad 0.05$

This represents a uniform $N^{2}$ and a uniformily sloping shelf. After six iterations, $w / l=312.49 \mathrm{~cm} / \mathrm{s}$ for the $n=1$ mode. The coupling coefficients are

$$
\begin{aligned}
& b_{n}=0.368 \times 10^{-2} \mathrm{~cm}^{-1 / 2} \\
& a_{n n}=0.18543 \times 10^{-8} \mathrm{~cm}^{-1} .
\end{aligned}
$$

This result can be compared to that obtained by Huthnance (1978) of $\omega / \ell=310 \mathrm{~cm} / \mathrm{s}$. Note that he had $h(0)=0$. 


\section{CHAPTER 4}

NEAR-INERTIAL COASTAL-TRAPPED WAVES WITH STRATIFICATION AND TOPOGRAPHY

Documentation for CROSS

A. Introduction

This program finds the wavenumbers (if any) at which the dispersion curves for free coastal-trapped waves approach $\omega=f$. Also determined is the lowest-order pressure field at $\omega=f$. Input parameters include arbitrary bottom topography and vertical stratification. Options include the choice of a free-surface or a rigid-lid boundary condition. The program is designed to be compatible with BIGLOAD2 (Chapter 3 ).

This program can also be used to find the vertical structures and phase speeds of flat-bottom baroclinic Kelvin waves for arbitrary vertical stratification.

\section{B. Formulation}

The solution procedure is based on the near-inertial analys is of Huthnance (1978, Section 6c, see also Chapman, 1983). For a coastal-trapped wave with frequency $\omega$ slightly less than $f$, i.e. $\omega=f(1-\gamma)$ where $\gamma \ll 1$, then the pressure may be assumed to take the form

$$
p=\left[p_{0}(z)+\gamma p_{1}(x, z)\right] e^{-\ell x}
$$

where $x$ is positive offshore, $z$ positive upwards and $l$ the alongshelf wavenumber. The topography is shown in Figure 1a. It can be shown that with these assumptions, the lowest order pressure field obeys

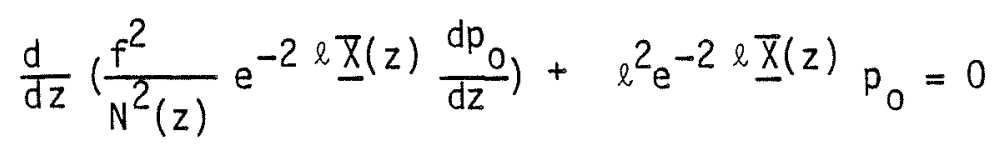

where $N^{2}(z)$ is the squared Brunt-Väisälä frequency, and $\underline{X}(z)$ is the inverse topography defined by $z=-h(\underline{\bar{X}})$ where $h$ is the depth. Note that the topography must be monotonic to be inverted uniquely. The program checks for this. Boundary conditions are 


$$
\begin{array}{ll}
\frac{d p_{0}}{d z}=0 & \text { at } z=-H \\
\frac{d p_{0}}{d z}+\frac{\delta N^{2}(0)}{g} p_{0}=0 & \text { at } z=0
\end{array}
$$

where $H$ is the maximum depth at $L<x<X M A X, g$ gravitational acceleration, and $\delta=1$ for a free surface or $\delta=0$ for a rigid lid. Thus, for known $f$, topography and stratification, equations $(4.1,4.2)$ can be solved to find the wavenumber $(s)$ a which $\omega=f$.

Solutions are found by a shooting technique in which (4.1) is represented in finite difference form and $(4.2 b)$ is assumed satisfied. Then $l$ is varied until the integration of (4.1) from $z=0$ to $z=-H$ results in a pressure distribution which satisfies $(4.2 a)$. The wavenumber $l$ is found to a relative fractional accuracy of $10^{-7}$.

C. Program Input

The user must supply such information as stratification, topography, the Coriolis parameter, etc. All program outputs are either in arbitrary or cgs units.

The contents of the input file (file 5) are as follows. They are designed to be similar to the contents of the input file used with BIGLOAD2.

1ine 1: NV DO1

$N V$ is the number of grid points (in the vertical) to be used in the solution. First, the topography is computed exactly as in BIGLOAD2 to obtain 25 depths. Then the topography between the coast and the flat bottom $(0<x<L)$ is filled with NV points by linear interpolation. The maximum NV is 101.

DD1 determines whether there is a rigid lid $(D D 1=0.0)$ or a free surface $(D D 1=1.0)$. This corresponds to $\delta$ in $(4.2 b)$.

\section{line 2: $F$ XMAX}

$F$ is the Coriolis parameter, which is multiplied by $10^{-5} \mathrm{~s}^{-1}$ within the program. Thus, $F=5.0$ corresponds to $f=5 . \times 10^{-5} \mathrm{~s}^{-1}$. 
XMAX is the offshore extent of the BIGLOAD2 grid in $\mathrm{km}$. It is used here only to insure that the original 25 depths (before interpolation) are computed as in BIGLOAD2.

1ine 3: NRX

This is the number of $[x, h(x)]$ pairs to be input. (NRX $\geq 1$ ). line 4 and following: $X H$

These are values of offshore distance $(x)$ in $\mathrm{km}$ and water depths $(h)$ in $m$. There must be NRX pairs, and the first pair must have $x=0$. The spacing in $x$ is arbitrary, and the program fills out the topography by linear interpolation. For values of $x$ greater than the last value read, the program assigns the last depth read.

NR DZR ALPH

These are parameters used for reading the profile of $\mathrm{N}^{2}$ (the BruntVäisälä frequency squared).

$N R$ is the number of $N^{2}$ values to be read. OZR is the vertical spacing of $\mathrm{N}^{2}$ values in $\mathrm{m}$. ALPH describes the exponential tail on the $\mathrm{N}^{2}$ profile. Often $\mathrm{N}^{2}$ is not available from surface to bottom. In this case, an exponential extrapolation is used:

$$
N^{2}=N_{0}^{2} \exp \left(\left(\zeta_{0}-\zeta\right) / A L P H\right)
$$

where

$\mathrm{N}_{0}^{2}$ is the last $\mathrm{N}^{2}$ value read, $\zeta_{0}$ is the depth of the last $N^{2}$ value read, and $\zeta$ is the depth of the point, i.e. $\zeta=-z$.

ALPH is then the exponential length scale of $\mathrm{N}^{2}$ decay, in $\mathrm{km}$.

CMLT

This is a conversion factor by which the input $N^{2}$ are multiplied in order to get units of $(\mathrm{rad} / \mathrm{s})^{2}$. Specifically,

$$
N^{2}\left(\operatorname{rad}^{2} / s^{2}\right)=\text { CMLT } \times N^{2} \text { (user units) }
$$

following lines: $N^{2}$ 
These are the values of $N^{2}$ in user units. There must be NR regularly spaced values. The first $N^{2}$ value should be at $z=0$, and $N^{2}$ should never equal zero.

NRS

This is the number of wavenumber searches to be made. For each search, an ( $l$ minimum, ' maximum, $\Delta l$ ) set is read. This allows several searches for the same mode or searches for several modes.

following lines: $\times 5 \times 6 \quad \times 7$

$x 5$ is the minimum $l$ to start the search

$x 6$ is the maximum $l$ to end the search

$X 7$ is the $\Delta l$ used to locate the solution.

The program multiplies these values by $10^{-7}$ to obtain $\mathrm{cm}^{-1}$. Thus, $(x 5, \times 6, X 7)=(2 ., 3 ., .1)$ corresponds to $\ell_{\min }=2 . \times 10^{-7} \mathrm{~cm}^{-1}$, $\ell_{\max }=3 . \times 10^{-7} \mathrm{~cm}^{-1}, \Delta \ell=0.1 \times 10^{-7} \mathrm{~cm}^{-1}$. The program then locates a root by shooting using $l=l_{\min }+n \Delta l \quad(n=0,1,2 \ldots)$ up to $l=l_{\max }$. If a root is located, Newton's method is used to home in on it. If no root is found between $\ell_{\min }$ and $l_{\max }$, then the search moves to the next choice for $\times 5, x 6, x 7$. There must be NRS sets of $\times 5, \times 6, \times 7$.

\section{General Comments}

i.) Identifying modes. The barotropic or Kelvin wave $(n=0)$ will have no zero crossings in pressure. It will exist only if a free surface is used $(D D 1=1.0)$. The first coastal-trapped wave $(n=1)$ will have one zero crossing, the second $(n=2)$ will have two, etc.

ii.) The program is probably best used when BIGLOAD2 predicts a dispersion curve which reaches $\omega \approx$.9f, above which BIGLOAD2 has problems. The BIGLOAD2 dispersion curve can be used to estimate the search parameters for CROSS. The same topography and stratification should be used in both. It may be dangerous to use CROSS if the dispersion curves are unknown, because they may never reach $\omega=$ $f$ and CROSS will only report that no root was found in the specific interval (i.e. CROSS cannot tell whether or not a dispersion curve ever reaches $\omega=f$, only whether or not it reaches $\omega=f$ in the specified interval). 
iii.) This program can find flat-bottom baroclinic Kelvin wave modal structures and phase speeds by using one depth and the desired stratification ( $N R X=1,[X, h]=[0,, H]$ ). Since Kelvin waves are nondispersive, the phase speed at $f$ is the same as at any other frequency.

iv.) If $X 5$ and $X 6$ are chosen such that two or more solutions for $\ell$ lie between the two values, then the program will only find one of the solutions.

E. Input Summary

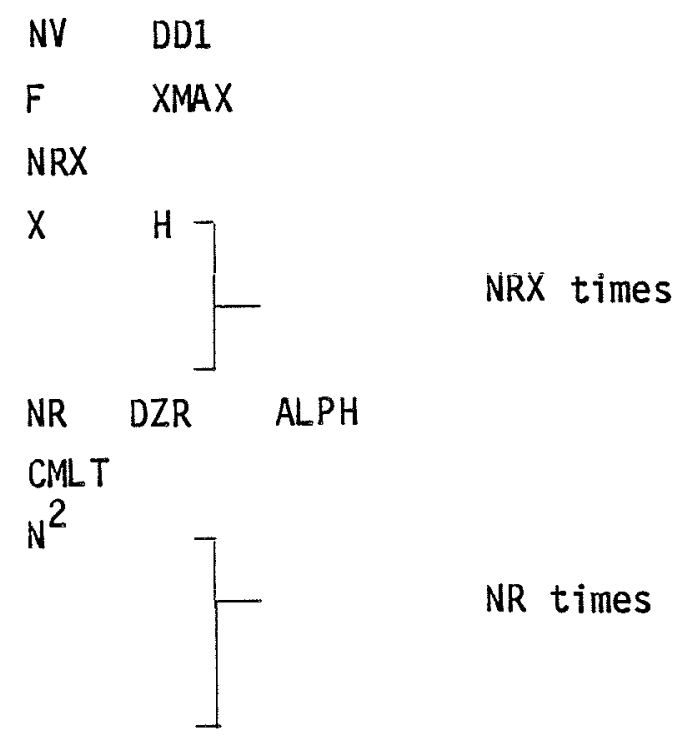

NRS

$\times 5 \times 6$

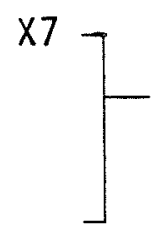

NRS times

F. Program Output

The program first lists the surface boundary condition chosen, and the parameters used ( $f, X M A X)$. Then $\Delta z$ is listed followed by the inverse topography at $z=-(n \Delta z)$ where $n=0,1,2 \ldots N V-1$. Next $N^{2}$ is 1isted also at $z=-(n \Delta z)$. 
For each search, if a solution is found, the wavenumber $\ell$ and phase speed $(f / \ell)$ are listed followed by the pressure structure $\left(p_{0} e^{-\ell x}\right)$ normalized by $\left(\int_{-H}^{0} p_{0}^{2} d z\right)^{1 / 2}$. The pressure is 1 isted at $z=-(n+1 / 2) \Delta z$ where $n=1,2,3 \ldots . . N V-1$. That is, the pressures are given midway between the topography grid points.

G. An Example

\begin{tabular}{|c|c|c|}
\hline 51 & & 0. \\
\hline 10. & & 200. \\
\hline 2 & & \\
\hline 0 & & 1. \\
\hline 100 & & 4000 \\
\hline 2 & & 5000 \\
\hline $1.0 E-6$ & & \\
\hline 56.25 & & \\
\hline 56.25 & & \\
\hline 2 & & \\
\hline 1. & 2. & .1 \\
\hline 2. & 3. & .1 \\
\hline
\end{tabular}

This represents a uniformly sloping shelf with uniform stratification. The analytical solution of $(4.1,4.2)$ is $\left.\quad \ell=\frac{n \pi}{L}\left[\left(\frac{N H}{f L}\right)^{2}-1\right)\right]^{-1 / 2}$ (Huthnance, 1978, p. 83) from which $\ell_{1}=1.11 \times 10^{-7} \mathrm{~cm}^{-1}, \ell_{2}=2.22 \times 10^{-7} \mathrm{~cm}^{-1}$. The values predicted by CROSS are $\ell_{1}=1.11 \times 10^{-7} \mathrm{~cm}^{-1}, \ell_{2}=2.22 \times 10^{-7} \mathrm{~cm}^{-1}$. 


\section{CHAPTER 5 \\ WIND-DRIVEN MOTIONS \\ Documentation for BIGDRV2}

\section{A. Introduction}

This program computes the velocity, pressure and density response of stratified shelf and slope waters to a time and space harmonic wind stress. Options include using

a) rigid lid or free surface,

b) "Tong wave" or general parameters,

c) alongshelf or cross-shelf winds.

The cross-shelf distributions of bottom resistance coefficient and of wind stress are at the user's discretion.

B. Formulation

The interior region (away from surface and bottom boundary layers) is described by the linear, inviscid equations:

$$
\begin{aligned}
\varepsilon u_{t}-f v & =\frac{-1}{\rho_{0}} p_{x} \\
v_{t}+f u & =\frac{-1}{\rho_{0}} p_{y} \\
0 & =-p_{z}-g \rho \\
u_{x}+v_{y}+w_{z} & =0 \\
0 & =\rho_{t}+w \rho_{o z} .
\end{aligned}
$$

The variables $u, v$ and $w$ are the velocity components in the $x, y$ and $z$ directions, respectively. The Coriolis parameter is $f$, the acceleration due to gravity is $g$, and the pressure is $p$. Density is defined by

$$
\hat{\rho}(x, y, z, t)=\rho_{0}(z)+\rho(x, y, z, t) .
$$


The Boussinesq approximation is made throughout. Finally, subscripts $x, y, z$ and $t$ represent partial differentiation. The quantity $\varepsilon$ is set to either 0 (1ong-wave approximation) or 1 (general frequency and wavenumber). Equations (5.1) can be reduced to a single field equation for pressure,

$$
0=p_{x x t}+\varepsilon p_{y y t}+\left(f^{2}+\varepsilon \frac{\partial^{2}}{\partial t^{2}}\right)\left(\frac{p}{N^{2}}\right)_{z t},
$$

where $N^{2}$ is the Brunt-Väisälä frequency squared.

The problem is solved by assuming wind stress in the form of

$$
\tau_{0}^{y}=T^{y}(x) \exp [i(\omega t+\ell y)] \text {, }
$$

or

$$
\tau_{0}^{x}=T^{x}(x) \exp [i(\omega t+\ell y)]
$$

and $a 11$ of the variables $(u, v, \rho, p)$ are assumed to have a similar $y$ and $t$ dependence. Given these assumptions, (5.2) reduces to

$$
0=p_{x x}-l^{2} \varepsilon p+\left(f^{2}-\varepsilon \omega^{2}\right)\left(\frac{p_{z}}{N^{2}}\right) \text {. }
$$

The boundary conditions are

$$
\begin{aligned}
& 0=w+h_{x} u+\left(f^{2}-\omega^{2}\right)^{-1}\left[-\left(f r v_{B}+i \omega r \varepsilon u_{B}\right)_{x}+\omega \ell \varepsilon r v_{B}+i \ell f \varepsilon r u_{B}\right] \\
& \text { at } z=-h(x) \text {, } \\
& 0=-\rho_{0} w+i \omega \delta g^{-1} p+\left(f^{2}-\varepsilon \omega^{2}\right)^{-1}\left[\left(i \omega \varepsilon T^{x}+f T^{y}\right)_{x}+\varepsilon \ell\left(-i f T^{x}-\omega T^{y}\right)\right] \\
& \text { at } z=0 \text {, } \\
& 0=u_{x} \\
& \text { at } x=X M A X \text {, }
\end{aligned}
$$

at $x=0$. 
The variables $u_{B}$ and $v_{B}$ are the interior velocities evaluated at the bottom:

$$
u_{B}=-i\left(f^{2}-\varepsilon \omega^{2}\right)^{-1}\left(\ell f p+\omega p_{x}\right) \mid z=-h
$$

and

$$
V_{B}=\left(f^{2}-\varepsilon \omega^{2}\right)^{-1}\left(f p_{x}+\varepsilon \omega \ell p\right) \mid z=-h .
$$

The parameter $\delta$ is either 0 (rigid-lid surface) or 1 (free surface) at the user's discretion. Implicit in $(5.4 a, b)$ is the assumption that the surface and bottom frictional boundary layers are infinitesimally thin. The offshore boundary condition, $(5.4 \mathrm{c})$ has been shown to be reasonably accurate for free coastal-trapped waves (Brink, 1982b), and is applied here as well.

The coastal boundary condition (5.4d) has been justified by $\mathrm{Clarke}$ and Brink (1985). It states that the net onshore transport (interior plus Ekman) sums to zero, with the further assumption that $u_{z} \cong 0$ at $x=0$. In practice, this appears to be reasonable. The work of Mitchum and Clarke (1986) suggests that the "coast" be placed such that

$$
h(0)=\frac{6 r(0)}{f} \text {, }
$$

where $r(x)$ is defined by

$$
\underline{I}_{B}=\rho_{0} \underline{r v}_{B} \text {. }
$$

The general problem defined by (5.3) and (5.4) reduces to that of $\mathrm{Clarke}$ and Brink (1985) when

$$
\begin{aligned}
\delta & =0 \\
\varepsilon & =0 \\
T^{x} & =0 \\
T_{x}{ }^{y} & =0 .
\end{aligned}
$$


Note that the cross-shelf component of wind stress only enters when the longwave assumption is not made. Our sensitivity studies suggest that the crossshelf wind stress is rarely an effective driving agency except near resonance with a coastal-trapped wave.

C. Program Input

The user provides an $\mathrm{N}^{2}$ profile, bottom topography information, choices of assumptions (e.g. rigid $1 \mathrm{id}$ ), the bottom resistance coefficient, wind stress profiles, $f, \omega$ and $\ell$. The program returns $v, u, o$ and $p$ in the form of amplitude and phase, as well as diagnostic information.

A full explanation of input is given here, and a compact listing in section 5E. All data are read from file 5 .

\section{1ine 1: ICCM}

This is the number of ( $w$, \& ) pairs for which the program will run. A11 other parameters stay the same for each run.

line 2: $F$ XMAX

$F$ is the Coriolis parameter, multiplied by $10^{-5} \mathrm{~s}^{-1}$ within the program. For example, $F=5$. represents $f=5 . \times 10^{-5} \mathrm{~s}^{-1}$.

XMAX is the offshore extent of the grid in $\mathrm{km}$. Typically, XMAX should be about twice the shelf-slope width.

\section{1ine 3: ILW IRL IXY}

ILW determines whether the long-wave assumption is made. It is $\varepsilon$ in section $5 B$.

If $I L W=1$, general frequency and wavenumber.

If ILW $=0$, long-wave $1 \mathrm{imit}$.

If ILW is neither 0 nor 1 , the program defaults to ILW $=0$.

IRL determines whether the rigid-lid assumption is made. It is $\delta$ in section $5 B$.

If $\mathrm{IRL}=1$, free surface.

If $I R L=0$, rigid lid.

If IRL is neither 0 nor 1 , the program defaults to $I R L=0$. 
IXY determines which wind stress component is used.

If IXY $=1$, cross-shelf $\left(T^{X}\right)$ winds.

If $I X Y=0$, a longshelf $\left(\mathrm{T}^{\mathrm{Y}}\right)$ winds.

If IXY is neither 0 nor 1 , the program defaults to IXY $=0$.

If the user sets $I X Y=1$ and ILW $=0$, the program automatically stops and prints out an error message.

line 4: NRX

This is the number of $[x, h(x)]$ pairs to be input. $50 \geq N R X \geq 1$ is required.

line 5 and following: $X H$

These are the values of offshore distance $(x)$ in $\mathrm{km}$ and water depth

(h) in $\mathrm{m}$. There must be NRX pairs, and the first pair must have $x=0$.

The spacing in $x$ is arbitrary, and the program fills out the topography by linear interpolation. For values of $x$ greater than the last value read, the program assigns the last depth read.

NR DZR ALPH

These are parameters used for reading the profile of $\mathrm{N}^{2}$ (the BruntVäisälä frequency squared).

$N R$ is the vertical spacing of $N^{2}$ values to be read.

$D Z R$ is the vertical spacing of $\mathrm{N}^{2}$ values in $\mathrm{m}$.

ALPH describes the exponential tail of the $N^{2}$ profile. Often $N^{2}$

is not available from surface to bottom. In this case, an exponential

extrapolation is used:

where

$$
N^{2}=N_{0}^{2} \exp \left(\left(\zeta_{0}-\zeta\right) / A L P H\right)
$$

$\mathrm{N}_{0}^{2}$ is the last $\mathrm{N}^{2}$ value read,

$\zeta_{0}$ is the depth of the last $N^{2}$ value read, and

$\zeta$ is the depth of the point, i.e. $\zeta=-z$.

ALPH is then the exponential length scale of $N^{2}$ decay, in $\mathrm{km}$.

CMLT

This is a conversion factor by which the input $N^{2}$ are multiplied in order to get units of $(\mathrm{rad} / \mathrm{s})^{2}$. Specifically,

$$
N^{2}\left(\operatorname{rad}^{2} / \mathrm{s}^{2}\right)=C M L T \times N^{2} \text { (user units). }
$$


following lines: $N^{2}$

These are the values of $\mathrm{N}^{2}$ in user units, one per line. There must be NR regularly spaced values. The first $N^{2}$ value should be at $z=0$, and $\mathrm{N}^{2}$ should never equal zero.

$\mathrm{NF}$

This is the number of $[x, r(x)]$ pairs to be read. NF $\geq 1$ is required. The format for reading the bottom resistance coefficient $r$ is exactly like that for depth $h$.

following lines: $X \quad R$

These are values of offshore distance $(x)$ in $\mathrm{km}$ and of the resistance coefficient $(r)$ in $\mathrm{cm} / \mathrm{s}$. There must be NF pairs, and the first pair must have $x=0$. The spacing in $x$ is arbitrary, and the program fills out $r$ by linear interpolation. For values of $x$ greater than the last value read, the program assigns the last $r$ value read.

NW

This is the number of values of $T(x)$ to be read. Whether it is $T^{x}$ or $T^{y}$ depends upon the choice of IXY in line 3. If $N W=0, T=1$ dyne $/ \mathrm{cm}^{2}$ for all $x$.

following lines: $X T$

These are values of offshore distance $(x)$ in $\mathrm{km}$ and wind stress amplitude in dyne $/ \mathrm{cm}^{2}$. If $N W=0$, these lines should not be inserted. The first pair must be for $x=0$. The $x$ spacing is arbitrary, and the program fills out the wind stress by linear interpolation. For values of $x$ greater than the last value read, the program assigns the last wind stress read.

following lines: W RL

These are the frequency, wavenumber $(\omega, \ell)$ pairs for which the program runs. There should be ICCM lines. Units are $\mathrm{s}^{-1}$ and $\mathrm{cm}^{-1}$ respectively. The program includes no internal multiplications for these parameters. 
D. General Comments

i.) Using $r=0$ results in a divide by zero. Thus, inviscid problems should not be attempted.

ii.) Using $\ell=0$ causes no problem until the program is about to print the last values of pressure. An error message will result, but there is nothing wrong with the program's output, which is virtually complete.

iii.) No external subroutines are required.

iv.) The program uses the same $25 \times 17$ stretched grid as in BIGLOAD2. 


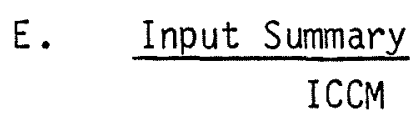

ILW IRL IXY

NRX

$x$

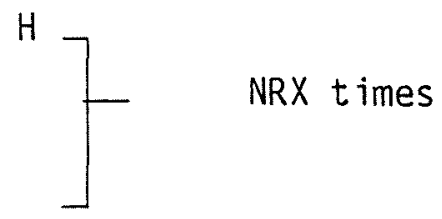

NR DZR ALPH

CMLT

$\mathrm{N}^{2}$

$x$

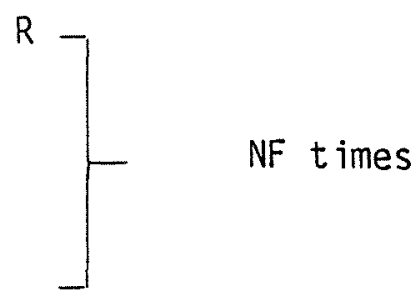

NW

$x$

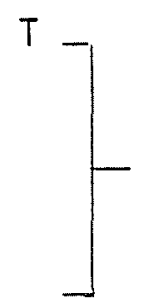

NW times

W

IL ICCM times 


\section{F. Program Output}

The program first lists $f$ and XMAX in $\mathrm{s}^{-1}$ and $\mathrm{cm}$ respectively. The assumptions chosen on 1 ine 3 of input are then stated.

Input functions are then listed:

i.) $N^{2}(\mathrm{rad} / \mathrm{s})^{2}$ at $x=X M A X$, beginning at $z=-h$ up to $z=0$ in increments of $\Delta z$ at $x=X \operatorname{MAX}$ (i.e. $h(X M A X) / 16$ ).

ii.) $r(x)(\mathrm{cm} / \mathrm{s})$, beginning at $x=0$ out to $x=X M A X$ in increments of $\Delta x$ (i.e. $X \operatorname{MAX} / 24)$.

iii.) $T(x)\left(\right.$ dyne $\left./ \mathrm{cm}^{2}\right)$ in the same format as $r(x)$.

Following this, the program prints out $\omega\left(\mathrm{s}^{-1}\right)$ and $\ell\left(\mathrm{cm}^{-1}\right)$, and the results for this particular input pair. All field variables $(v, u, \rho, p)$ are listed as amplitude and phase at each grid point, beginning at the bottom for each $x$. For each $x$, water depth $h(\mathrm{~cm})$ and $\Delta x(\mathrm{~cm})$ are also given. The phase is negative for wind leading the response. The field variables are:

iv.) $v(\mathrm{~cm} / \mathrm{s})$, followed by the $v$ contribution to kinetic energy per unit length of coast $(\mathrm{erg} / \mathrm{cm})$, and the alongshelf bottom stress beginning at $x=0\left(\right.$ dyne $\left./ \mathrm{cm}^{2}\right)$.

v.) $u(\mathrm{~cm} / \mathrm{s})$, followed by the $u$ contribution to kinetic energy per unit length of coast $(\mathrm{erg} / \mathrm{cm})$.

vi.) $\rho\left(\sigma_{t}\right.$ units), followed by the $\rho$ contribution to fluctuating potential energy per unit length of coast ( $\mathrm{erg} / \mathrm{cm})$. This is followed immediately by the free-surface height contribution to fluctuating potential energy. The free-surface contribution is set to zero if a rigid lid is imposed. At this point, the total (kinetic plus potential) fluctuating energy per unit length of coast $(\mathrm{erg} / \mathrm{cm})$ is given, along with the ratio of kinetic to potential energy $R$ (Brink, 1982b). For $R \geq 10$, the response is generally highly barotropic, and for $R \hat{\imath}$, it can be regarded as very baroclinic.

vii.) p (dyne $\left./ \mathrm{cm}^{2}\right)$. 
G. An Example

1

10.0200 .

110

2

0. 30 .

100. 4000 .

25000.5 .

$1.0 \mathrm{E}-06$

1.375

1.375

1

$0.0 \quad 0.05$

0

$\begin{array}{ll}1.0 \mathrm{E}-05 & 2.0 \mathrm{E}-08\end{array}$

The resulting output has the following energy components :

$v \rightarrow 2.94 \times 10^{14} \mathrm{erg} / \mathrm{cm}$

$u \rightarrow 0.08 \times 10^{14} \mathrm{erg} / \mathrm{cm}$

$\rho \rightarrow 0.31 \times 10^{14} \mathrm{erg} / \mathrm{cm}$

$p \rightarrow 0.45 \times 10^{12} \mathrm{erg} / \mathrm{cm}$

and $R=9.6$.

The alongshelf velocity (Figure 2) is uniform in depth at $x=0$ at $34.2 \mathrm{~cm} / \mathrm{s}$ and a phase of $-9^{\circ}$. The $v$ maximum is at the surface at $x=8.33 \mathrm{~km}$ $\left(85,-48^{\circ}\right)$.

The cross-shelf velocity is depth-independent at $x=0\left(2.5,-21^{\circ}\right)$, and has a maximum at the surface at $x=8.33 \mathrm{~km}\left(6.6,-136^{\circ}\right)$.

The maximum in density is at the bottom at $x=8.33 \mathrm{~km}$ with $\rho=0.032 \sigma_{t}$ and a phase of $-39^{\circ}$. Density goes nearly to zero at the surface, and its phase is consequently unreliable there. When a rigid lid is used and $N W=0$, density fluctuations are zero at the free surface in the long-wave limit. 


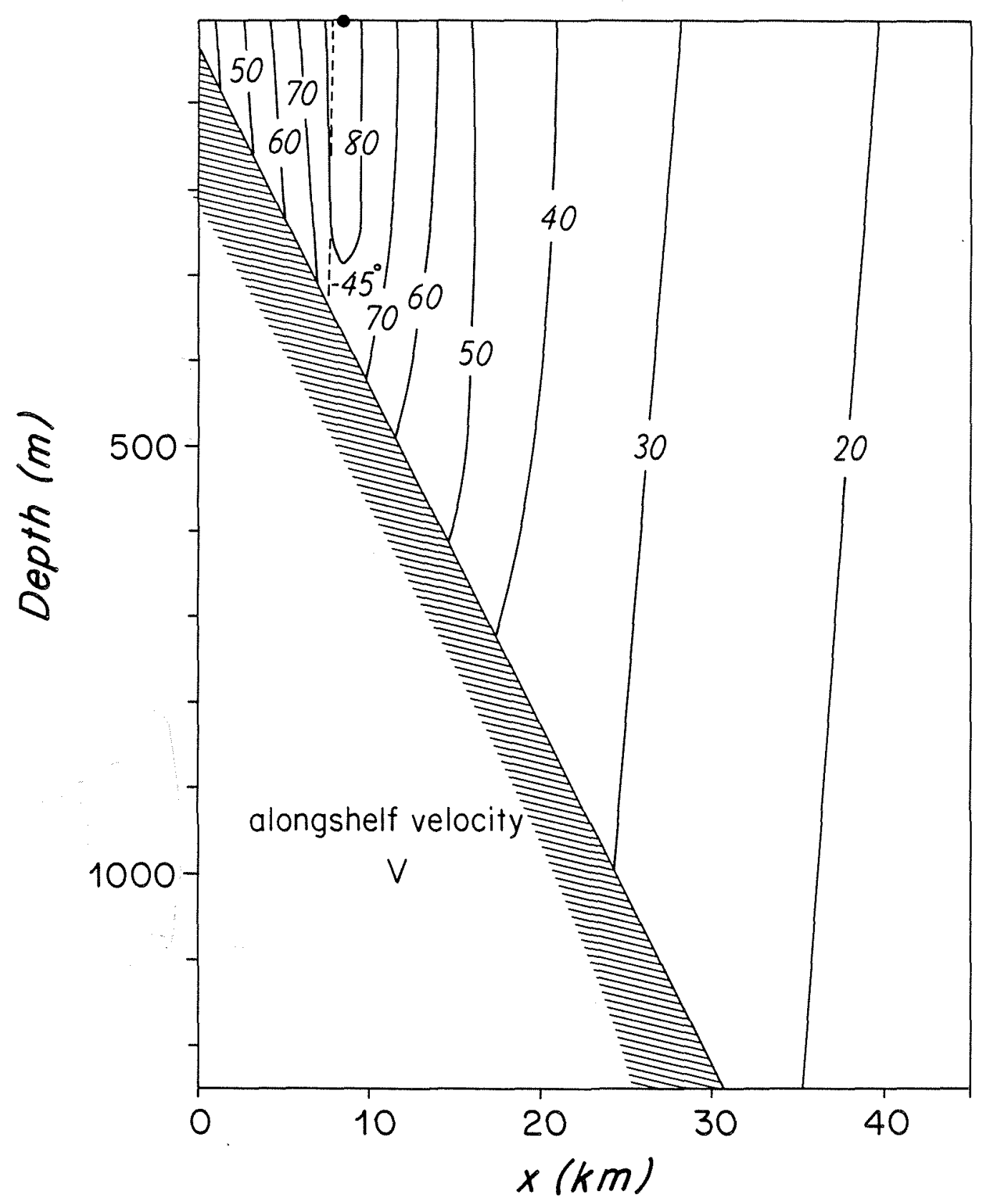

Figure 2: Alongshelf velocity for the example in section 5G. Amplitude $(\mathrm{cm} / \mathrm{s})$ is shown in solid lines and phase is shown by dashed contours. Only the upper $1250 \mathrm{~m}$ is shown. 
The pressure is depth-independent and at a maximum at $x=0(0.190 x$ $10^{5}$ dyne $/ \mathrm{cm}^{2}$, phase $\left.=131^{\circ}\right)$. To get sea level, divide by $\mathrm{g}=981 \mathrm{~cm} / \mathrm{s}^{2}$ to obtain $19 \mathrm{~cm}$.

All fields become weaker far offshore and at great depth. The $v$ and $p$ fields have a roughly $180^{\circ}$ phase change far offshore. The strength and structure of response vary radically near $(\omega, \ell)$ resonances with free coastaltrapped waves. 


\section{Word of Caution}

We have performed what we feel are extensive tests with all of the programs contained herein. However, we cannot guarantee that the programs will give sensible results in all situations. That is, it may be possible to find parameter combinations for which a program will complete the run, but the computed results will not make physical sense. Therefore, we cannot be responsible for the ways in which the programs are applied. On the other hand, if actual programming bugs or inconsistencies appear which are not mentioned in this document, please contact us with the details. 
Acknowledgements

We thank the many people who helped us with these programs, both in setting up the original efforts, and by their comments as users.

This work was supported by National Science Foundation (NSF) grant OCE84-08563. The publication of the second edition was supported by National Science Foundation (NSF) grant OCE84-17769. 


\section{REFERENCES}

Brink, K. H., 1982a. The effect of bottom friction on low-frequency coastal trapped waves. Journal of Physical Oceanography, 12, 127-133.

Brink, K. H., 1982b. A comparison of long coastal trapped wave theory with observations off Peru. Journal of Physical 0ceanography, 12, 897-913.

Brink, K. H., 1983. Low-frequency free wave and wind-driven motions over a submarine bank. Journal of Physical Oceanography, 13, 103-116.

Brink, K. H. and J. S. Allen, 1978. On the effect of bottom friction on barotropic motion over the continental shelf. Journal of Physical Oceanography, 8 , 919-922.

Buchwald, V. T. and J. K. Adams, 1968. The propagation of continental shelf waves. Proceedings of the Royal Society of London, A305, 235-250.

Chapman, D. C., 1983. On the influence of stratification and continental shelf and slope topography on the dispersion of subinertial coastally trapped waves. Journal of Physical Oceanography, 13, 1641-1652.

Clarke, A. J. and K. H. Brink, 1985. The response of stratified, frictional shelf and slope waters to fluctuating large-scale, low-frequency wind forcing. Journal of Physical Oceanography, 15, 439-453.

$\mathrm{C}$ larke, A. J. and S. Van Gorder, 1986. A method for estimating wind-driven, time-dependent, stratified shelf and slope water flow. Journal of Physical Oceanography, 16, 1013-1028.

Huthnance, J.M., 1978. On coastal trapped waves: analysis and numerical calculation by inverse iteration. Journal of Physical Oceanography, $\underline{8}$, 74-92.

Mitchum, G. T. and A. J. Clarke, 1986. The frictional nearshore response to forcing by synoptic scale winds. Journal of Physical Oceanography, 16, 934-946.

Mysak, L. A., P. M. LeB lond and W. J. Emery, 1979. Trench waves. Journal of Physical 0ceanography, 9, 1001-1013.

Pedlosky, J., 1979. Geophysical Fluid Dynamics. Springer-Verlag, New York, 624 pp.

Wang, D-P. and C. N. K. Mooers, 1976. Coastal trapped waves in a continuously stratified ocean. Journal of Physical 0ceanography, $\underline{6}, 853-863$. 


\section{Program BTCSW Listing}

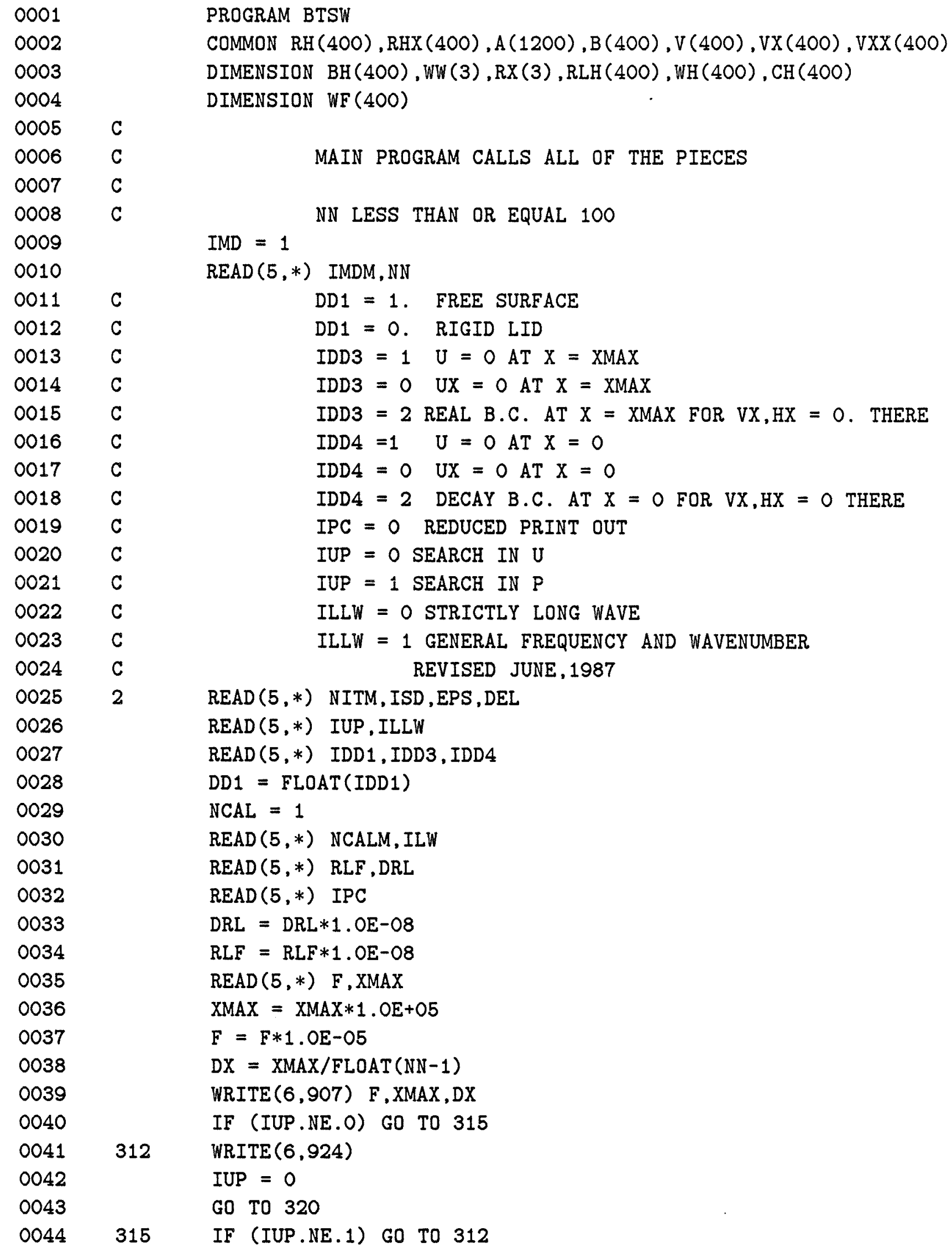




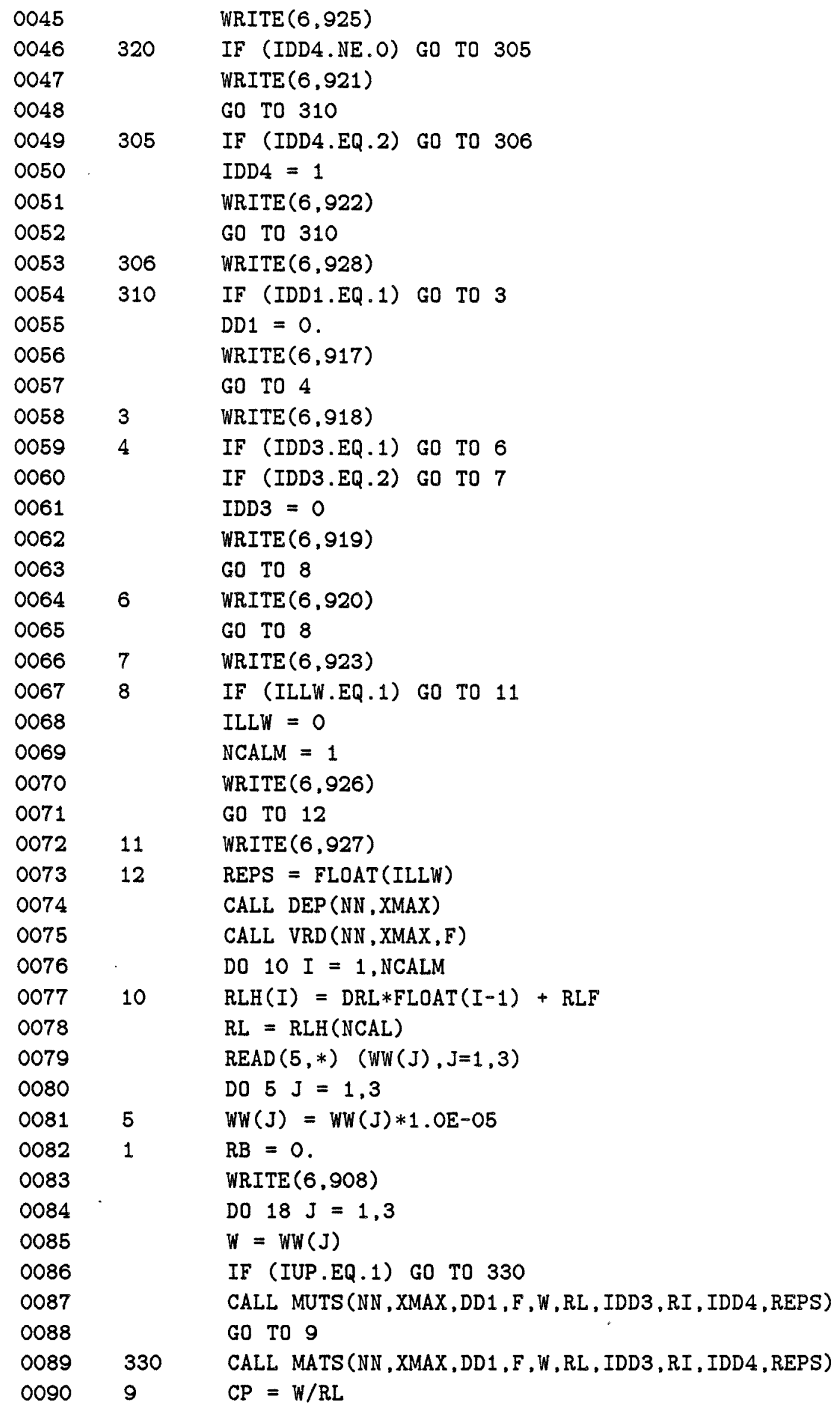




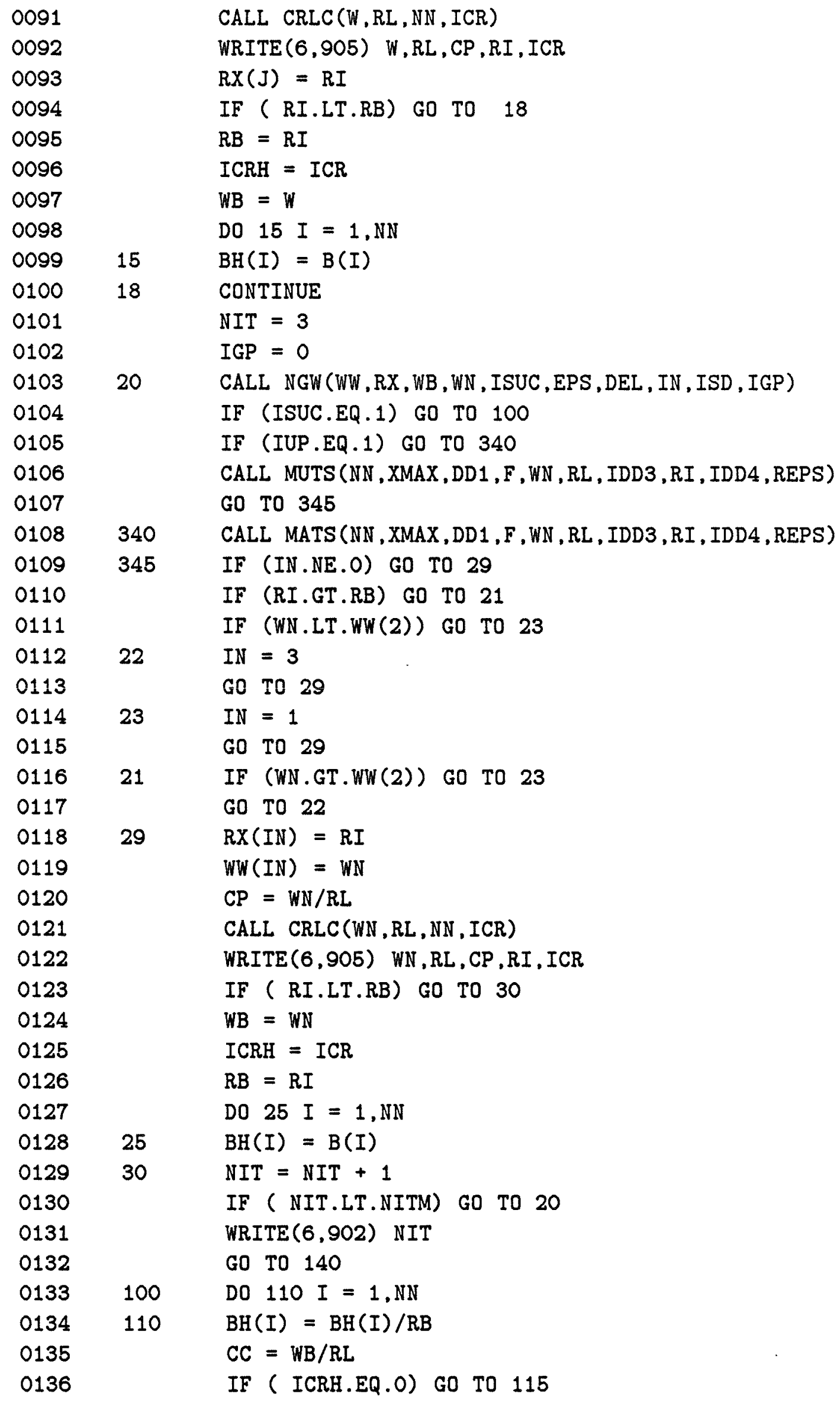

0091

0092

0093

0094

0095

0096

0097

0098

0099

0100

0101

0102

0103

0104

0105

0106

0107

0108

0109

0110

0111

0112

0113

0114

0115

0116

0117

0118

0119

0120

0121

0122

0123

0124

0125

0126

0127

0128

0129

0130

0131

0132

0133

0134

0135

0136

CALL CRLC (W, RL, NN, ICR)

WRITE $(6,905)$ W,RL, CP, RI, ICR

$\mathrm{RX}(\mathrm{J})=\mathrm{RI}$

IF ( RI.LT.RB) GO TO 18

$\mathrm{RB}=\mathrm{RI}$

$I C R H=I C R$

$W B=W$

DO $15 \mathrm{I}=1, \mathrm{NN}$

$B H(I)=B(I)$

CONTINUE

$N I T=3$

$I G P=0$

20 CALL NGW (WW , RX, WB, WN, ISUC , EPS , DEL , IN, ISD , IGP)

IF (ISUC.EQ.1) GO TO 100

IF (IUP.EQ.1) GO TO 340

CALL MUTS (NN, XMAX,DD1 , F, WN, RL, IDD3 , RI, IDD4 , REPS)

GO TO 345

340

CALL MATS (NN , XMAX, DD 1, F, WN, RL, IDD3 , RI, IDD4, REPS)

345

IF (IN.NE.O) GO TO 29

IF (RI.GT.RB) GO TO 21

IF (WN.LT.WW(2)) GO TO 23

$22 \quad$ IN $=3$

GO TO 29

23 IN $=1$

GO TO 29

21 IF (WN.GT.WW(2)) GO TO 23

GO TO 22

29

$\mathrm{RX}(\mathrm{IN})=\mathrm{RI}$

$W W(I N)=W N$

$\mathrm{CP}=W N / \mathrm{RL}$

CALL CRLC (WN, RL, NN, ICR)

WRITE $(6,905)$ WN, RL, CP,RI,ICR

IF ( RI.LT.RB) GO TO 30

$W B=W N$

ICRH $=$ ICR

$\mathrm{RB}=\mathrm{RI}$

DO $25 \mathrm{I}=1, \mathrm{NN}$

25

$\mathrm{BH}(I)=\mathrm{B}(\mathrm{I})$

$N I T=N I T+1$

IF (NIT.LT.NITM) GO TO 20

WRITE $(6,902)$ NIT

GO TO 140

100

DO $110 I=1, \mathrm{NN}$

$\mathrm{BH}(I)=\mathrm{BH}(I) / \mathrm{RB}$

$\mathrm{CC}=W B / \mathrm{RL}$

IF ( ICRH.EQ.O) GO TO 115 


\begin{tabular}{|c|c|c|}
\hline 0137 & & WRITE $(6,911)$ ICRH \\
\hline 0138 & 115 & WRITE (6,903) WB, RL, CC,EPS,DX,NIT \\
\hline 0139 & & IF (NCAL.EQ.1) GO TO 120 \\
\hline 0140 & & IF (IPC.EQ.0) GO TO 150 \\
\hline 0141 & 120 & IF (IUP.EQ.1) GO TO 350 \\
\hline 0142 & & WRITE $(6,913)$ \\
\hline 0143 & & GO TO 360 \\
\hline 0144 & 350 & WRITE $(6,912)$ \\
\hline 0145 & 360 & $\operatorname{WRITE}(6,904) \quad(\mathrm{BH}(I), I=1, \mathrm{NN})$ \\
\hline 0146 & & IF (IUP.EQ.O) GO TO 135 \\
\hline 0147 & & CALL MUTS (NN , XMAX, DD1, F, WB , RL, IDD3, RI, IDD4, REPS) \\
\hline 0148 & & DO $143 I=1, N N$ \\
\hline 0149 & 143 & $B(I)=B(I) / R I$ \\
\hline 0150 & & WRITE $(6,913)$ \\
\hline 0151 & & $\operatorname{WRITE}(6,904) \quad(B(I), I=1, N N)$ \\
\hline 0152 & 135 & IF (RH(1).EQ.0.0) GO TO 150 \\
\hline 0153 & & CALL MATS (NN, XMAX,DD1,F,WB, RL, IDD3, RI, IDD4, REPS) \\
\hline 0154 & & DO $130 I=1, N N$ \\
\hline 0155 & 130 & $B(I)=B(I) / R I$ \\
\hline 0156 & & IF (IUP.EQ.1) GO TO 145 \\
\hline 0157 & & WRITE $(6,912)$ \\
\hline 0158 & & $\operatorname{WRITE}(6,904) \quad(B(I), I=1, N N)$ \\
\hline 0159 & 145 & IF (ILW.EQ.O) GO TO 150 \\
\hline 0160 & & IF (NCAL.NE.1) GO TO 150 \\
\hline 0161 & & IF ( RH(1).EQ.0.) GO TO 150 \\
\hline 0162 & & IF (IDD4.NE.1) GO TO 150 \\
\hline 0163 & & $\operatorname{WRITE}(6,908)$ \\
\hline 0164 & CCCC & $\operatorname{ccc}$ \\
\hline 0165 & & CALL LGWV (NN, XMAX, F,WF,WB,RL,DD1) \\
\hline 0166 & $\operatorname{CCCC}$ & $\mathrm{CCC}$ \\
\hline 0167 & 150 & $W H(N C A L)=W B$ \\
\hline 0168 & & $\mathrm{CH}(\mathrm{NCAL})=\mathrm{CC}$ \\
\hline 0169 & & $\mathrm{NCAL}=\mathrm{NCAL}+1$ \\
\hline 0170 & & IF ( NCAL.GT.NCALM) GO TO 250 \\
\hline 0171 & & $\mathrm{RL}=\mathrm{RLH}(\mathrm{NCAL})$ \\
\hline 0172 & & IF (NCAL.GE.3) GO TO 200 \\
\hline 0173 & & $W W(2)=C C * R L$ \\
\hline 0174 & & GO TO 205 \\
\hline 0175 & 200 & $I 1=N C A L-2$ \\
\hline 0176 & & $I 2=N C A L-1$ \\
\hline 0177 & & $C G=(W H(I 2)-W H(I 1)) /(R L H(I 2)-R L H(I 1))$ \\
\hline 0178 & & $W W(2)=W H(I 2)+C G *(R L H(N C A L)-R L H(I 2))$ \\
\hline 0179 & 205 & $W W(1)=W W(2) *(1 .-D E L)$ \\
\hline 0180 & & $W W(3)=W W(2) *(1 .+D E L)$ \\
\hline 0181 & & GO TO 1 \\
\hline 0182 & 250 & WRITE $(6,909)$ \\
\hline
\end{tabular}




\begin{tabular}{|c|c|c|}
\hline 0183 & & DO $260 I=1, N C A L M$ \\
\hline 0184 & 260 & $\operatorname{WRITE}(6,910)$ WH(I), RLH(I), CH(I) \\
\hline 0185 & & $I M D=I M D+1$ \\
\hline 0186 & & IF (IMD.LE.IMDM) GO TO 2 \\
\hline 0187 & 902 & FORMAT (//' USED UP',I3,' ITERATIONS'/) \\
\hline 0188 & 903 & FORMAT $(/ /$, CONVERGED: W, L,C,EPS,DX,NIT $=', 5 \mathrm{E} 15.5, I 5)$ \\
\hline 0189 & 904 & FORMAT $(10 \mathrm{OE} 13.5)$ \\
\hline 0190 & 905 & FORMAT $\left(/^{\prime} \quad W, R L, C P, R I, I C R=', 4 E 15.5, I 10\right)$ \\
\hline 0191 & 907 & $\operatorname{FORMAT}(/ /, \quad F, X M A X, D X=', 3 E 15.5 /)$ \\
\hline 0192 & 908 & $\operatorname{FORMAT}(/ / /)$ \\
\hline 0193 & 909 & FORMAT $(/ / /$ \\
\hline 0194 & 910 & FORMAT (3E15.5) \\
\hline 0195 & 911 & FORMAT (/' SOLUTION HAS ',I3,' CRITICAL LAYERS'/) \\
\hline 0196 & 912 & $\operatorname{FORMAT}(/ \cdot \quad \mathrm{ZETA} \cdot /)$ \\
\hline 0197 & 913 & FORMAT $(/, \quad \mathrm{U} / /)$ \\
\hline 0198 & 917 & RIGID LID $/$ ) \\
\hline 0199 & 918 & FORMAT (/' FREE SURFACE'/) \\
\hline 0200 & 919 & FORMAT ( $\quad$ UX $=0$ AT $X=X M A X ' /)$ \\
\hline 0201 & 920 & FORMAT $(\cdot \quad U=0$ AT $X=X M A X ' /)$ \\
\hline 0202 & 921 & FORMAT $(\cdot \quad \mathrm{UX}=0$ AT $\mathrm{X}=0 \% /)$ \\
\hline 0203 & 922 & FORMAT $(\cdot \quad U=0$ AT $X=0 \% /)$ \\
\hline 0204 & 923 & FORMAT(' REAL B.C.AT X = XMAX') \\
\hline 0205 & 924 & FORMAT $\left(/^{\prime}\right.$ SEARCH IN U') \\
\hline 0206 & 925 & FORMAT (/' SEARCH IN P') \\
\hline 0207 & 926 & FORMAT(' LONG WAVE EXACTLY') \\
\hline 0208 & 927 & FORMAT (' GENERAL FREQUENCY AND WAVENUMBER') \\
\hline 0209 & 928 & FORMAT ( DECAY CONDITION AT X $\left.=0^{\circ}\right)$ \\
\hline 0210 & 140 & STOP \\
\hline 0211 & & END \\
\hline
\end{tabular}

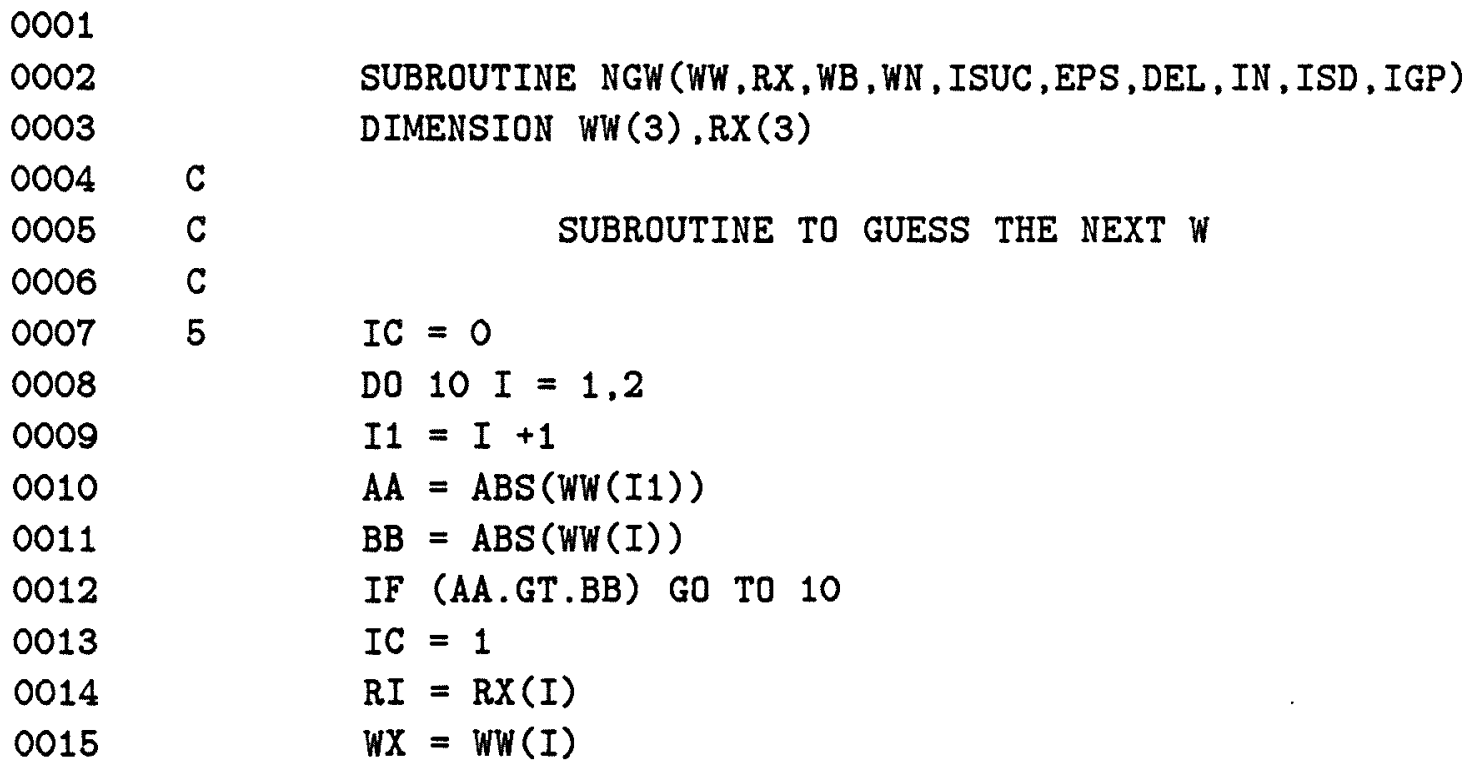




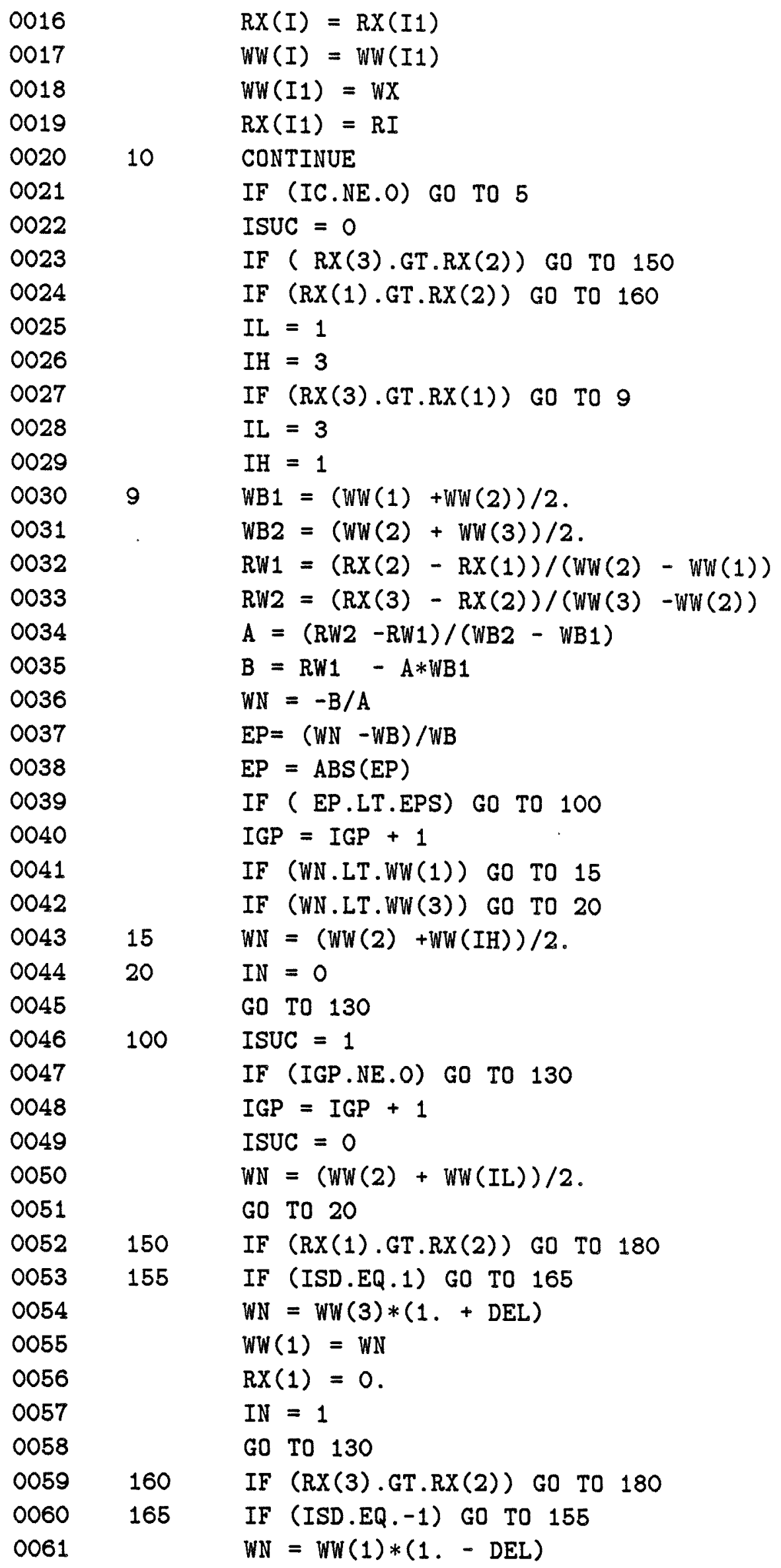




$\begin{array}{lll}0062 & & \text { WW }(3)=W N \\ 0063 & & R X(3)=0 . \\ 0064 & & \operatorname{IN~}=3 \\ 0065 & & \text { GO TO 130 } \\ 0066 & 180 & \text { IF }(R X(3) . G T . R X(1)) \text { GO TO } 155 \\ 0067 & & \text { GO TO 165 } \\ 0068 & 130 & \text { RETURN } \\ 0069 & & \text { END }\end{array}$

0001

0002

SUBROUTINE CALC(NN, RX)

0003

0004

COMMON RH (400), RHX (400), A(1200),B(400),V (400), VX (400), VXX (400)

DOUBLE PRECISION RI,DSQRT

$0005 \quad \mathrm{C}$

$0006 \quad \mathrm{C}$

SUBROUTINE TO CALCULATE THE INTEGRAL OF RESPONSE SQUARED

$0007 \quad C$

0008

0009

0010

0011

0012

0013

0014

0015

$\mathrm{RI}=(B(1) * * 2+B(N N) * * 2) / 2$.

$\mathrm{NX}=\mathrm{NN}-1$

DO $5 I=2, \mathrm{NX}$

$R I=R I+B(I) * * 2$

$\mathrm{RI}=\mathrm{DSQRT}(\mathrm{RI})$

$\mathrm{RX}=\mathrm{RI}$

RETURN

END

0001

0002

SUBROUTINE DEP(NN, XMAX)

COMMON RH (400), $\operatorname{RHX}(400), A(1200), B(400), V(400), \operatorname{VX}(400), \operatorname{VXX}(400)$

$\operatorname{READ}(5, *)$ NRX

$0005 \quad \mathrm{C}$

$0006 \quad \mathrm{C}$

SUBROUTINE TO READ AND INTERPOLATE THE DEPTH PROFILE

$\mathrm{RH}=\mathrm{DEPTH}$

RHX $=X$ DERIVATIVE OF DEPTH

$0008 \quad \mathrm{C}$

$0009 \quad \mathrm{C}$

0010

0011

DO $10 I=1, N R X$

$\operatorname{READ}(5, *) \quad A(I), B(I)$

0012

$A(I)=A(I) * 1.0 E+05$

$0013 \quad 10$

$B(I)=B(I) * 100$.

0014

0015

0016

$\mathrm{DX}=\mathrm{XMAX} / \mathrm{FLOAT}(\mathrm{NN}-1)$

$R H(1)=B(1)$

DO $20 \mathrm{~N}=2, \mathrm{NN}$

0017

$\mathrm{X}=\mathrm{DX} * \operatorname{FLOAT}(\mathbb{N}-1)$ 


\begin{tabular}{|c|c|c|}
\hline 0018 & & IF $(X . G T . A(N R X))$ GO TO 15 \\
\hline 0019 & & $I C=0$ \\
\hline 0020 & & DO $8 \mathrm{~J}=2, \mathrm{NRX}$ \\
\hline 0021 & & IF (IC.NE.O) GO TO 8 \\
\hline 0022 & & $I=J$ \\
\hline 0023 & & IF (X.GT.A(I)) GO TO 8 \\
\hline 0024 & & $I C=I$ \\
\hline 0025 & 8 & CONTINUE \\
\hline 0026 & & $I M=I-1$ \\
\hline 0027 & & $A A=(B(I)-B(I M)) /(A(I)-A(I M))$ \\
\hline 0028 & & $X X=X-A(I M)$ \\
\hline 0029 & & $R H(N)=B(I M)+A A * X X$ \\
\hline 0030 & & GO TO 20 \\
\hline 0031 & 15 & $R H(N)=B(N R X)$ \\
\hline 0032 & 20 & CONTINUE \\
\hline 0033 & & $R H X(1)=(R H(2)-R H(1)) / D X$ \\
\hline 0034 & & $N M=N N-1$ \\
\hline 0035 & & $\operatorname{RHX}(N N)=(R H(N N)-R H(N M)) / D X$ \\
\hline 0036 & & $\mathrm{D} 2=2 . * \mathrm{DX}$ \\
\hline 0037 & & DO $30 \mathrm{~N}=2, \mathrm{NM}$ \\
\hline 0038 & & $I P=N+1$ \\
\hline 0039 & & $I M=N-1$ \\
\hline 0040 & 30 & $\operatorname{RHX}(\mathrm{N})=(\mathrm{RH}(\mathrm{IP})-\mathrm{RH}(\mathrm{IM})) / \mathrm{D} 2$ \\
\hline 0041 & & WRITE $(6,903)$ \\
\hline 0042 & & $\operatorname{WRITE}(6,902) \quad(\mathrm{RH}(\mathrm{N}), \mathrm{N}=1, \mathrm{NN})$ \\
\hline 0043 & 902 & FORMAT (1OE13.5) \\
\hline 0044 & 903 & FORMAT $\left(/ /^{\prime}\right.$ DEPTH IN CM'/) \\
\hline 0045 & & RETURN \\
\hline 0046 & & END \\
\hline
\end{tabular}

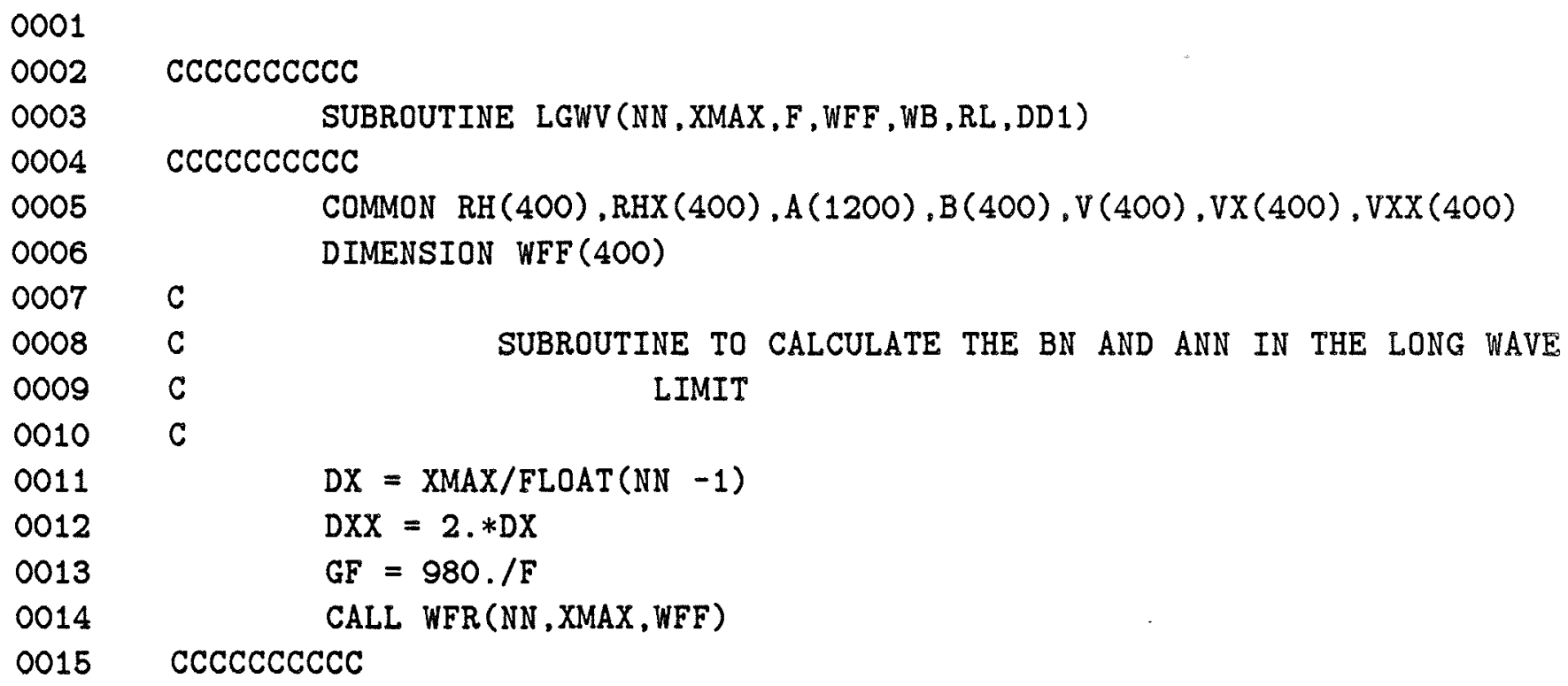




\begin{tabular}{|c|c|c|}
\hline 0016 & & IF (DD1.NE.0.) GO TO 200 \\
\hline 0017 & $\operatorname{ccccC}$ & $\operatorname{CCC}$ \\
\hline 0018 & & $A(1)=0$ \\
\hline 0019 & & DO $100 \mathrm{~N}=2, \mathrm{NN}$ \\
\hline 0020 & & $A(N)=(\operatorname{RHX}(N) * B(N)+\operatorname{RHX}(1) * B(1)) / 2$ \\
\hline 0021 & & $N X=N-1$ \\
\hline 0022 & & IF (NX.LE.1) GO TO 90 \\
\hline 0023 & & DO $20 I=2, N X$ \\
\hline 0024 & 20 & $A(N)=A(N)+R H X(I) * B(I)$ \\
\hline 0025 & 90 & $A(N)=A(N) * D X$ \\
\hline 0026 & & $A(N)=A(N)+R H(1) * B(1)-R H(N) * B(N)$ \\
\hline 0027 & 100 & $A(N)=-G F * A(N)$ \\
\hline 0028 & & $N X=N N-1$ \\
\hline 0029 & & $W F=\operatorname{RHX}(1) *(A(1) / R H(1)) * * 2$ \\
\hline 0030 & & $W F=W F+\operatorname{RHX}(N N) *(A(N N) / R H(N N)) * * 2$ \\
\hline 0031 & & $I F Z=0$ \\
\hline 0032 & & $W F=W F / 2$ \\
\hline 0033 & & DO $150 \mathrm{~N}=2, \mathrm{NX}$ \\
\hline 0034 & & IF ( IFZ.NE.O) GO TO 150 \\
\hline 0035 & & IF (RHX(N).NE.O.) GO TO 140 \\
\hline 0036 & & $I F Z=N$ \\
\hline 0037 & 140 & $W F=W F+R H X(N) *(A(N) / R H(N)) * * 2$ \\
\hline 0038 & 150 & CONTINUE \\
\hline 0039 & & $W F=W F * D X$ \\
\hline 0040 & & $W F=S Q R T(W F * W F)$ \\
\hline 0041 & & $W F=S Q R T(W F)$ \\
\hline 0042 & & DO $160 \mathrm{~N}=1, \mathrm{NN}$ \\
\hline 0043 & 160 & $A(N)=A(N) / W F$ \\
\hline 0044 & & $\mathrm{NH}=\mathrm{IFZ}-1$ \\
\hline 0045 & & $\mathrm{PX}=(\mathrm{A}(2)-\mathrm{A}(1)) /(\mathrm{DX} * \mathrm{RH}(1))$ \\
\hline 0046 & & $\mathrm{WF}=0.5 * \mathrm{PX} * \mathrm{PX} * \mathrm{WFF}(1)$ \\
\hline 0047 & & $\mathrm{BN}=0.5 * \mathrm{RHX}(\mathrm{NH}) * \mathrm{~A}(\mathrm{NH}) /(\mathrm{RH}(\mathrm{NH}) * * 2)$ \\
\hline 0048 & & $\mathrm{NH}=\mathrm{NH}-1$ \\
\hline 0049 & & DO $180 \mathrm{~N}=2, \mathrm{NH}$ \\
\hline 0050 & & $\mathrm{BN}=\mathrm{BN}+\mathrm{RHX}(\mathrm{N}) * \mathrm{~A}(\mathrm{~N}) /(\mathrm{RH}(\mathrm{N}) * * 2)$ \\
\hline 0051 & & $I 1=N-1$ \\
\hline 0052 & & $I 2=N+1$ \\
\hline 0053 & & $P X=(A(I 2)-A(I 1)) / D X X$ \\
\hline 0054 & & $\mathrm{PX}=\mathrm{PX} / \mathrm{RH}(\mathrm{N})$ \\
\hline 0055 & 180 & $W F=W F+P X * P X * W F F(N)$ \\
\hline 0056 & & $\mathrm{BN}=\mathrm{BN} * \mathrm{DX}$ \\
\hline 0057 & & $W F=W F * R H(1) * D X$ \\
\hline 0058 & & WRITE $(6,905)$ \\
\hline 0059 & & WRITE $(6,901)$ WF \\
\hline 0060 & & WRITE $(6,903) \mathrm{BN}$ \\
\hline 0061 & & $\operatorname{WRITE}(6,904)$ \\
\hline
\end{tabular}




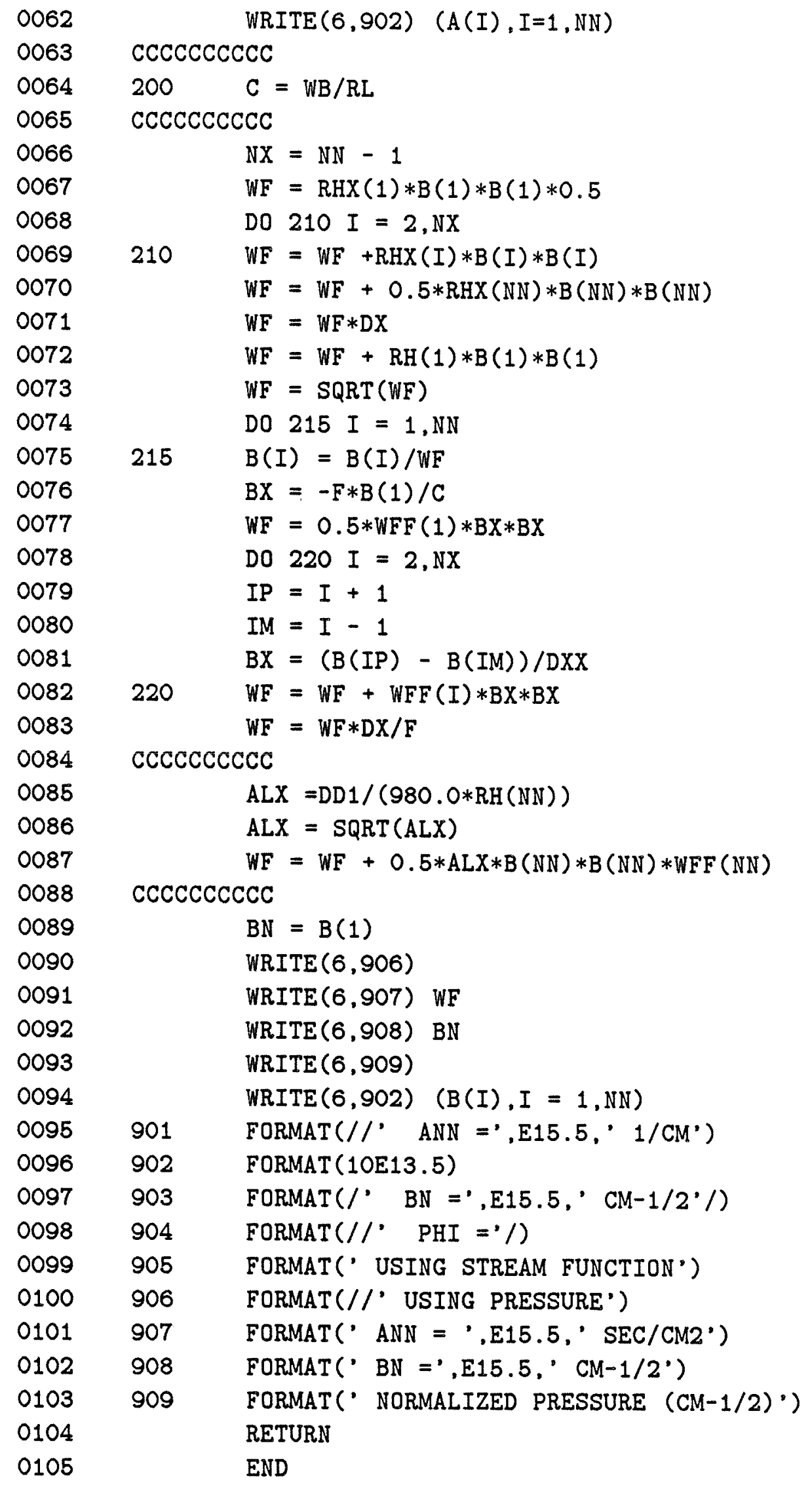




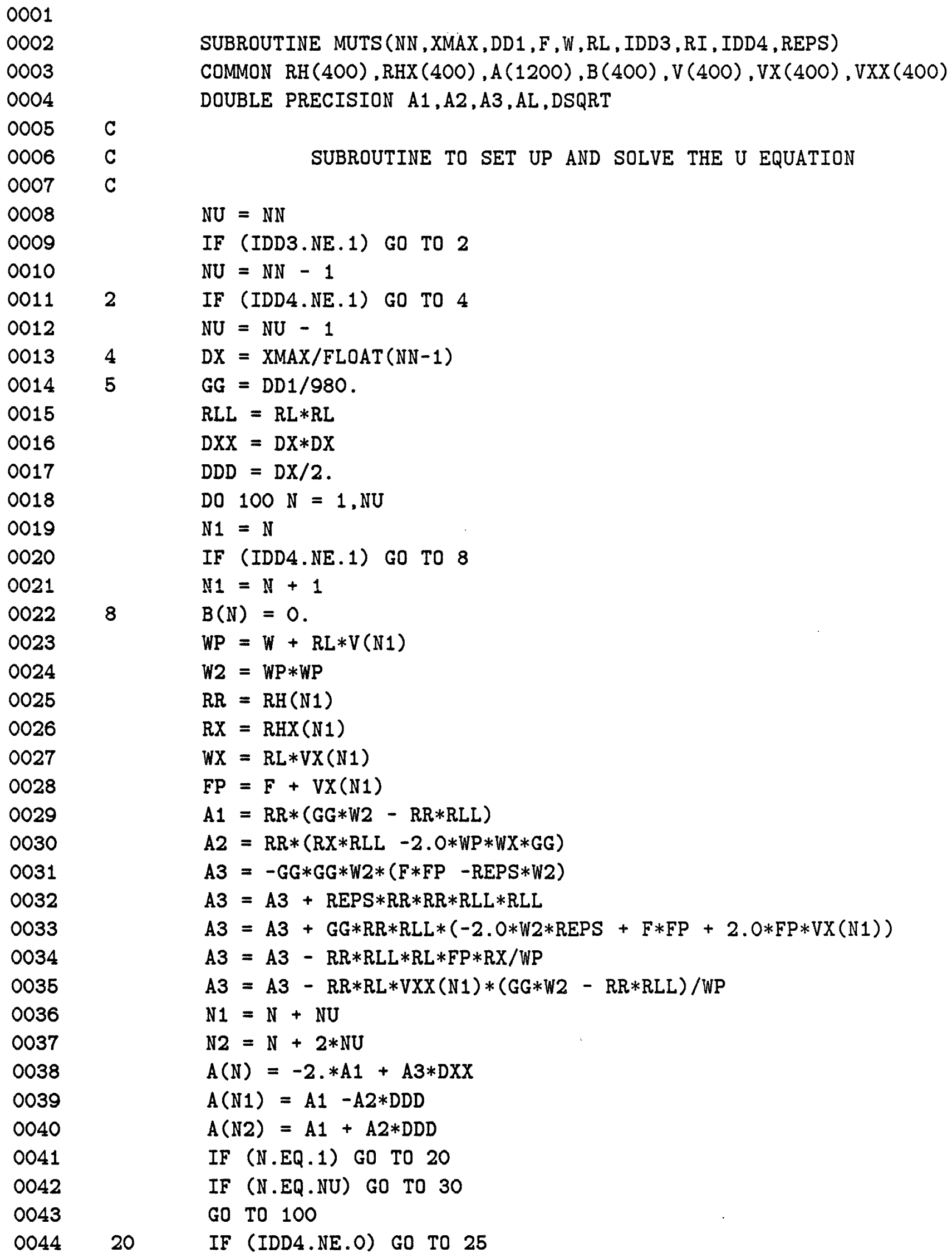




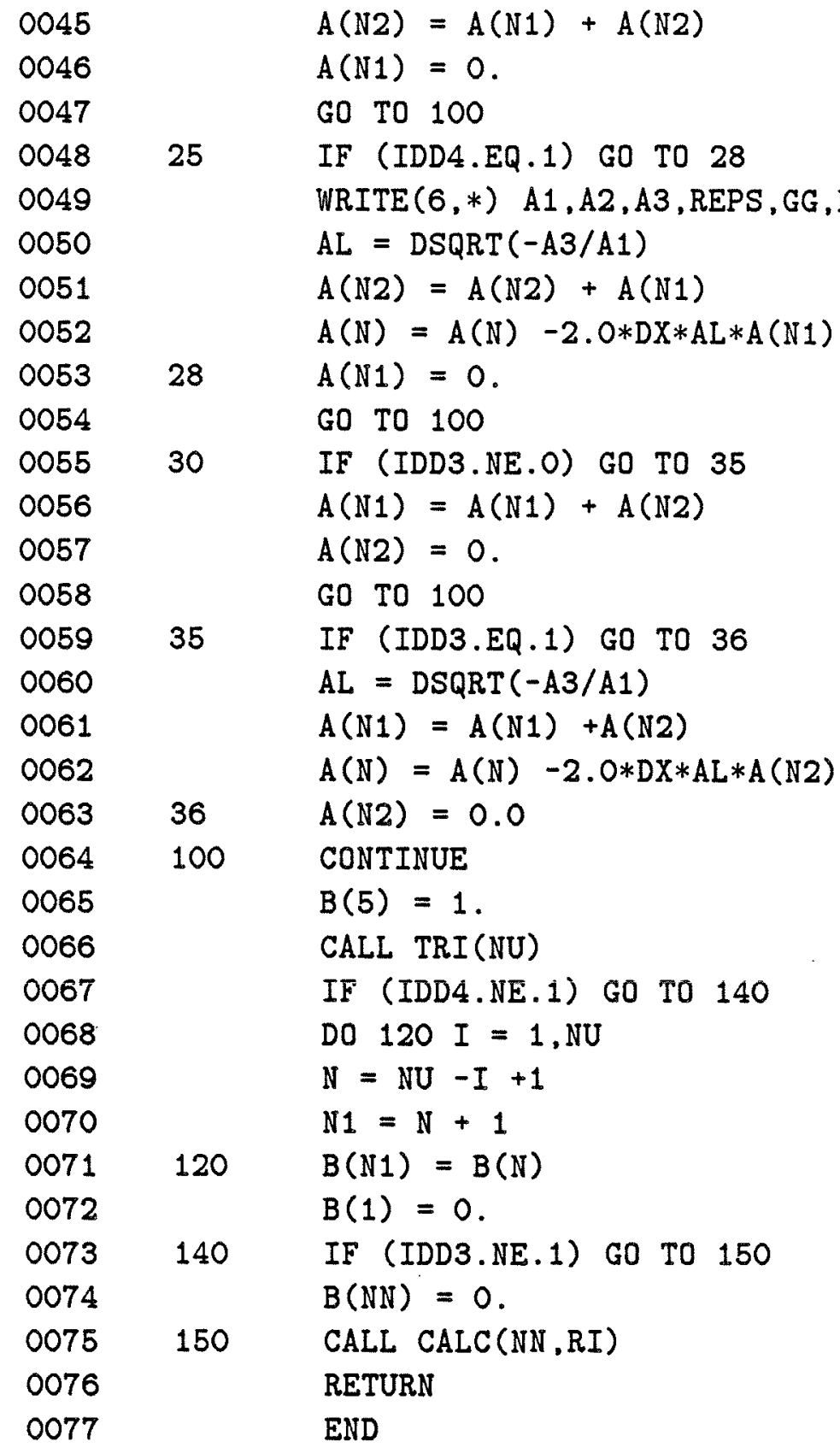

0001

0002

0003

$0004 \quad C$

$0005 \mathrm{C}$

$0006 \quad \mathrm{C}$

$0007 \quad \mathrm{C}$

$0008 \quad \mathrm{C}$

$0009 \mathrm{C}$

SUBROUTINE VRD (NN, XMAX,F)

COMMON RH (400), RHX (400), A(1200), B (400), V (400), VX (400), VXX (400)

0010

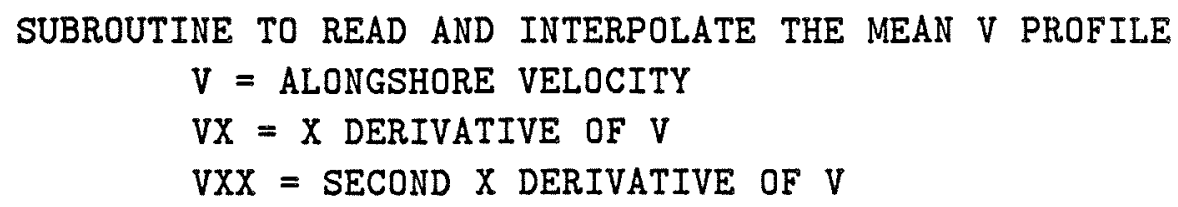




\begin{tabular}{|c|c|c|}
\hline \multirow{2}{*}{\multicolumn{2}{|c|}{$\begin{array}{l}0011 \\
0012\end{array}$}} & $\operatorname{READ}(5, *)$ NRD \\
\hline & & IF (NRD.EQ.O) GO TO 200 \\
\hline 0013 & & DO $5 \mathrm{I}=1, \mathrm{NRD}$ \\
\hline 0014 & & $\operatorname{READ}(5, *) \quad A(I), B(I)$ \\
\hline 0015 & C & $\mathrm{A}=$ DISTANCE FROM SHORE IN KM \\
\hline 0016 & C & $\mathrm{B}=\mathrm{V}$ IN $\mathrm{CM} / \mathrm{SEC}$ \\
\hline 0017 & 5 & $A(I)=A(I) * 1.0 E+05$ \\
\hline 0018 & 10 & DO $100 \mathrm{~N}=1, \mathrm{NN}$ \\
\hline 0019 & & $X=D X * F L O A T(N-1)$ \\
\hline 0020 & & IF (X.GT.A(NRD)) GO TO 90 \\
\hline 0021 & & IF (X.LT.A(1)) GO TO 80 \\
\hline 0022 & & $\mathrm{~J}=0$ \\
\hline 0023 & & DO $20 I=2, N R D$ \\
\hline 0024 & & IF (J.NE.O) GO TO 20 \\
\hline 0025 & & IF (X.GT.A(I)) GO TO 20 \\
\hline 0026 & & $J=I$ \\
\hline 0027 & 20 & CONTINUE \\
\hline 0028 & & $J J=J-1$ \\
\hline 0029 & & $X X=A(J)-X$ \\
\hline 0030 & & $X Y=A(J)-A(J J)$ \\
\hline 0031 & & $V(N)=B(J)-X X *(B(J)-B(J J)) / X Y$ \\
\hline 0032 & & GO TO 100 \\
\hline 0033 & 80 & $V(N)=0$ \\
\hline 0034 & & GO TO 100 \\
\hline 0035 & 90 & $V(N)=B(N R D)$ \\
\hline 0036 & 100 & CONTINUE \\
\hline 0037 & & $V X(1)=(V(2)-V(1)) / D X$ \\
\hline 0038 & & $N Q=N N-1$ \\
\hline 0039 & & $V X(N N)=(V(N N)-V(N Q)) / D X$ \\
\hline 0040 & & $\mathrm{DXX}=\mathrm{DX} * \mathrm{DX}$ \\
\hline 0041 & & $\mathrm{DZ}=2 . * \mathrm{DX}$ \\
\hline 0042 & & $\operatorname{VXX}(1)=0$ \\
\hline 0043 & & $\operatorname{VXX}(N N)=0$ \\
\hline 0044 & & DO $120 \mathrm{~N}=2, \mathrm{NQ}$ \\
\hline 0045 & & $I 1=N-1$ \\
\hline 0046 & & $I 2=N+1$ \\
\hline 0047 & & $V X(N)=(V(I 2)-V(I 1)) / D Z$ \\
\hline 0048 & 120 & $V X X(N)=(V(I 2)-2 * * V(N)+V(I 1)) / D X X$ \\
\hline 0049 & & WRITE $(6,904)$ \\
\hline 0050 & & $\operatorname{WRITE}(6,903) \quad(\mathrm{V}(\mathrm{N}), \mathrm{N}=1, \mathrm{NN})$ \\
\hline 0051 & & $I S T=0$ \\
\hline 0052 & & DO $150 \mathrm{~N}=1, \mathrm{NN}$ \\
\hline 0053 & & $\mathrm{Q}=-\mathrm{RHX}(\mathrm{N}) *(\mathrm{~F}+\mathrm{VX}(\mathrm{N}))+\mathrm{RH}(\mathrm{N}) * \mathrm{VXX}(\mathrm{N})$ \\
\hline 0054 & & $A(N)=Q$ \\
\hline 0055 & & IF (IST.NE.0) GO TO 150 \\
\hline 0056 & & IF (N.NE.1) GO TO 130 \\
\hline
\end{tabular}




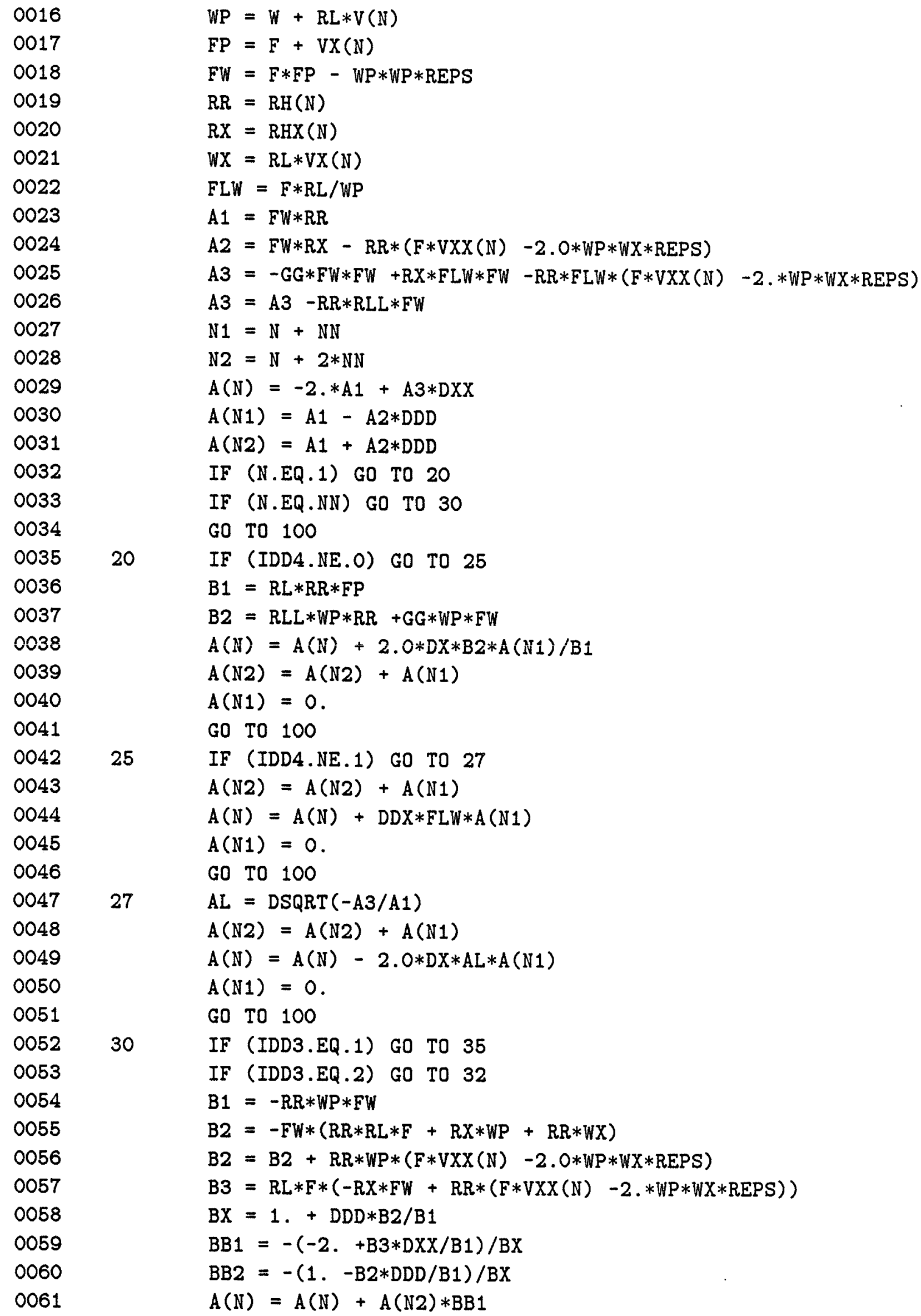




\begin{tabular}{|c|c|c|}
\hline 0062 & & $A(N 1)=A(N 1)+A(N 2) * B B 2$ \\
\hline 0063 & & $A(N 2)=0$ \\
\hline 0064 & & GO TO 100 \\
\hline 0065 & 32 & $\mathrm{AL}=\operatorname{DSQRT}(-\mathrm{A} 3 / \mathrm{A} 1)$ \\
\hline 0066 & & $A(N 1)=A(N 1)+A(N 2)$ \\
\hline 0067 & & $A(N)=A(N)-2.0 * D X * A L * A(N 2)$ \\
\hline 0068 & & $A(N 2)=0$ \\
\hline 0069 & & GO TO 100 \\
\hline 0070 & 35 & $A(N 1)=A(N 1)+A(N 2)$ \\
\hline 0071 & & $A(N)=A(N)-D D X * F L W * A(N 2)$ \\
\hline 0072 & & $A(N 2)=0$ \\
\hline 0073 & 100 & CONTINUE \\
\hline 0074 & & $B(5)=0.00001$ \\
\hline 0075 & & $E Q Q=1.0 E-36$ \\
\hline 0076 & & $I K K=0$ \\
\hline 0077 & & DO $105 \mathrm{I}=1, \mathrm{NN}$ \\
\hline 0078 & & $A Q=A B S(A(I))$ \\
\hline 0079 & & IF (AQ.GT.EQQ) GO TO 105 \\
\hline 0080 & & $I K K=1$ \\
\hline 0081 & 105 & CONTINUE \\
\hline 0082 & & IF (IKK.EQ.1) GO TO 115 \\
\hline 0083 & & CALL TRI $(N N)$ \\
\hline 0084 & & CALL CALC (NN,RI) \\
\hline 0085 & & GO TO 110 \\
\hline 0086 & 115 & $\operatorname{WRITE}(6,901)$ \\
\hline 0087 & 901 & FORMAT(' NUMERICAL PROBLEM: SMALL DIAGONAL ELEMENT') \\
\hline 0088 & 110 & RETURN \\
\hline 0089 & & END \\
\hline
\end{tabular}

0001

0002

0003

SUBROUTINE CRLC (W, RL, NN, ICR)

COMMON RH (400), RHX (400), A(1200), B (400), V (400), VX (400), VXX (400)

$0004 \quad C$

$0005 \quad \mathrm{C}$

SUBROUTINE TO CHECK FOR CRITICAL LAYERS

$0006 \quad \mathrm{C}$

$0007 \quad I C R=0$

$0008 \quad$ DO $100 \mathrm{~N}=1, \mathrm{NN}$

$0009 \quad \mathrm{WP}=\mathrm{W}+\mathrm{RL} * \mathrm{~V}(\mathrm{~N})$

0010 IF (N.NE.1) GO TO 30

$0011 \quad P Q=W P$

0012 GO TO 100

$0013 \quad 30 \quad P Q=W P / P Q$

0014 IF (PQ.GT.O.) GO TO 40

$0015 \quad I C R=I C R+1$ 


$\begin{array}{lll}0016 & 40 & \text { PQ }=\text { WP } \\ 0017 & 100 & \text { CONTINUE } \\ 0018 & & \text { RETURN } \\ 0019 & & \text { END }\end{array}$

0001

0002

0003

0004

$0005 \quad \mathrm{C}$

$0006 \quad \mathrm{C}$

$0007 \quad C$

$0008 \quad \mathrm{C}$

$0009 \quad \mathrm{C}$

$0010 \quad \mathrm{C}$

$0011 \mathrm{C}$

$0012 \quad C$

SUBROUTINE TRI(N)

COMMON RH (400), RHX (400), A(1200), B (400), V (400), VX (400), VXX (400)

DOUBLE PRECISION AA,BB

0013

0014

0015

0016

0017

0018

0019

0020

0021

0022

0023

0024

0025

0026

0027

0028

0029

0030

0031

0032

0033

$C$
$C$
$C$
$C$
$C$

\author{
SUBROUTINE TO SOLVE A TRIDIAGONAL MATRIX BY GAUSSIAN \\ ELIMINATION
}

STORE MAIN DIAGONAL FIRST

O,LOWER DIAGONAL

UPPER DIAGONAL, 0

$$
\begin{array}{ll}
N 3=N+1 \\
N 2=2 * N \\
N N=N-1 \\
D O 5 I=1, N N \\
I I=N 3+I \\
A A=A(I I) / A(I) \\
I 2=I+1 \\
I 3=N 2+I \\
B B=A(I 2)-A A * A(I 3) \\
A(I 2)=B B \\
B B=B(I 2)-A A * B(I) \\
B(I 2)=B B \\
D O 10 I J=1, N N \\
I=N 3-I J \\
B(I)=B(I) / A(I) \\
I I=I+N 2-1 \\
I P=I-1 \\
B B=B(I P)-A(I I) * B(I) \\
B(I P)=B B \\
B(1)=B(1) / A(1) \\
R E T U R N \\
E N D
\end{array}
$$$$
10 \quad B(I P)=B B
$$

0001

0002 


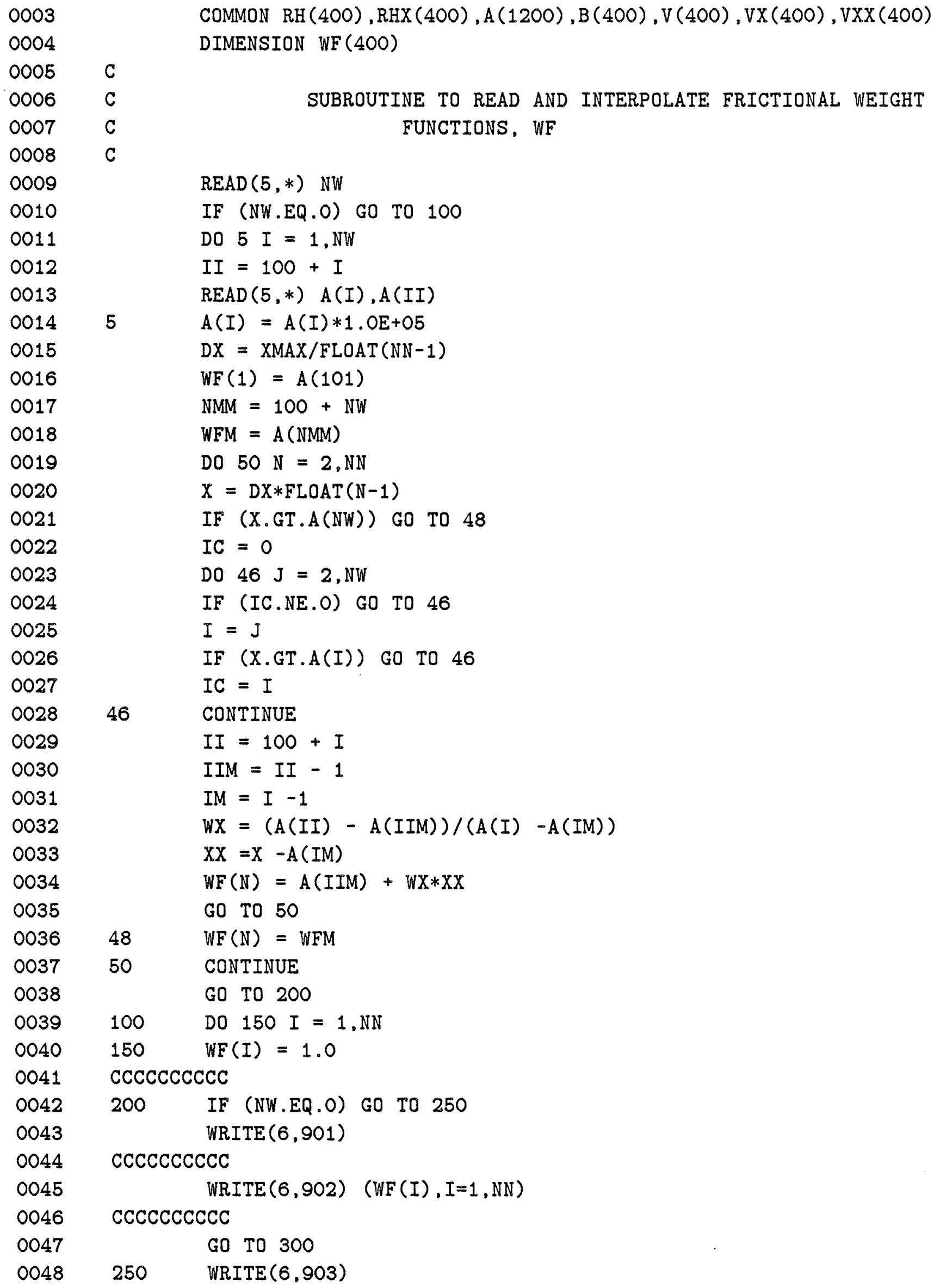


$0049 \quad \operatorname{cccccccccc}$

0050901 FORMAT (/' FRICTION WEIGHT FUNCTION')

$0051902 \quad$ FORMAT(1OE12.5)

$0052 \quad \operatorname{CcCCCCCCCC}$

0053903 FORMAT ( / FRICTION WEIGHT FUNCTION $=1.0$ EVERYWHERE')

$0054300 \quad$ RETURN

$0055 \quad \operatorname{CCCCCCCCCC}$

$0056 \quad$ END 


\section{Program BIGLOAD2 Listing}

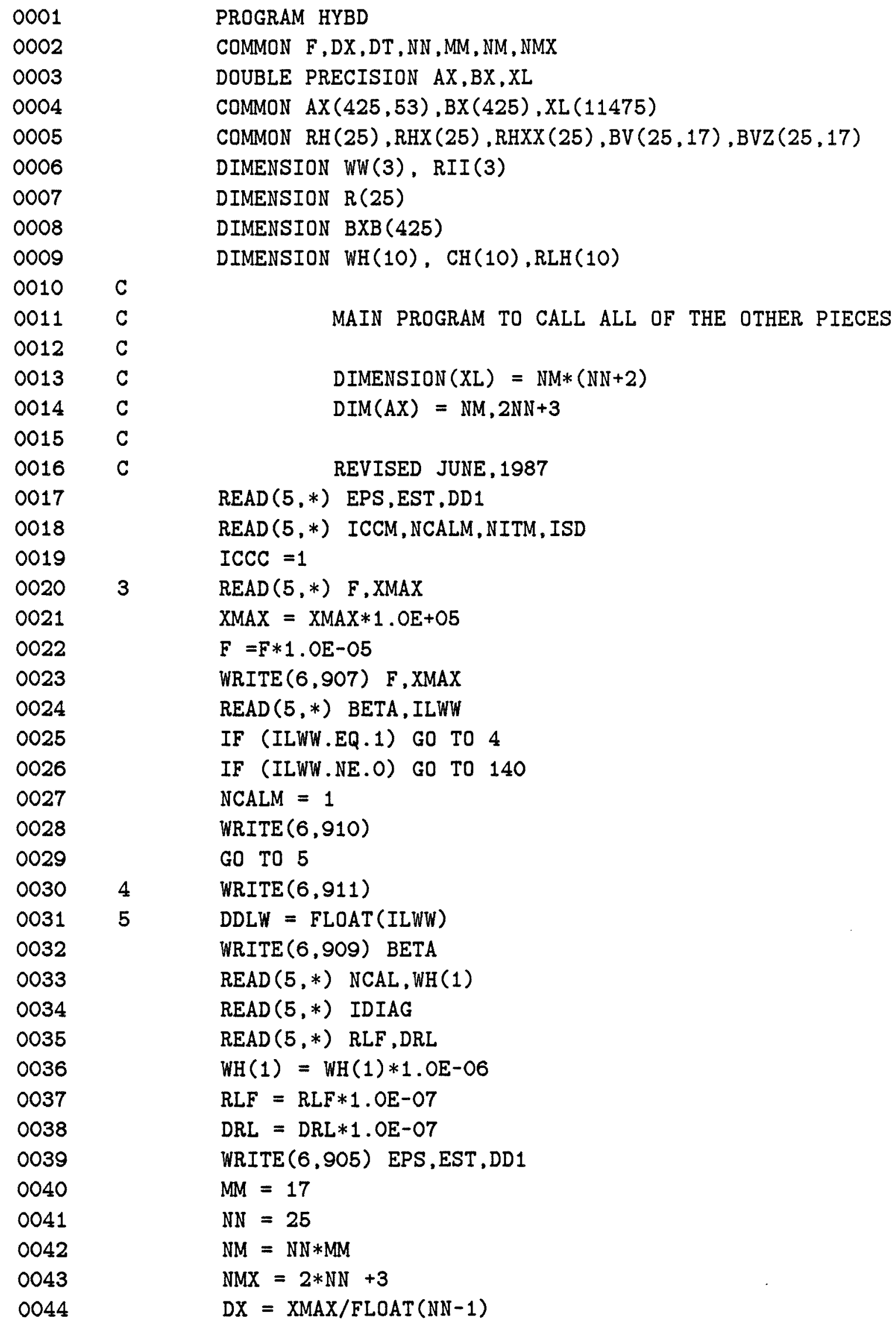

0044

COMMON F,DX,DT,NN, MM, NM, NMX

DOUBLE PRECISION AX,BX,XL

COMMON AX $(425,53), B X(425), X L(11475)$

COMMON RH(25), RHX (25), RHXX (25), BV $(25,17), \operatorname{BVZ}(25,17)$

DIMENSION WW(3), RII(3)

DIMENSION $R(25)$

DIMENSION BXB(425)

DIMENSION WH(10), CH(10), RLH(10)

MAIN PROGRAM TO CALL ALL OF THE OTHER PIECES

$$
\operatorname{DIMENSION}(X L)=\mathrm{NM} *(N N+2)
$$

$\operatorname{DIM}(A X)=\mathrm{NM}, 2 \mathrm{NN}+3$

REVISED JUNE, 1987

$\operatorname{READ}(5, *)$ EPS,EST,DD1

$\operatorname{READ}(5, *)$ ICCM, NCALM, NITM, ISD

ICCC $=1$

$\operatorname{READ}(5, *) \quad F, X M A X$

$\mathrm{XMAX}=\mathrm{XMAX} * 1 . \mathrm{OE}+05$

$F=F * 1.0 E-05$

WRITE $(6,907) \quad F, X M A X$

$\operatorname{READ}(5, *)$ BETA, ILWW

IF (ILWW.EQ.1) GO TO 4

IF (ILWW.NE.O) GO TO 140

NCALM $=1$

WRITE $(6,910)$

GO TO 5

WRITE $(6,911)$

DDLW = FLOAT (ILWW)

WRITE $(6.909)$ BETA

$\operatorname{READ}(5, *)$ NCAL , WH (1)

$\operatorname{READ}(5, *)$ IDIAG

$\operatorname{READ}(5, *)$ RLF , DRL

$W H(1)=W H(1) * 1.0 E-06$

$\mathrm{RLF}=\mathrm{RLF} * 1.0 \mathrm{E}-07$

$\mathrm{DRL}=\mathrm{DRL} * 1.0 \mathrm{E}-07$

WRITE $(6,905)$ EPS,EST,DD1

$M M=17$

$\mathrm{NN}=25$

$\mathrm{NM}=\mathrm{NN} * \mathrm{MM}$

$\mathrm{NMX}=2 * \mathrm{NN}+3$

$\mathrm{DX}=\mathrm{XMAX} / \mathrm{FLOAT}(\mathrm{NN}-1)$ 


\begin{tabular}{|c|c|c|}
\hline 0045 & & $\mathrm{DT}=1 . / \mathrm{FLOAT}(\mathrm{MM}-1)$ \\
\hline 0046 & & DO $50 I=1$, NCALM \\
\hline 0047 & 50 & $\operatorname{RLH}(I)=\mathrm{RLF}+\mathrm{DRL} * \mathrm{FLOAT}(I-1)$ \\
\hline 0048 & & $\mathrm{RL}=\mathrm{RLH}(\mathrm{NCAL})$ \\
\hline 0049 & & $\operatorname{READ}(5, *) \quad(W W(J), J=1,3)$ \\
\hline 0050 & & DO $6 \mathrm{~J}=1.3$ \\
\hline 0051 & 6 & $W W(J)=W W(J) * 1.0 E-06$ \\
\hline 0052 & & CALL DEP \\
\hline 0053 & & CALL NSQ \\
\hline 0054 & 1 & $R I B=0$. \\
\hline 0055 & & $I=1$ \\
\hline 0056 & 15 & $W=W W(I)$ \\
\hline 0057 & & CALL MATS(RL,W,DD1,RI, IER, BETA,DDLW) \\
\hline 0058 & & IF (IER.NE.O) GO TO 140 \\
\hline 0059 & & $R I I(I)=R I$ \\
\hline 0060 & & IF (RI.LT.RIB) GO TO 18 \\
\hline 0061 & & $R I B=R I$ \\
\hline 0062 & & $W B=W$ \\
\hline 0063 & & $I B=I$ \\
\hline 0064 & & DO $10 \mathrm{IJ}=1, \mathrm{NM}$ \\
\hline 0065 & 10 & $\mathrm{BXB}(I J)=\mathrm{BX}(I J)$ \\
\hline 0066 & 18 & $I=I+1$ \\
\hline 0067 & & IF (I.EQ.2) GO TO 15 \\
\hline 0068 & & IF (I.EQ.4) GO TO 19 \\
\hline 0069 & & IF (RII(1).LT.RII(2)) GO TO 15 \\
\hline 0070 & & $W W(3)=W W(1) *(1 .-E S T)$ \\
\hline 0071 & & GO TO 15 \\
\hline 0072 & 19 & $N I T=3$ \\
\hline 0073 & & $I G P=0$ \\
\hline 0074 & 20 & CALL NGSW (WW, RII,WB, WN, ISUC,EPS, IN, IGP, EST, ISD) \\
\hline 0075 & & IF (WN.GT.F) GO TO 140 \\
\hline 0076 & & IF (ISUC.EQ.2) GO TO 140 \\
\hline 0077 & & IF (ISUC.EQ.1) GO TO 100 \\
\hline 0078 & & CALL MATS(RL,WN,DD1,RI, IER, BETA,DDLW) \\
\hline 0079 & & IF (IER.NE.O) GO TO 140 \\
\hline 0080 & & IF (IN.NE.O) GO TO 24 \\
\hline 0081 & & IF (RI.GT.RIB) GO TO 21 \\
\hline 0082 & & IF (WN.LT.WW(2)) GO TO 23 \\
\hline 0083 & 22 & $I N=3$ \\
\hline 0084 & & GO TO 24 \\
\hline 0085 & 23 & $\mathrm{IN}=1$ \\
\hline 0086 & & GO TO 24 \\
\hline 0087 & 21 & IF (WN.LT.WW(2)) GO TO 22 \\
\hline 0088 & & GO TO 23 \\
\hline 0089 & 24 & $W W(I N)=W N$ \\
\hline 0090 & & $R I I(I N)=R I$ \\
\hline
\end{tabular}




\begin{tabular}{|c|c|c|}
\hline 0091 & & IF (RI.LT.RIB) GO TO 30 \\
\hline 0092 & & $W B=W N$ \\
\hline 0093 & & $R I B=R I$ \\
\hline 0094 & & DO $25 \mathrm{I}=1, \mathrm{NM}$ \\
\hline 0095 & 25 & $B X B(I)=B X(I)$ \\
\hline 0096 & 30 & $N I T=N I T+1$ \\
\hline 0097 & & IF (NIT.LT.NITM) GO TO 20 \\
\hline 0098 & & WRITE $(6,902) \quad N I T$ \\
\hline 0099 & & GO TO 140 \\
\hline 0100 & 100 & $\mathrm{RN}=\operatorname{SQRT}(\mathrm{RIB})$ \\
\hline 0101 & $\operatorname{CcccccC}$ & $\operatorname{CCC}$ \\
\hline 0102 & & $R N=R N * B X B(M M) / A B S(B X B(M M))$ \\
\hline 0103 & $\operatorname{ccccccc}$ & $\operatorname{ccc}$ \\
\hline 0104 & & DO $110 I=1, \mathrm{NM}$ \\
\hline 0105 & 110 & $B X(I)=B X B(I) / R N$ \\
\hline 0106 & & $C C=W B / R L$ \\
\hline 0107 & & WRITE $(6,903)$ WB, RL, CC,EPS, NIT \\
\hline 0108 & & IF (NCAL.NE.1) GO TO 125 \\
\hline 0109 & & CALL LGWH (WB, RL, DD1, R, BETA, DDLW) \\
\hline 0110 & & IF (IDIAG.EQ.O) GO TO 125 \\
\hline 0111 & & CALL UCAL (WB, RL, BETA, DDLW) \\
\hline 0112 & $\operatorname{ccccccC}$ & $\operatorname{CCC}$ \\
\hline 0113 & & CALL RHOC(DD1) \\
\hline 0114 & $\operatorname{ccccccc}$ & $\operatorname{ccC}$ \\
\hline 0115 & 125 & WRITE $(6,908)$ \\
\hline 0116 & & DO $130 \mathrm{~N}=1 . \mathrm{NN}$ \\
\hline 0117 & & $X=D X * F L O A T(N-1)$ \\
\hline 0118 & & $\mathrm{DZ}=\mathrm{RH}(\mathrm{N}) * \mathrm{DT}$ \\
\hline 0119 & & WRITE $(6,904) \quad X, R H(N), D Z$ \\
\hline 0120 & & $M L=1+M M *(N-1)$ \\
\hline 0121 & & $\mathrm{MH}=\mathrm{MM} * \mathrm{~N}$ \\
\hline 0122 & & $\operatorname{WRITE}(6,901) \quad(B X(M), M=M L, M H)$ \\
\hline 0123 & 130 & CONTINUE \\
\hline 0124 & & CALL DIAG (WB, RL,DDLW) \\
\hline 0125 & & $W H(N C A L)=W B$ \\
\hline 0126 & & $\mathrm{CH}(\mathrm{NCAL})=\mathrm{CC}$ \\
\hline 0127 & & $\mathrm{NCAL}=\mathrm{NCAL}+1$ \\
\hline 0128 & & IF (NCAL.GT.NCALM) GO TO 140 \\
\hline 0129 & & $\mathrm{RL}=\mathrm{RLH}(\mathrm{NCAL})$ \\
\hline 0130 & & IF (NCAL.GE.3) GO TO 200 \\
\hline 0131 & & $W W(2)=C C * R L$ \\
\hline 0132 & & GO TO 205 \\
\hline 0133 & 200 & $I 1=N C A L-2$ \\
\hline 0134 & & $I 2=N C A L-1$ \\
\hline 0135 & & $\mathrm{CG}=(\mathrm{WH}(\mathrm{I} 2)-\mathrm{WH}(\mathrm{I} 1)) /(\mathrm{RLH}(\mathrm{I} 2)-\operatorname{RLH}(\mathrm{I} 1))$ \\
\hline 0136 & & $W W(2)=W H(I 2)+C G *(R L H(N C A L)-R L H(I 2))$ \\
\hline
\end{tabular}




\begin{tabular}{|c|c|c|}
\hline 0137 & 205 & $W W(1)=W W(2) *(1.0-E S T)$ \\
\hline 0138 & & $W W(3)=W W(2) *(1.0+E S T)$ \\
\hline 0139 & & IF (WW(1).LT.O.) GO TO 140 \\
\hline 0140 & & IF (WW (3).GT.F) GO TO 140 \\
\hline 0141 & & GO TO 1 \\
\hline 0142 & 140 & $I C C C=I C C C+1$ \\
\hline 0143 & & IF (ICCC.LE.ICCM) GO TO 3 \\
\hline 0144 & 901 & FORMAT $(2 X, 10 E 12.5)$ \\
\hline 0145 & 902 & FORMAT $(/ /$, USED UP ',I5,' ITERATIONS'//) \\
\hline 0146 & 903 & FORMAT $(/ / /, \quad$ CONVERGED: W,L,C,EPS,NIT $=', 4 E 15.5, I 10 / /)$ \\
\hline 0147 & 904 & $\operatorname{FORMAT}\left(/^{\prime} \quad X, \mathrm{H}, \mathrm{DZ}==^{\prime}, 3 \mathrm{E} 15.5\right)$ \\
\hline 0148 & 905 & FORMAT $\left(/{ }^{\prime} \quad\right.$ EPS,EST,DD1 $\left.=\prime, 2 \mathrm{E} 15.5, \mathrm{~F} 10.2 /\right)$ \\
\hline 0149 & 906 & FORMAT (3F 10.5) \\
\hline 0150 & 907 & FORMAT $(/ /, \quad F, X M A X=', 2 E 15.5 / /)$ \\
\hline 0151 & 908 & FORMAT $(/ / \cdot$ PRESSURE'/) \\
\hline 0152 & 909 & FORMAT $\left(/{ }^{\prime}\right.$ BETA $=$ ',E15.5) \\
\hline 0153 & 910 & FORMAT(' LONG WAVE LIMIT') \\
\hline 0154 & 911 & FORMAT (' GENERAL FREQUENCY AND WAVENUMBER') \\
\hline 0155 & & STOP \\
\hline 0156 & & END \\
\hline
\end{tabular}

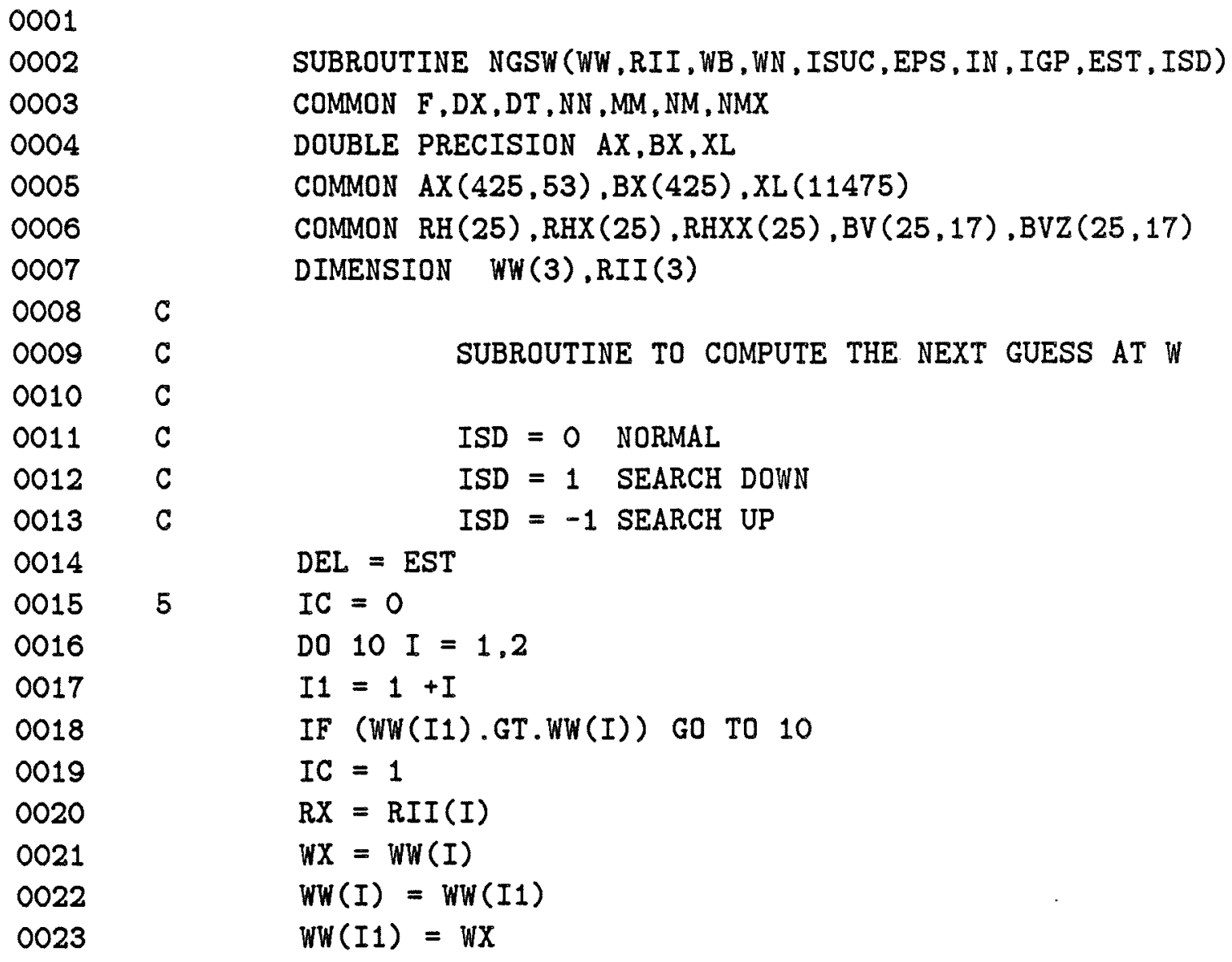




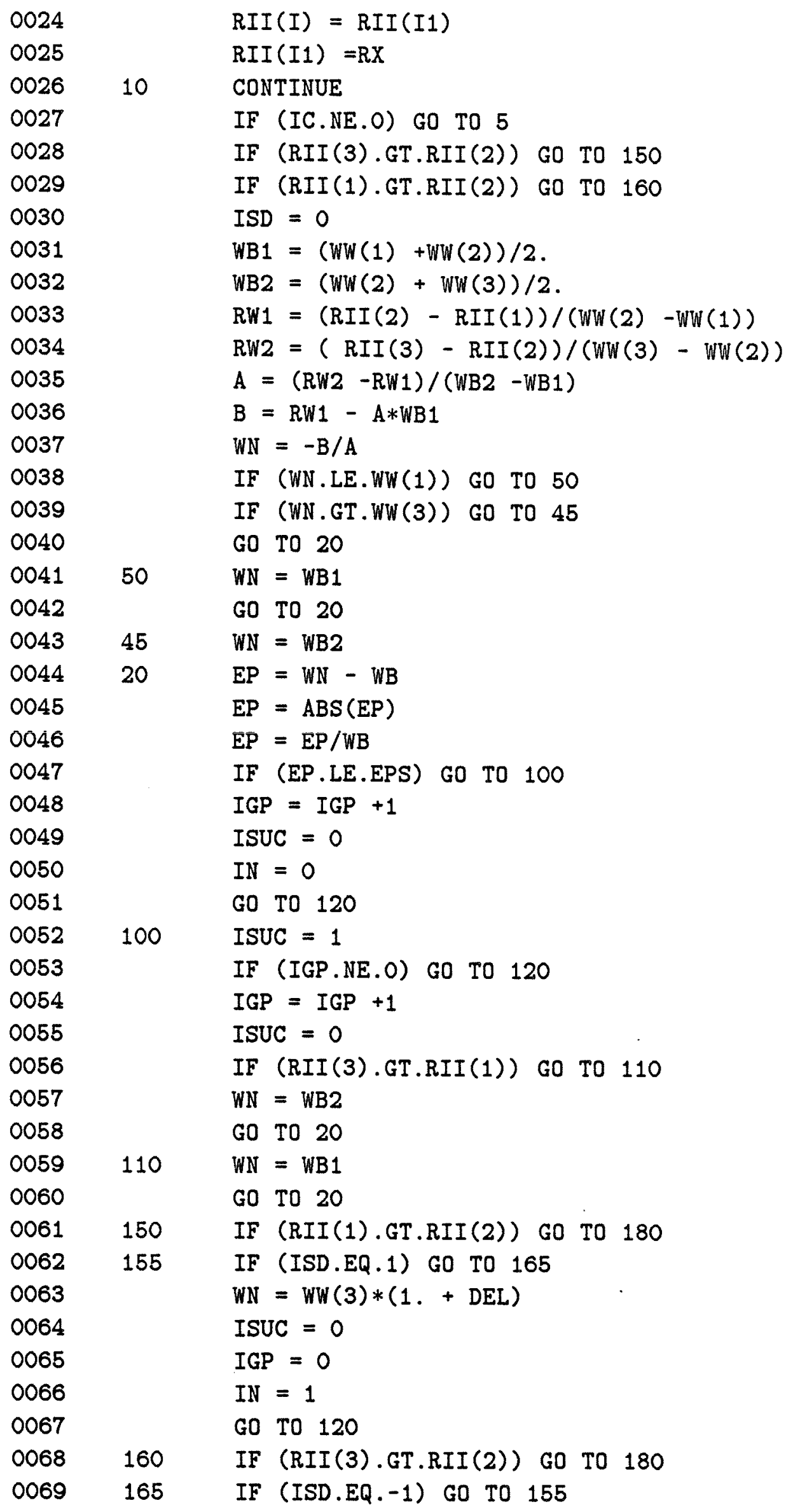




$\begin{array}{lll}0070 & & \text { WN }=W W(1) *(1 .- \text { DEL }) \\ 0071 & & \text { ISUC }=0 \\ 0072 & & \text { IGP }=0 \\ 0073 & & \text { IN }=3 \\ 0074 & & \text { GO TO } 120 \\ 0075 & 180 & \text { IF }(R I I(3) . \text { GT.RII(1)) GO TO } 155 \\ 0076 & & \text { GO TO 165 } \\ 0077 & 120 & \text { IF }(W N . L E .0 .) \text { GO TO } 125 \\ 0078 & & \text { GO TO 130 } \\ 0079 & 125 & \text { ISUC }=2 \\ 0080 & 130 & \text { RETURN } \\ 0081 & & \text { END }\end{array}$

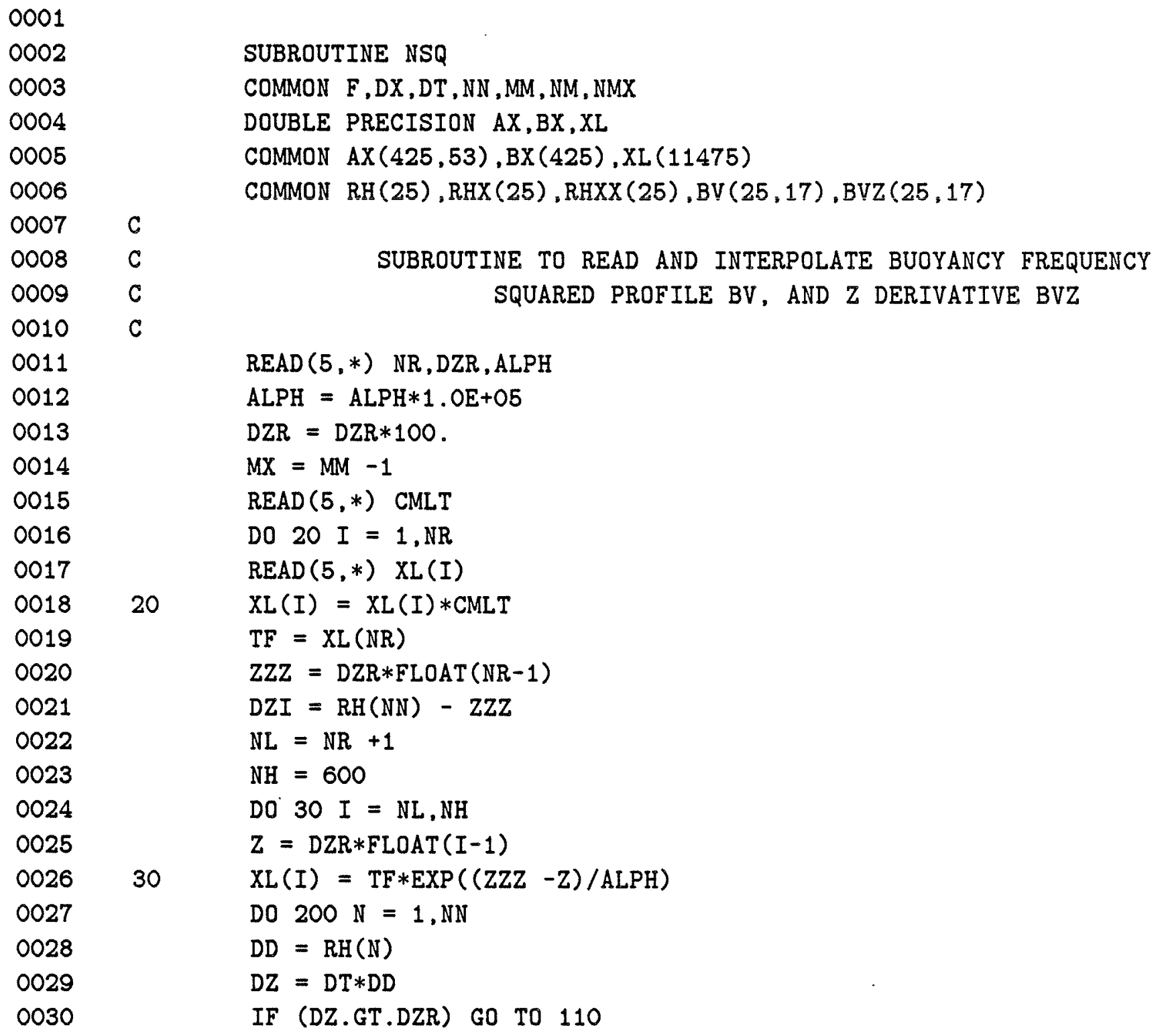




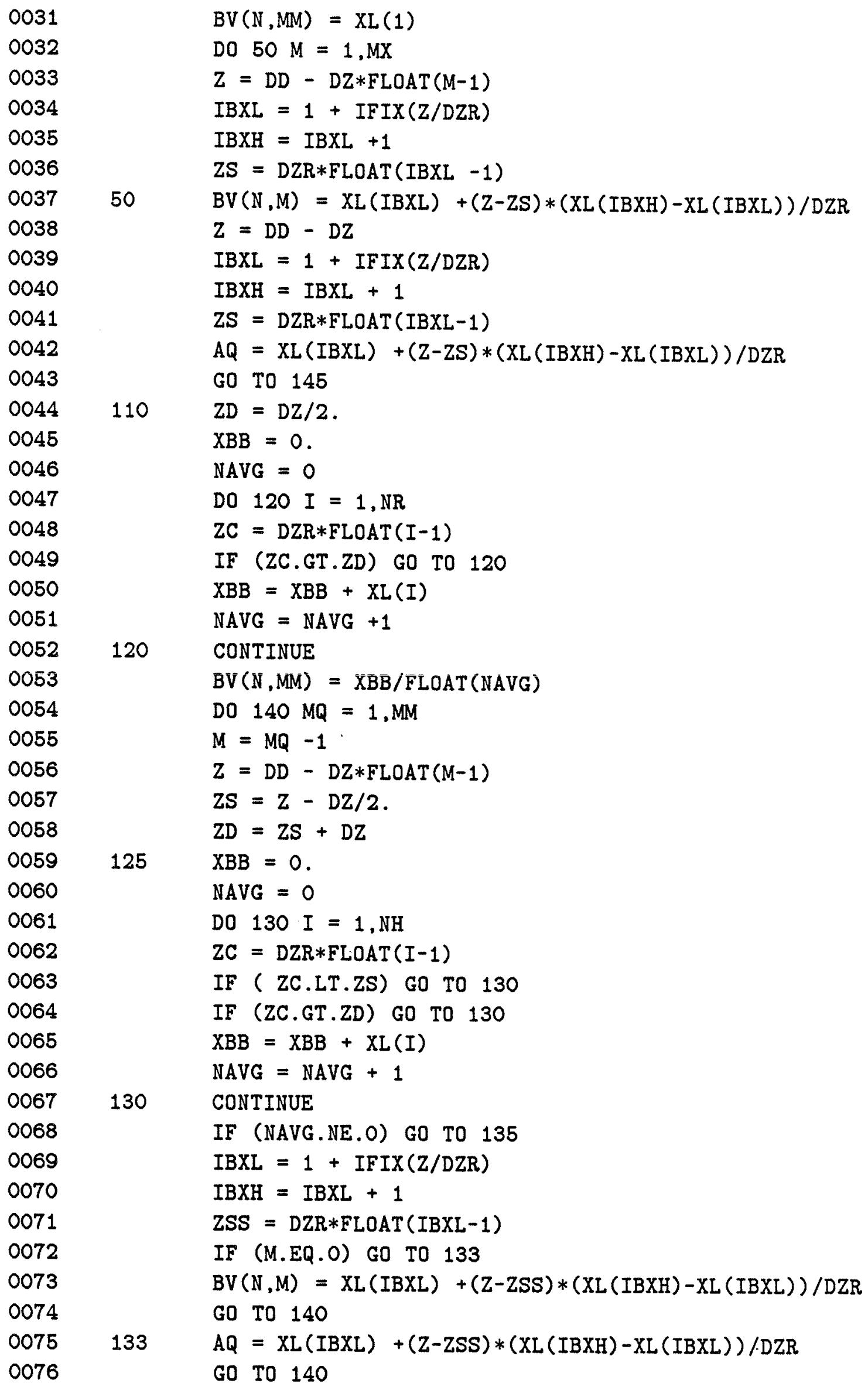




\begin{tabular}{|c|c|c|}
\hline 0077 & 135 & IF (M.EQ.O) GO TO 138 \\
\hline 0078 & & $B V(N, M)=X B B / F L O A T(N A V G)$ \\
\hline 0079 & & GO TO 140 \\
\hline 0080 & 138 & $A Q=X B B / F L O A T(N A V G)$ \\
\hline 0081 & 140 & CONTINUE \\
\hline 0082 & 145 & DO $150 M=2, M X$ \\
\hline 0083 & & $I P=M+1$ \\
\hline 0084 & & $I M=M-1$ \\
\hline 0085 & 150 & $B V Z(N, M)=(B V(N, I P)-B V(N, I M)) /(2 . * D Z)$ \\
\hline 0086 & & $B V Z(\mathbb{N}, 1)=(B V(\mathbb{N}, 2)-A Q) /(2.0 * D Z)$ \\
\hline 0087 & & $B V Z(N, M M)=(B V(N, M M)-B V(N, M X)) / D Z$ \\
\hline 0088 & 200 & CONTINUE \\
\hline 0089 & & WRITE $(6,901)$ \\
\hline 0090 & & $\operatorname{WRITE}(6,902) \quad(\mathrm{BV}(\mathrm{NN}, \mathrm{J}), \mathrm{J}=1, \mathrm{MM})$ \\
\hline 0091 & 901 & FORMAT $\left(/ /{ }^{\prime}\right.$ NSQUARED AT XMAX '/) \\
\hline 0092 & 902 & FORMAT $(2 \mathrm{X}, 10 \mathrm{E} 12.5)$ \\
\hline 0093 & 250 & RETURN \\
\hline 0094 & & END \\
\hline
\end{tabular}

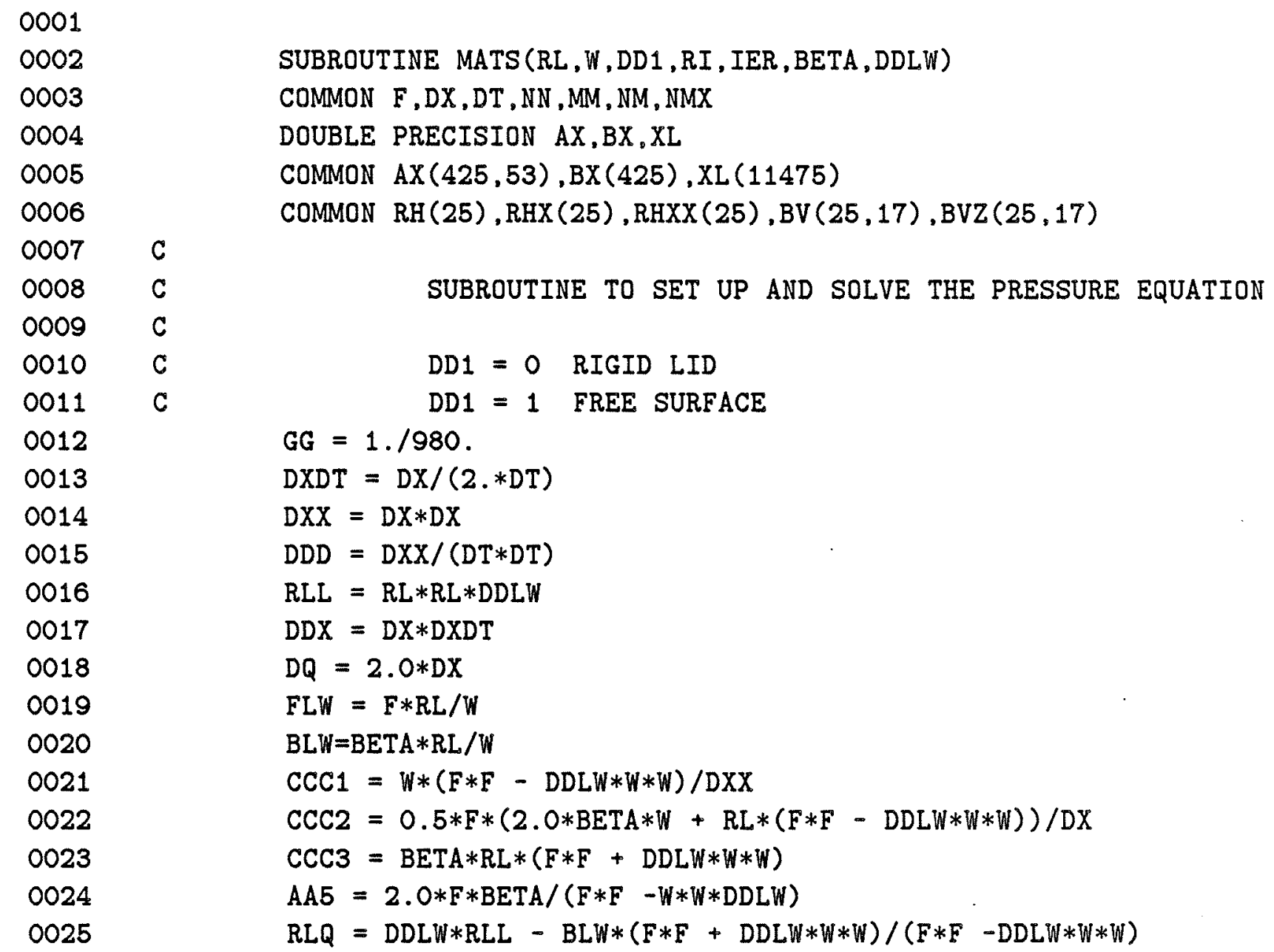




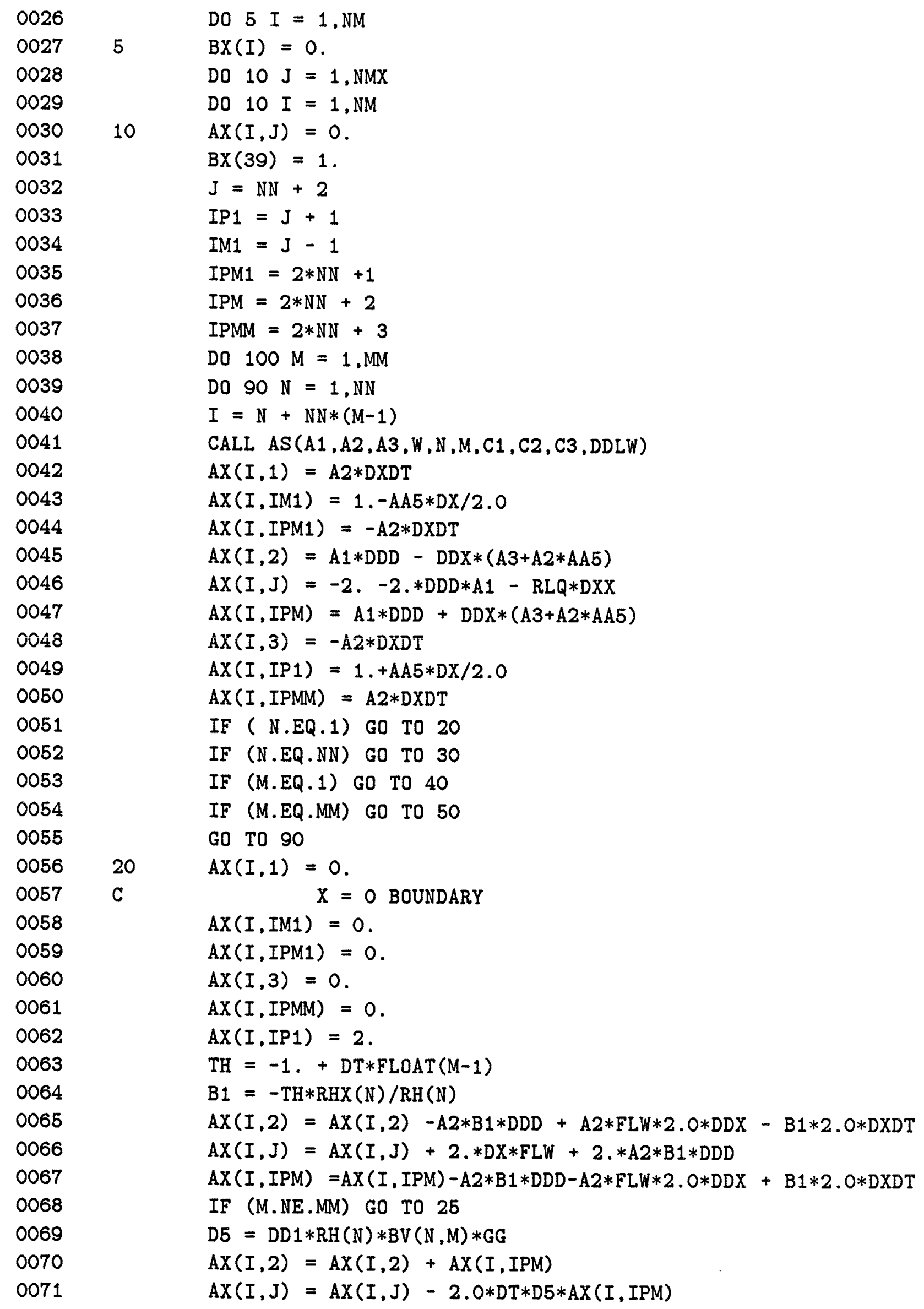




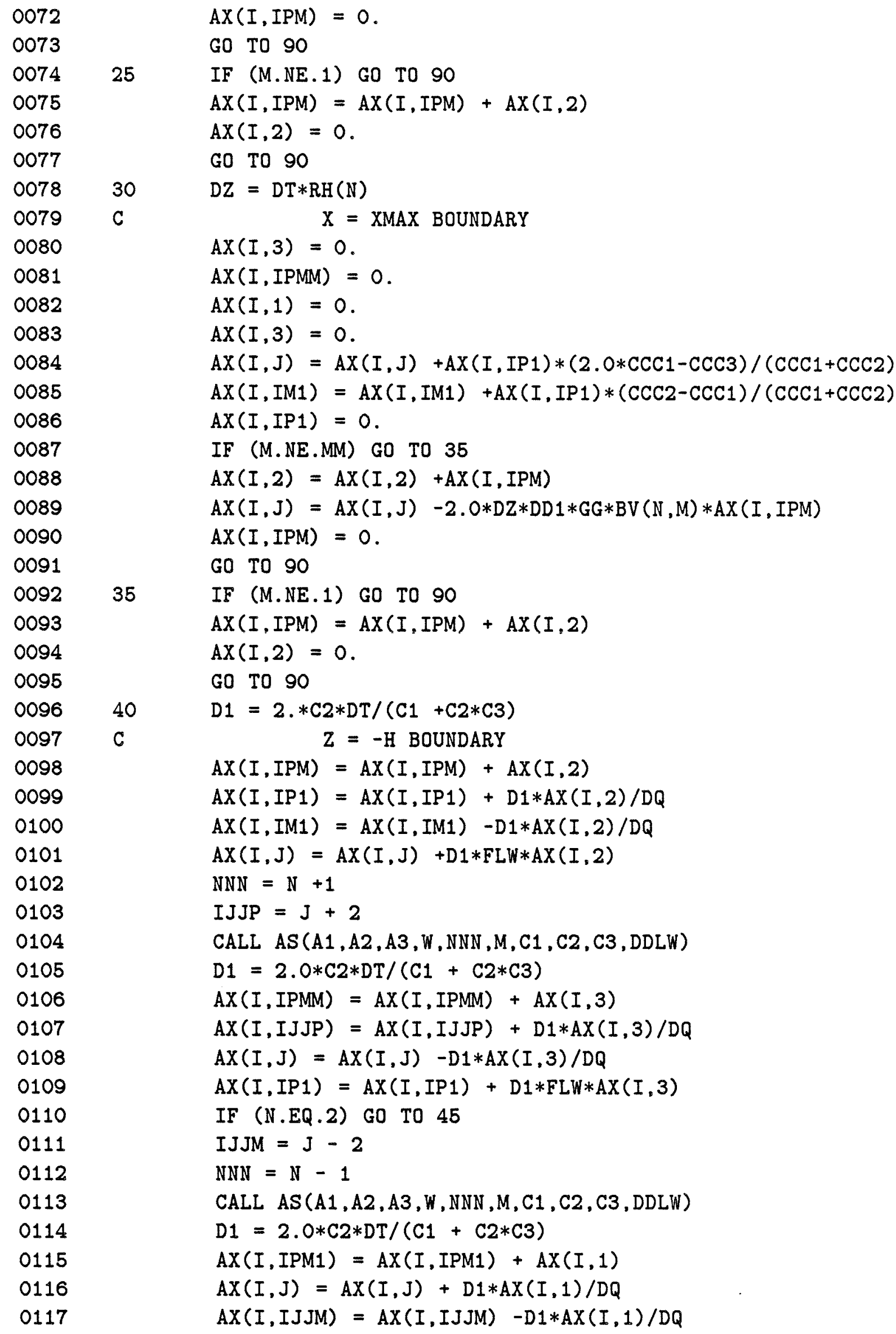




\begin{tabular}{|c|c|c|}
\hline 0118 & & $\operatorname{AX}(I, I M 1)=A X(I, I M 1)+D 1 * F L W * A X(I, 1)$ \\
\hline 0119 & & GO TO 48 \\
\hline 0120 & 45 & $\operatorname{AX}(I, I P M 1)=A X(I, I P M 1)+A X(I, 1)$ \\
\hline 0121 & 48 & $\operatorname{AX}(I, 1)=0$ \\
\hline 0122 & & $A X(I, 2)=0$ \\
\hline 0123 & & $A X(I, 3)=0$ \\
\hline 0124 & & GO TO 90 \\
\hline 0125 & 50 & $A X(I, 1)=0$ \\
\hline 0126 & C & $\mathrm{Z}=0$ BOUNDARY \\
\hline 0127 & & $A X(I, 3)=0$ \\
\hline 0128 & & $\mathrm{D} 5=\mathrm{RH}(\mathrm{N}) * \mathrm{DD} 1 * \mathrm{BV}(\mathrm{N}, \mathrm{M}) * \mathrm{GG}$ \\
\hline 0129 & & $A X(I, 2)=A X(I, 2)+A X(I, I P M)$ \\
\hline 0130 & & $\operatorname{AX}(I, J)=A X(I, J)-D 5 * 2.0 * D T * A X(I, I P M)$ \\
\hline 0131 & & $A X(I, I M 1)=A X(I, I M 1)-D 5 * 2.0 * D T * A X(I, I P M 1)$ \\
\hline 0132 & & $A X(I, I P 1)=A X(I, I P 1)-D 5 * D T * 2.0 * A X(I, I P M M)$ \\
\hline 0133 & & $A X(I, I P M 1)=0.0$ \\
\hline 0134 & & $A X(I, I P M M)=0.0$ \\
\hline 0135 & & $A X(I, I P M)=0.0$ \\
\hline 0136 & 90 & CONTINUE \\
\hline 0137 & 100 & CONTINUE \\
\hline 0138 & & $N D D=N N+1$ \\
\hline 0139 & & NNS $=\mathrm{NM}$ \\
\hline 0140 & & CALL LEQT1B (AX, MM , NDD , NDD , NM , BX, $1, N M, O, X L, I E R)$ \\
\hline 0141 & C & LEQT1B IS AN IMSL ROUTINE \\
\hline 0142 & & CALL CALI(RI) \\
\hline 0143 & & $\mathrm{CC}=\mathrm{W} / \mathrm{RL}$ \\
\hline 0144 & & WRITE $(6,901)$ W,RL,CC,RI, IER \\
\hline 0145 & 901 & FORMAT ( /, W,L,C,RI,IER $\left.={ }^{\prime}, 4 \mathrm{E} 15.5, I 10\right)$ \\
\hline 0146 & & RETURN \\
\hline 0147 & & END \\
\hline
\end{tabular}

0001

0002

0003

SUBROUTINE AS (A1,A2,A3,W,N,M,C1,C2,C3,DDLW)

COMMON F,DX,DT,NN,MM, NM, NMX

0004

DOUBLE PRECISION AX,BX,XL

0005

COMMON AX $(425,53), B X(425), X L(11475)$

0006

$0007 \quad C$

$0008 \quad \mathrm{C}$

COMMON RH(25), RHX (25), RHXX (25), BV $(25,17), \operatorname{BVZ}(25,17)$

$0009 \quad \mathrm{C}$

SUBROUTINE TO COMPUTE COEFFICIENTS FOR MATRIX

0010

$F 2=F * F$

0011

$W 2=W * W * D D L W$

0012

$\mathrm{TZ}=1 . / \mathrm{RH}(\mathrm{N})$

0013

$\mathrm{TH}=-1 .+\mathrm{DT} * \mathrm{FLOAT}(\mathrm{M}-1)$ 


$\begin{array}{ll}0014 & \mathrm{TX}=-\mathrm{RHX}(\mathrm{N}) * \mathrm{TH} * \mathrm{TZ} \\ 0015 & \mathrm{AA}=(\mathrm{RHX}(\mathrm{N}) / \mathrm{RH}(\mathrm{N})) * * 2 \\ 0016 & \mathrm{TXX}=(2 . * \mathrm{AA}-\mathrm{RHXX}(\mathrm{N}) / \mathrm{RH}(\mathrm{N})) * \mathrm{TH} \\ 0017 & \mathrm{BW}=\mathrm{BV}(\mathrm{N}, \mathrm{M}) \\ 0018 & \mathrm{BWW}=\mathrm{BW} * \mathrm{BW} \\ 0019 & \mathrm{~A} 1=\mathrm{TX} * \mathrm{TX}+\mathrm{TZ} * \mathrm{TZ} *(\mathrm{~F} 2-\mathrm{W} 2) / \mathrm{BW} \\ 0020 & \mathrm{~A} 2=\mathrm{TX} \\ 0021 & \mathrm{~A} 3=\mathrm{TXX}-\mathrm{TZ} * \mathrm{BVZ}(\mathrm{N}, \mathrm{M}) *(\mathrm{~F} 2-\mathrm{W} 2) / \mathrm{BWW} \\ 0022 & \mathrm{C} 1=\mathrm{TZ} \\ 0023 & \mathrm{C} 2=\mathrm{RHX}(\mathrm{N}) * \mathrm{BV}(\mathrm{N}, 1) /(\mathrm{F} 2-\mathrm{W} 2) \\ 0024 & \mathrm{C} 3=\mathrm{C} 1 * \mathrm{RHX}(\mathrm{N}) \\ 0025 & \mathrm{RETURN} \\ 0026 & \mathrm{END}\end{array}$

0001

0002

SUBROUTINE DEP

0003

COMMON F,DX,DT,NN,MM,NM,NMX

0004

DOUBLE PRECISION AX,BX,XL

COMMON AX $(425,53), B X(425), X L(11475)$

COMMON RH (25), $\operatorname{RHX}(25), \operatorname{RHXX}(25), \operatorname{BV}(25,17), \operatorname{BVZ}(25,17)$

$0007 \quad C$

SUBROUTINE TO READ AND INTERPOLATE DEPTH PROFILE

$0008 \quad \mathrm{C}$

$\mathrm{RH}=\mathrm{DEPTH}$

RHX $=X$ DERIVATIVE OF DEPTH

$0010 \quad C$

$0011 \quad \mathrm{C}$

RHXX = SECOND $X$ DERIVATIVE OF DEPTH

$0012 \quad \mathrm{C}$

0013

0014

0015

0016

0017

0018

0019

0020

0021

0022

0023

0024

0025

0026

0027

0028

0029

0030

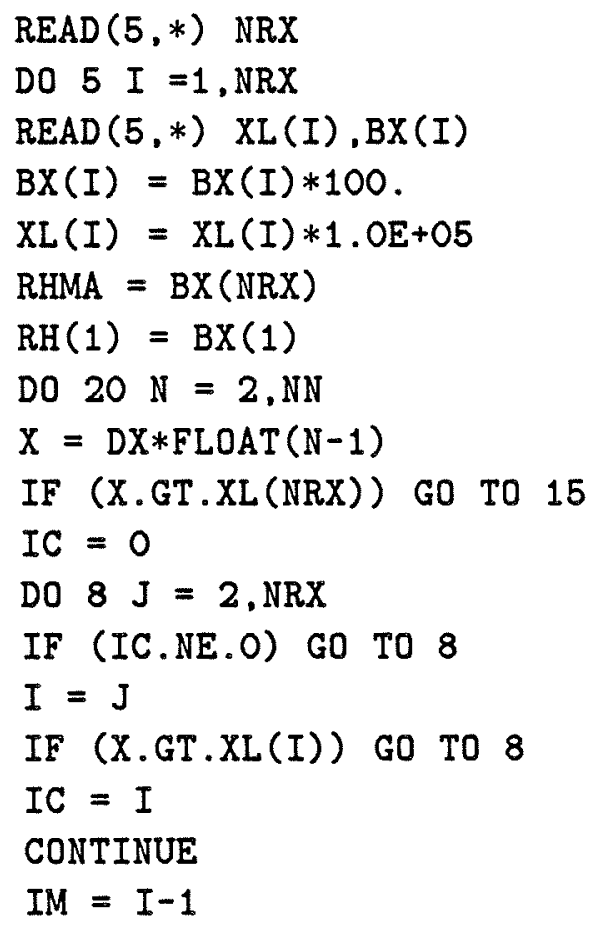




$\begin{array}{lll}0031 & & R H X(N)=(B X(I)-B X(I M)) /(X L(I)-X L(I M)) \\ 0032 & & X X=X-X L(I M) \\ 0033 & & R H(N)=B X(I M)+R H X(N) * X X \\ 0034 & & \text { GO TO } 20 \\ 0035 & 15 & R H(N)=R H M A \\ 0036 & 20 & \text { CONTINUE } \\ 0037 & & R H X(1)=(R H(2)-R H(1)) / D X \\ 0038 & & R H X X(1)=0 . \\ 0039 & & D 2=2 . D X \\ 0040 & & D X X=D X * D X \\ 0041 & & N X=N N-1 \\ 0042 & & D O 30 N=2, N X \\ 0043 & & I P=N+1 \\ 0044 & & I M=N-1 \\ 0045 & & R H X(N)=(R H(I P)-R H(I M)) / D 2 \\ 0046 & 30 & R H X X(N)=(R H(I P)-2 . * R H(N)+R H(I M)) / D X X \\ 0047 & & R H X(N N)=0 . \\ 0048 & & R H X X(N N)=0 . \\ 0049 & & R E T U N \\ 0050 & & E N D\end{array}$

0001

0002

0003

SUBROUTINE CALI(RIX)

COMMON F,DX,DT,NN, MM , NM, NMX

DOUBLE PRECISION AX,BX,XL

COMMON AX $(425,53), B X(425), X L(11475)$

COMMON RH(25), RHX (25), $\operatorname{RHXX}(25), \operatorname{BV}(25,17), \operatorname{BVZ}(25,17)$

DOUBLE PRECISION RI,RZ

0007

$0008 \mathrm{C}$

$0009 \quad \mathrm{C}$

SUBROUTINE TO CALCULATE THE INTEGRAL OF RESPONSE SQUARED

$0010 \quad \mathrm{C}$

$0011 \mathrm{C}$

FIRST, REORDER THE MATRIX

0012

0013

0014

0015

0016

0017

0018

0019

0020

0021

0022

0023

DO $2 \mathrm{M}=1, \mathrm{MM}$

DO $2 \mathrm{~N}=1, \mathrm{NN}$

$\mathrm{IN}=\mathrm{N}+\mathrm{NN} *(\mathrm{M}-1)$

$I I=M+M M *(N-1)$

$\mathrm{XL}(I I)=\mathrm{BX}(\mathrm{IN})$

DO $3 I=1, N M$

$\mathrm{BX}(I)=\mathrm{XL}(I)$

$\mathrm{RI}=0$.

$\mathrm{RR}=0$.

$\mathrm{RZ}=0$.

DO $50 \mathrm{~N}=1, \mathrm{NN}$

IF (N.EQ.1) GO TO 5 


\begin{tabular}{|c|c|c|}
\hline 0024 & & IF (N.NE.NN) GO TO 10 \\
\hline 0025 & 5 & $D X X=D X / 2$ \\
\hline 0026 & & GO TO 15 \\
\hline 0027 & 10 & $D X X=D X$ \\
\hline 0028 & 15 & DO $50 \mathrm{M}=1 . \mathrm{MM}$ \\
\hline 0029 & & $\mathrm{DZ}=\mathrm{DT} * \mathrm{RH}(\mathrm{N})$ \\
\hline 0030 & & IF (M.EQ.1) GO TO 25 \\
\hline 0031 & & IF (M.NE.MM) GO TO 30 \\
\hline 0032 & 25 & $\mathrm{DZZ}=\mathrm{DZ} / 2$ \\
\hline 0033 & & GO TO 35 \\
\hline 0034 & 30 & $\mathrm{DZZ}=\mathrm{DZ}$ \\
\hline 0035 & 35 & $I=(N-1) * M M+M$ \\
\hline 0036 & & $\mathrm{RZ}=\mathrm{RZ}+\mathrm{DZZ} * \mathrm{DXX}$ \\
\hline 0037 & & $R I=R I+D Z Z * D X X * B X(I) * * 2$ \\
\hline 0038 & 50 & CONTINUE \\
\hline 0039 & & $R I=R I / R Z$ \\
\hline 0040 & & $\mathrm{RIX}=\mathrm{RI}$ \\
\hline 0041 & & RETURN \\
\hline 0042 & & END \\
\hline
\end{tabular}

0001

0002

0003

0004

0005

0006

0007

0008

0009

0010

0011

0012

0013

0014

0015

0016

0017

0018

0019

0020

0021

SUBROUTINE DIAG(W,RL,DDLW)

COMMON F,DX,DT,NN,MM,NM,NMX

DOUBLE PRECISION AX,BX,XL

COMMON AX $(425,53), B X(425), X L(11475)$

COMMON RH (25), $\operatorname{RHX}(25), \operatorname{RHXX}(25), \operatorname{BV}(25,17), \operatorname{BVZ}(25,17)$

SUBROUTINE TO COMPUTE MOMENTUM DIAGNOSTICS

C

C

C

$\mathrm{N}=5$

$\mathrm{I}=\mathrm{N} * \mathrm{MM}$

$I P=I+M M$

$I M=I-M M$

$\mathrm{PX}=(\mathrm{BX}(\mathrm{IP})-\mathrm{BX}(\mathrm{IM})) /(2 . * \mathrm{DX})$

$\mathrm{F} 2=\mathrm{F} * \mathrm{~F}-\mathrm{W} * W * \mathrm{DDL} W$

$\mathrm{VT}=\mathrm{W} *(\mathrm{~F} * \mathrm{PX}+\mathrm{DDLW} * \mathrm{RL} * \mathrm{~W} * \mathrm{BX}(\mathrm{I})) / \mathrm{F} 2$

$F U=-F *(R L * F * B X(I)+W * P X) / F 2$

$\mathrm{PY}=\mathrm{RL} * \mathrm{BX}(\mathrm{I})$

$\mathrm{X}=\mathrm{DX} * \mathrm{FLOAT}(\mathrm{N}-1)$

WRITE $(6,901) X$

WRITE $(6,902)$ VT,FU,PY

0022901

FORMAT $\left(/ /\right.$, Y MOMENTUM TERMS AT $Z=0, X==^{\prime}$, E15.5)

$0023 \quad 902$

0024

FORMAT $(/ \cdot$ VT,FU,PY $=$, 3E15.5/)

RETURN

END 


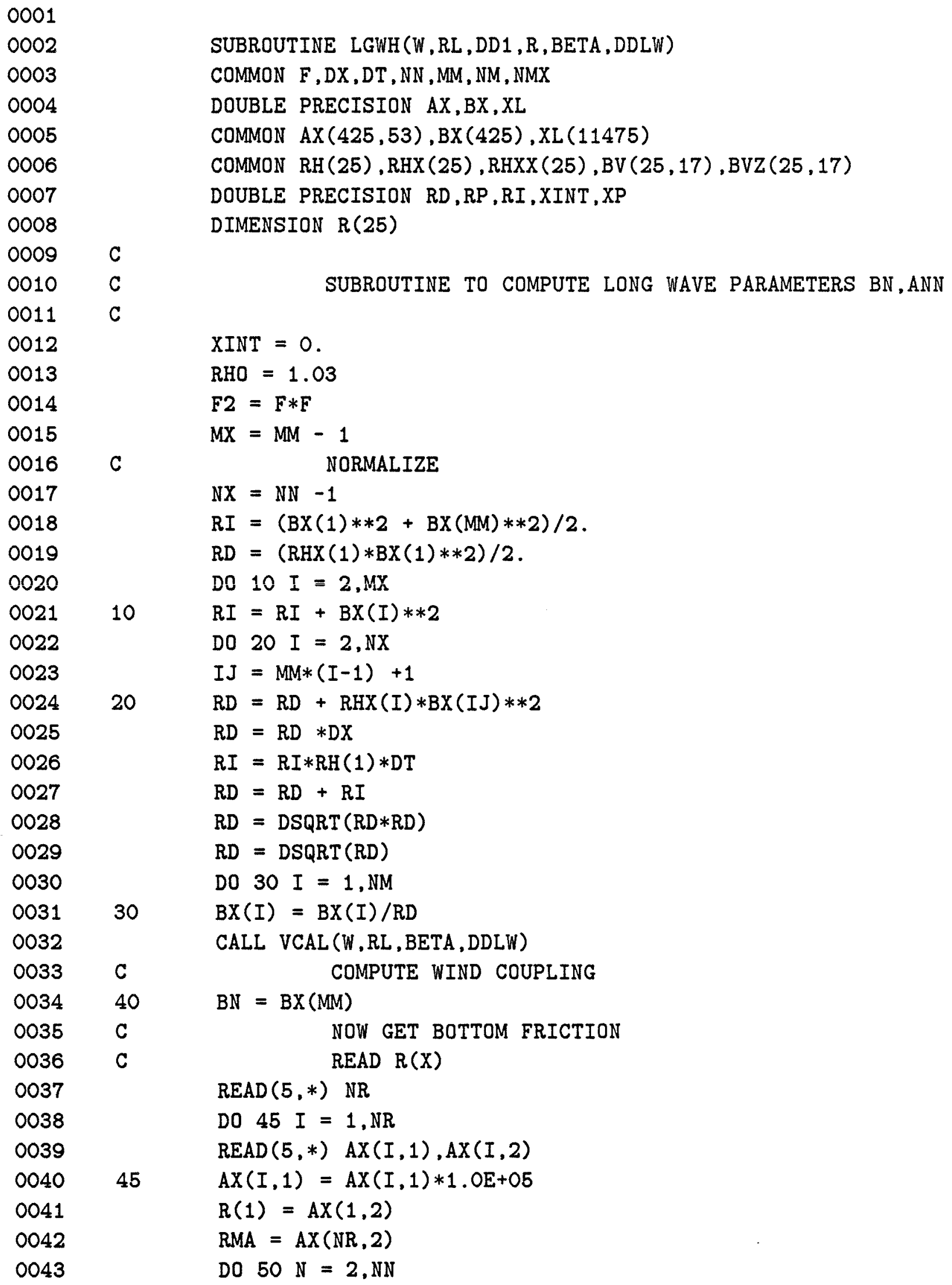




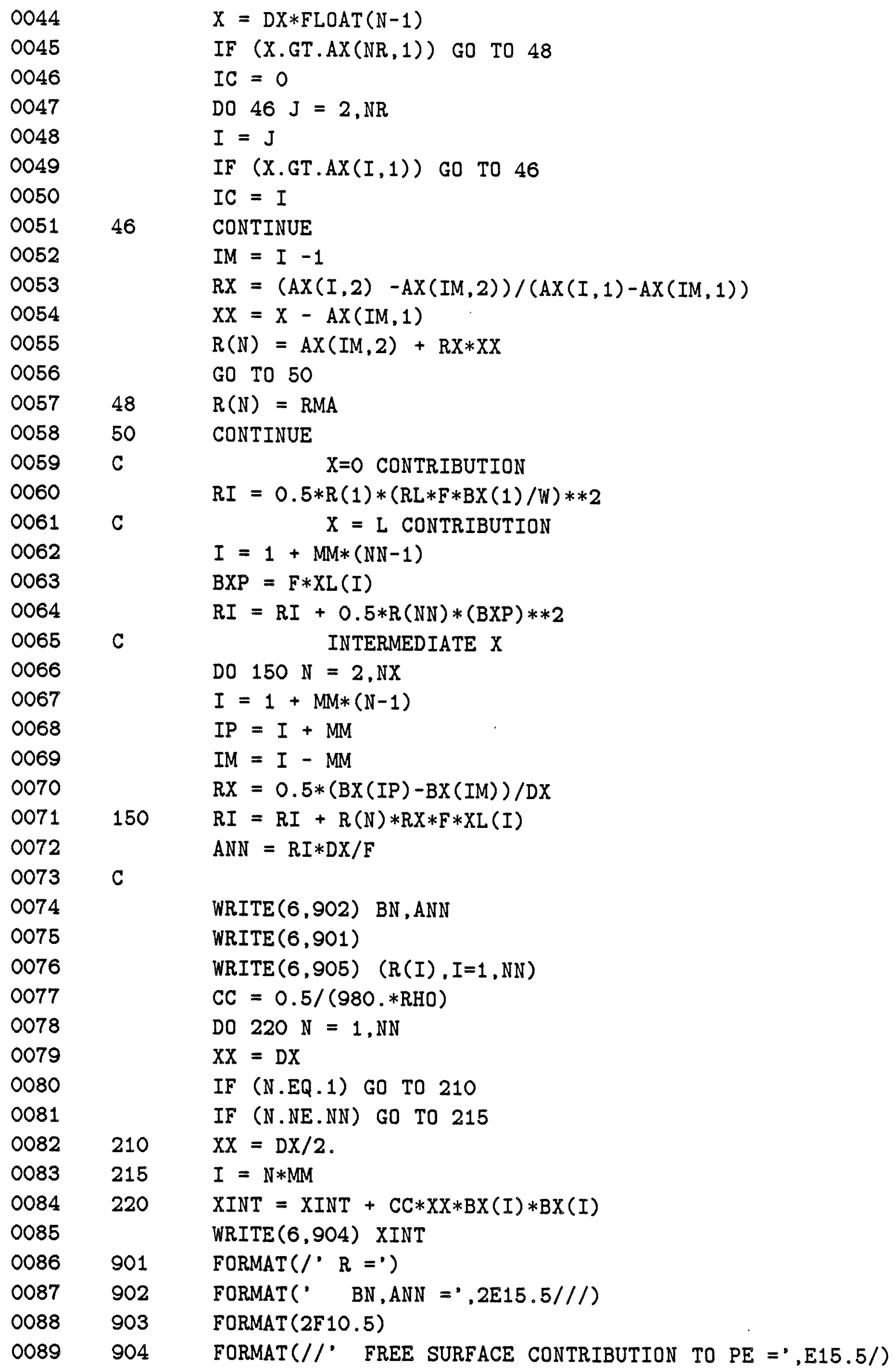




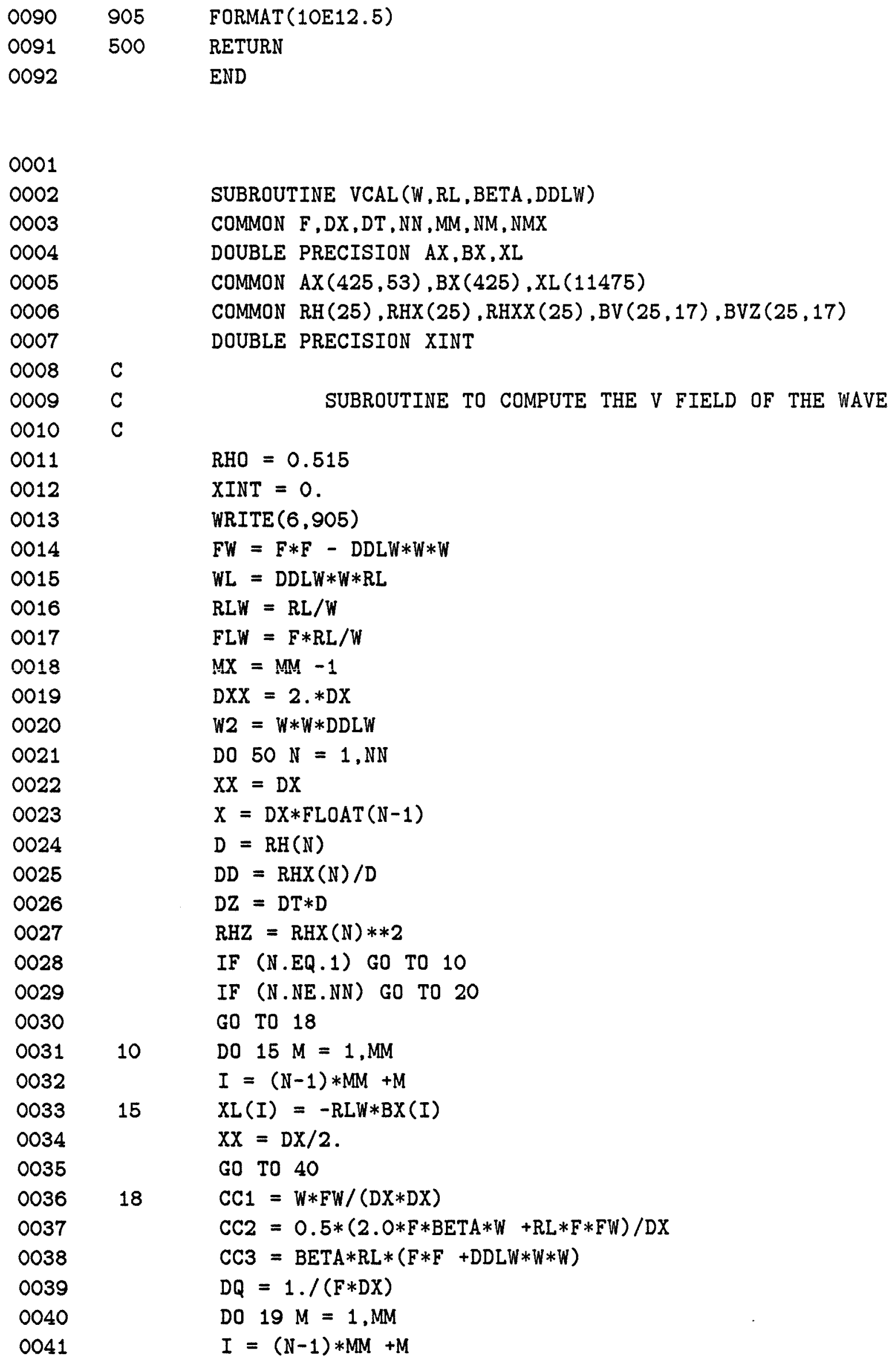




\begin{tabular}{|c|c|c|}
\hline 0042 & & $I M=I-M M$ \\
\hline 0043 & & $\mathrm{XP}=\mathrm{BX}(I) *(2.0 * \mathrm{CC} 1-\mathrm{CC} 3) /(\mathrm{CC} 1+\mathrm{CC} 2)$ \\
\hline 0044 & & $X P=X P+B X(I M) *(C C 2-C C 1) /(C C 1+C C 2)$ \\
\hline 0045 & & $X P X=(X P-B X(I M)) /(2.0 * D X)$ \\
\hline 0046 & 19 & $X L(I)=(F * X P X+W L * B X(I)) / F W$ \\
\hline 0047 & & $\mathrm{XX}=\mathrm{DX} / 2$ \\
\hline 0048 & & GO TO 40 \\
\hline 0049 & 20 & $I=(N-1) * M M+1$ \\
\hline 0050 & & $I P=I+M M$ \\
\hline 0051 & & $I M=I-M M$ \\
\hline 0052 & & CALL AS (A1,A2,A3,W,N,1,C1,C2,C3,DDLW) \\
\hline 0053 & & $\mathrm{CQ}=\mathrm{C} 2 * \mathrm{C} 3 /(\mathrm{C} 1+\mathrm{C} 2 * \mathrm{C} 3)$ \\
\hline 0054 & & $X P X=(1.0-C Q) *(B X(I P)-B X(I M)) / D X X$ \\
\hline 0055 & & $\mathrm{XPX}=\mathrm{XPX}-\mathrm{CQ} * \mathrm{FLW} * \mathrm{BX}(\mathrm{I})$ \\
\hline 0056 & & $X L(I)=(W L * B X(I)+F * X P X) / F W$ \\
\hline 0057 & & $I=N * M M$ \\
\hline 0058 & & $I P=I+M M$ \\
\hline 0059 & & $I M=I-M M$ \\
\hline 0060 & & $X P X=(B X(I P)-B X(I M)) / D X X$ \\
\hline 0061 & & $X L(I)=(W L * B X(I)+F * X P X) / F W$ \\
\hline 0062 & & DO $30 \mathrm{M}=2, \mathrm{MX}$ \\
\hline 0063 & & $I=(N-1) * M M+M$ \\
\hline 0064 & & $I P=I+M M$ \\
\hline 0065 & & $I M=I-M M$ \\
\hline 0066 & & $I 2=I+1$ \\
\hline 0067 & & $I 1=I-1$ \\
\hline 0068 & & $X P X=(B X(I P)-B X(I M)) / D X X$ \\
\hline 0069 & & $\mathrm{~T}=-1 .+\mathrm{DT} * \mathrm{FLOAT}(\mathrm{M}-1)$ \\
\hline 0070 & & $\mathrm{XPT}=(\mathrm{BX}(I 2)-\mathrm{BX}(I 1)) /(2 . * \mathrm{DT})$ \\
\hline 0071 & & $X P X=X P X-T * D D * X P T$ \\
\hline 0072 & 30 & $X L(I)=(W L * B X(I)+F * X P X) / F W$ \\
\hline 0073 & 40 & Do $45 \mathrm{M}=1, \mathrm{MM}$ \\
\hline 0074 & & $I=(N-1) * M M+M$ \\
\hline 0075 & & $Z Z=D Z$ \\
\hline 0076 & & IF (M.EQ.1) GO TO 42 \\
\hline 0077 & & IF (M.NE.MM) GO TO 45 \\
\hline 0078 & 42 & $\mathrm{ZZ}=\mathrm{DZ} / 2$ \\
\hline 0079 & 45 & $\mathrm{XINT}=\mathrm{XINT}+\mathrm{RHO} * \mathrm{XL}(\mathrm{I}) * \mathrm{XL}(\mathrm{I}) * \mathrm{XX} * \mathrm{ZZ}$ \\
\hline 0080 & & WRITE $(6,904) \quad X, D, D Z$ \\
\hline 0081 & & $I L=(N-1) * M M+1$ \\
\hline 0082 & & $\mathrm{IH}=\mathrm{N} * \mathrm{MM}$ \\
\hline 0083 & & $\operatorname{WRITE}(6,901) \quad(X L(I J), I J=I L, I H)$ \\
\hline 0084 & 50 & CONTINUE \\
\hline 0085 & & WRITE $(6,902) \quad X I N T$ \\
\hline 0086 & 901 & FORMAT $(2 \mathrm{X}, 10 \mathrm{E} 12.5)$ \\
\hline 0087 & 902 & FORMAT $\left(/ /{ }^{\prime}\right.$ V CONTRIBUTION TO $\left.\mathrm{KE}={ }^{\prime}, \mathrm{E} 15.5 /\right)$ \\
\hline
\end{tabular}




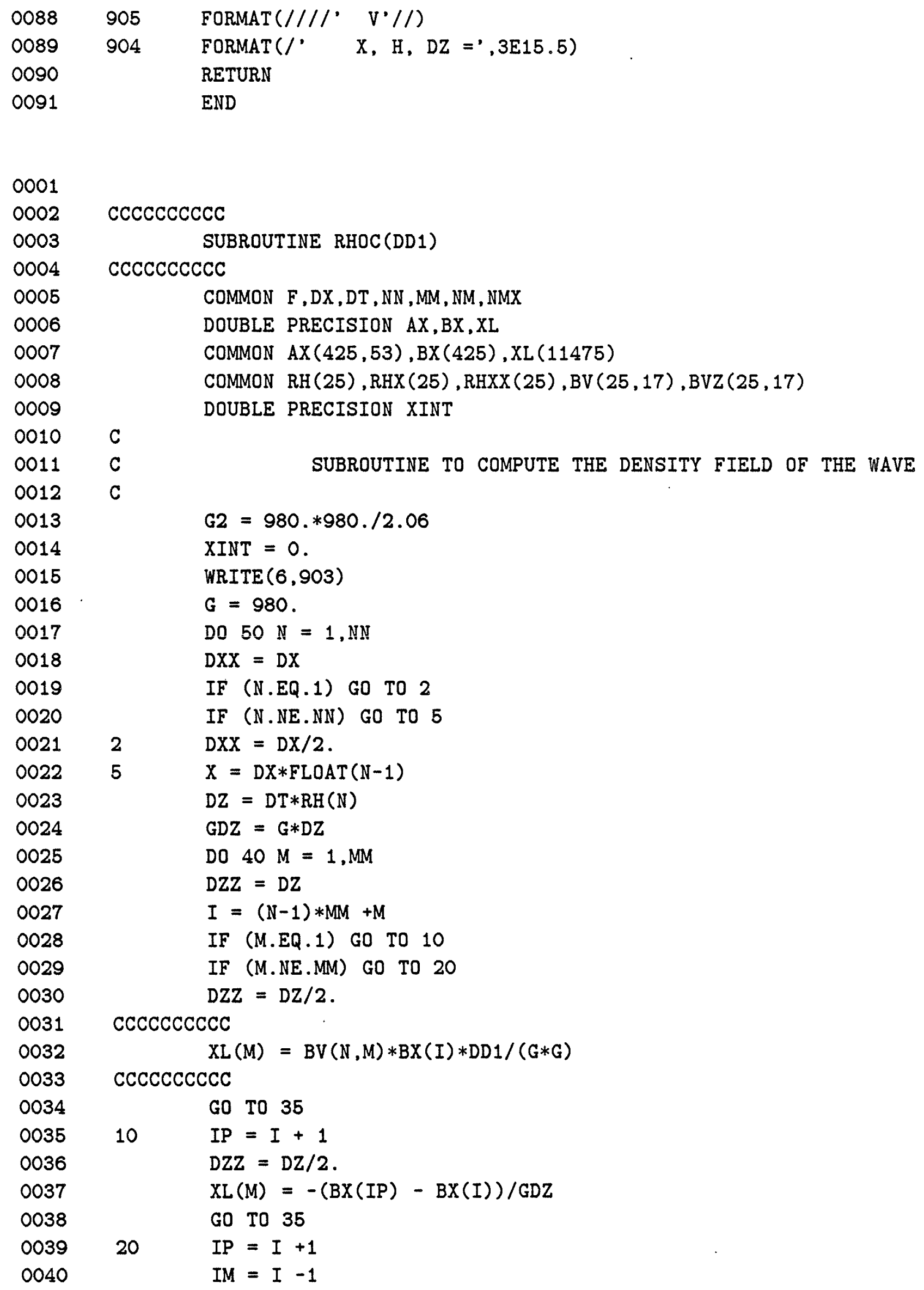




\begin{tabular}{|c|c|c|}
\hline 0041 & & $X L(M)=-(B X(I P)-B X(I M)) /(2 * * G D Z)$ \\
\hline 0042 & 35 & $X X=G 2 * X L(M) * X L(M) / B V(N, M)$ \\
\hline 0043 & & $X I N T=X I N T+X X * D Z Z * D X X$ \\
\hline 0044 & 40 & CONTINUE \\
\hline 0045 & & $\operatorname{WRITE}(6,901) \quad \mathrm{X}, \mathrm{RH}(\mathrm{N}), \mathrm{DZ}$ \\
\hline 0046 & 50 & $\operatorname{WRITE}(6,902) \quad(X L(M), M=1, M M)$ \\
\hline 0047 & & WRITE $(6,904) \quad X I N T$ \\
\hline 0048 & 901 & FORMAT $\left(/^{\prime} \quad X, D, D Z=^{\prime}, 3 E 15.5\right)$ \\
\hline 0049 & 902 & FORMAT $(2 X, 10 E 12.5)$ \\
\hline 0050 & 903 & FORMAT $(/ / /$, RHO'/) \\
\hline 0051 & 904 & FORMAT $\left(/ /{ }^{\prime}\right.$ RHO CONTRIBUTION TO PE $={ }^{\circ}$, E15.5/) \\
\hline 0052 & & RETURN \\
\hline 0053 & & END \\
\hline
\end{tabular}

0001

0002

0003

SUBROUTINE UCAL (W, RL, BETA, DDLW)

COMMON F,DX,DT,NN,MM,NM, NMX

DOUBLE PRECISION AX,BX,XL

COMMON AX (425,53),BX(425),XL(11475)

COMMON RH (25), RHX (25), RHXX $(25), \operatorname{BV}(25,17), \operatorname{BVZ}(25,17)$

DOUBLE PRECISION XINT

0008

C

$0009 \quad \mathrm{C}$

SUBROUTINE TO COMPUTE THE U FIELD OF THE WAVE

$0010 \quad \mathrm{C}$

0011

0012

0013

0014

0015

0016

0017

0018

0019

0020

0021

0022

0023

0024

0025

0026

0027

0028

0029

0030

$$
\begin{aligned}
& \text { RHO }=0.515 \\
& X I N T=0 . \\
& F W=F * F-D D L W * W * W \\
& F L=F * R L \\
& W R I T E(6,903) \\
& D O 100 N=1, N N \\
& D X X=D X \\
& X=D X * F L O A T(N-1) \\
& D Z=D T * R H(N) \\
& D O 5 I=1, M M \\
& X L(I)=0 . \\
& I F(N . E Q \cdot 1) \text { GO TO } 90 \\
& I F(N . E Q \cdot N N) \text { GO TO } 110 \\
& D D=R H X(N) / R H(N) \\
& D O 85 M=1, M M \\
& I=(N-1) * M M+M \\
& I P=I+M M \\
& I M=I-M M \\
& T=-1 .+D T * F L O A T(M-1) \\
& I F(M . E Q .1) \text { GO TO } 10 \\
& I F(M . E Q . M M) \text { GO TO } 15
\end{aligned}
$$




\begin{tabular}{|c|c|c|}
\hline 0032 & & GO TO 20 \\
\hline 0033 & 10 & $I 1=I+1$ \\
\hline 0034 & & $X P T=(B X(I 1)-B X(I)) / D T$ \\
\hline 0035 & & GO TO 25 \\
\hline 0036 & 15 & $\mathrm{XPT}=0$. \\
\hline 0037 & & GO TO 25 \\
\hline 0038 & 20 & $I 2=I+1$ \\
\hline 0039 & & $I 1=I-1$ \\
\hline 0040 & & $X P T=(B X(I 2)-B X(I 1)) /(2 . * D T)$ \\
\hline 0041 & 25 & $X P X=(B X(I P)-B X(I M)) /(2 . * D X)$ \\
\hline 0042 & & $X P X=X P X-T * D D * X P T$ \\
\hline 0043 & 85 & $X L(M)=-(W * X P X+F L * B X(I)) / F W$ \\
\hline 0044 & & GO TO 90 \\
\hline 0045 & 110 & $C C 1=W * F W /(D X * D X)$ \\
\hline 0046 & & $\mathrm{CC} 2=0.5 *(2.0 * \mathrm{~F} * \mathrm{BETA} * \mathrm{~W}+\mathrm{RL} * \mathrm{~F} * \mathrm{FW}) / \mathrm{DX}$ \\
\hline 0047 & & $\mathrm{CC} 3=\mathrm{BETA} * \mathrm{RL} *(\mathrm{~F} * \mathrm{~F}+\mathrm{DDLW} * \mathrm{~W} * \mathrm{~W})$ \\
\hline 0048 & & $\mathrm{DXX}=\mathrm{DX} / 2$ \\
\hline 0049 & & DO $120 \mathrm{M}=1, \mathrm{MM}$ \\
\hline 0050 & & $I=(N N-1) * M M+M$ \\
\hline 0051 & & $I M=I-M M$ \\
\hline 0052 & & $\mathrm{XPIM}=\mathrm{BX}(\mathrm{I}) *(2.0 * \mathrm{CC} 1-\mathrm{CC} 3) /(\mathrm{CC} 1+\mathrm{CC} 2)$ \\
\hline 0053 & & $\mathrm{XPIM}=\mathrm{XPIM}+\mathrm{BX}(\mathrm{IM}) *(\mathrm{CC} 2-\mathrm{CC} 1) /(\mathrm{CC} 1+\mathrm{CC} 2)$ \\
\hline 0054 & 120 & $X L(M)=-(F L * B X(I)+W * 0.5 *(X P I M-B X(I M)) / D X) / F W$ \\
\hline 0055 & 90 & DO $95 \mathrm{M}=1, \mathrm{MM}$ \\
\hline 0056 & & $\mathrm{DZZ}=\mathrm{DZ}$ \\
\hline 0057 & & IF (M.EQ.1) GO TO 92 \\
\hline 0058 & & IF (M.NE.MM) GO TO 95 \\
\hline 0059 & 92 & $\mathrm{DZZ}=\mathrm{DZ} / 2$ \\
\hline 0060 & 95 & $X I N T=X I N T+R H O * X L(M) * X L(M) * D X X * D Z Z$ \\
\hline 0061 & & $\operatorname{WRITE}(6,901) \quad \mathrm{X}, \mathrm{RH}(\mathrm{N}), \mathrm{DZ}$ \\
\hline 0062 & & $\operatorname{WRITE}(6,902) \quad(X L(M), M=1, M M)$ \\
\hline 0063 & 100 & CONTINUE \\
\hline 0064 & & WRITE $(6,904) \quad X I N T$ \\
\hline 0065 & 901 & FORMAT $\left(/{ }^{\prime} \quad X, D, D Z=', 3 E 15.5\right)$ \\
\hline 0066 & 902 & FORMAT $(2 X, 10 E 12.5)$ \\
\hline 0067 & 903 & $\operatorname{FORMAT}(/ / / \cdot \quad U \cdot /)$ \\
\hline 0068 & 904 & FORMAT $\left(/ /\right.$, U CONTRIBUTION TO $\left.\mathrm{KE}={ }^{\prime}, \mathrm{E} 15.5 /\right)$ \\
\hline 0069 & & RETURN \\
\hline 0070 & & END \\
\hline
\end{tabular}




\section{Program CROSS Listing}

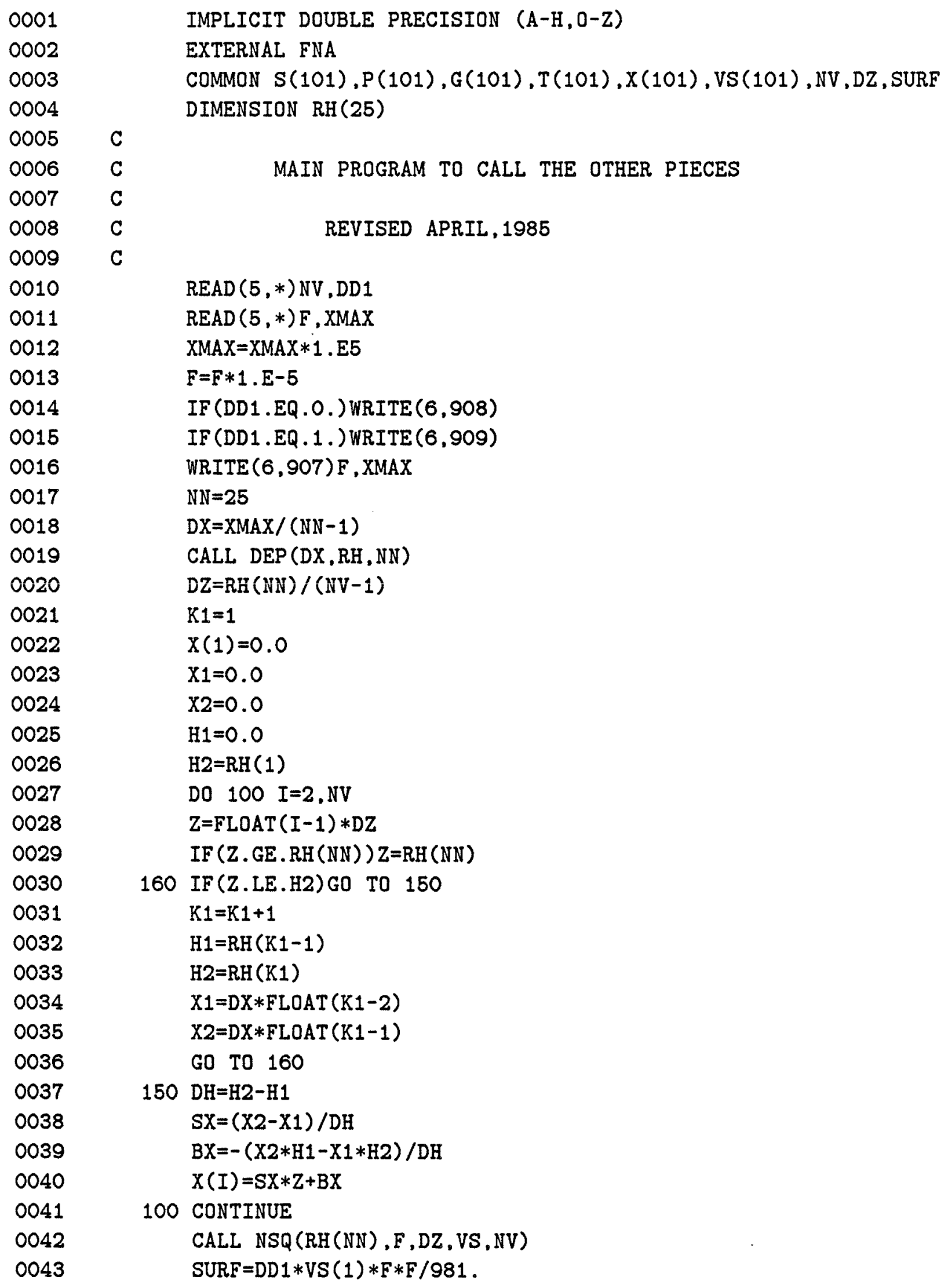




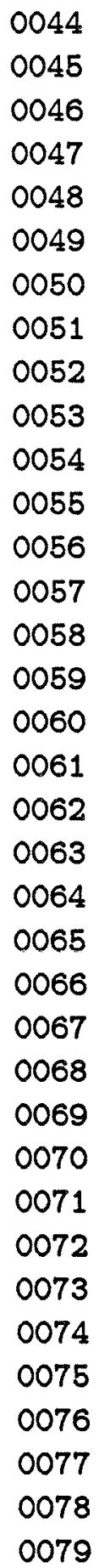




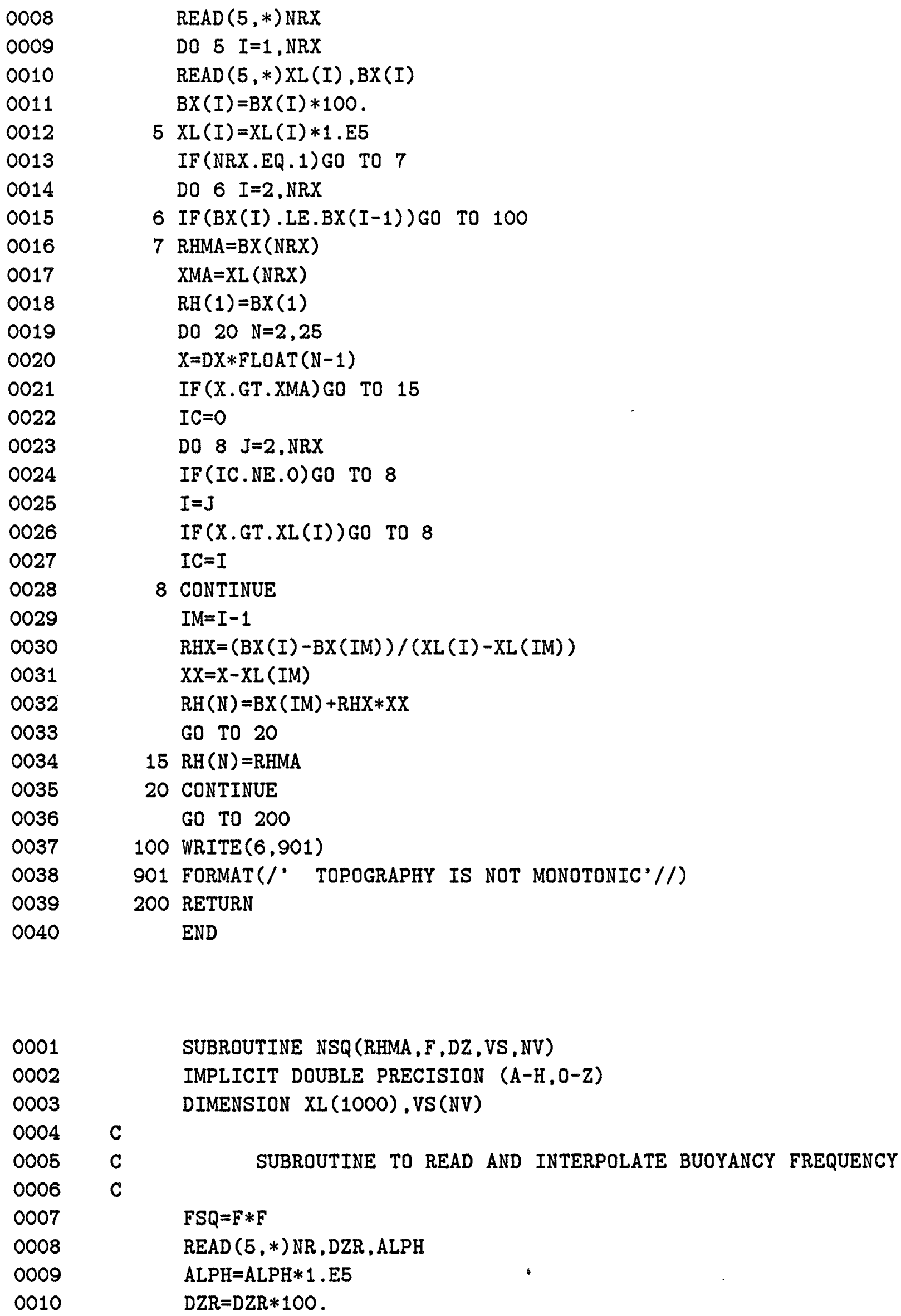




\begin{tabular}{|c|c|c|}
\hline 0011 & & $\operatorname{READ}(5, *) \operatorname{CMLT}$ \\
\hline 0012 & & DO $20 I=1 . N R$ \\
\hline 0013 & & $\operatorname{READ}(5, *) \operatorname{XL}(I)$ \\
\hline 0014 & 20 & $\mathrm{XL}(I)=\mathrm{XL}(I) * \mathrm{CMLT}$ \\
\hline 0015 & & $T F=X L(N R)$ \\
\hline 0016 & & $Z Z Z=D Z R * F L O A T(N R-1)$ \\
\hline 0017 & & $I=N R+1$ \\
\hline 0018 & 50 & $Z=D Z R * F L O A T(I-1)$ \\
\hline 0019 & & $\mathrm{XL}(\mathrm{I})=\mathrm{TF} * \mathrm{DEXP}((\mathrm{ZZZ}-\mathrm{Z}) / \mathrm{ALPH})$ \\
\hline 0020 & & IF (Z.GT.RHMA)GO TO 100 \\
\hline 0021 & & $I=I+1$ \\
\hline 0022 & & GO TO 50 \\
\hline 0023 & 100 & $\mathrm{~K} 1=1$ \\
\hline 0024 & & $\operatorname{VS}(1)=X L(1) / F S Q$ \\
\hline 0025 & & $\mathrm{H} 1=0.0$ \\
\hline 0026 & & $\mathrm{H} 2=\mathrm{DZR}$ \\
\hline 0027 & & DO $200 I=2, N V$ \\
\hline 0028 & & $Z=F L O A T(I-1) * D Z$ \\
\hline 0029 & & IF (Z .GE. RHMA) Z=RHMA \\
\hline 0030 & 160 & IF (Z.LE.H2)GO TO 150 \\
\hline 0031 & & $\mathrm{~K} 1=\mathrm{K} 1+1$ \\
\hline 0032 & & $\mathrm{H} 1=\mathrm{FLOAT}(\mathrm{K} 1-1) * \mathrm{DZR}$ \\
\hline 0033 & & $\mathrm{H} 2=\mathrm{FLOAT}(\mathrm{K} 1) * \mathrm{DZR}$ \\
\hline 0034 & & GO TO 160 \\
\hline 0035 & 150 & $\mathrm{DH}=\mathrm{H} 2-\mathrm{H} 1$ \\
\hline 0036 & & $S N=(X L(K 1+1)-X L(K 1)) / D H$ \\
\hline 0037 & & $\mathrm{BN}=-(\mathrm{XL}(\mathrm{K} 1+1) * \mathrm{H} 1-\mathrm{XL}(\mathrm{K} 1) * \mathrm{H} 2) / \mathrm{DH}$ \\
\hline 0038 & & $\operatorname{VS}(I)=(S N * Z+B N) / F S Q$ \\
\hline 0039 & 200 & CONTINUE \\
\hline 0040 & & RETURN \\
\hline 0041 & & END \\
\hline
\end{tabular}

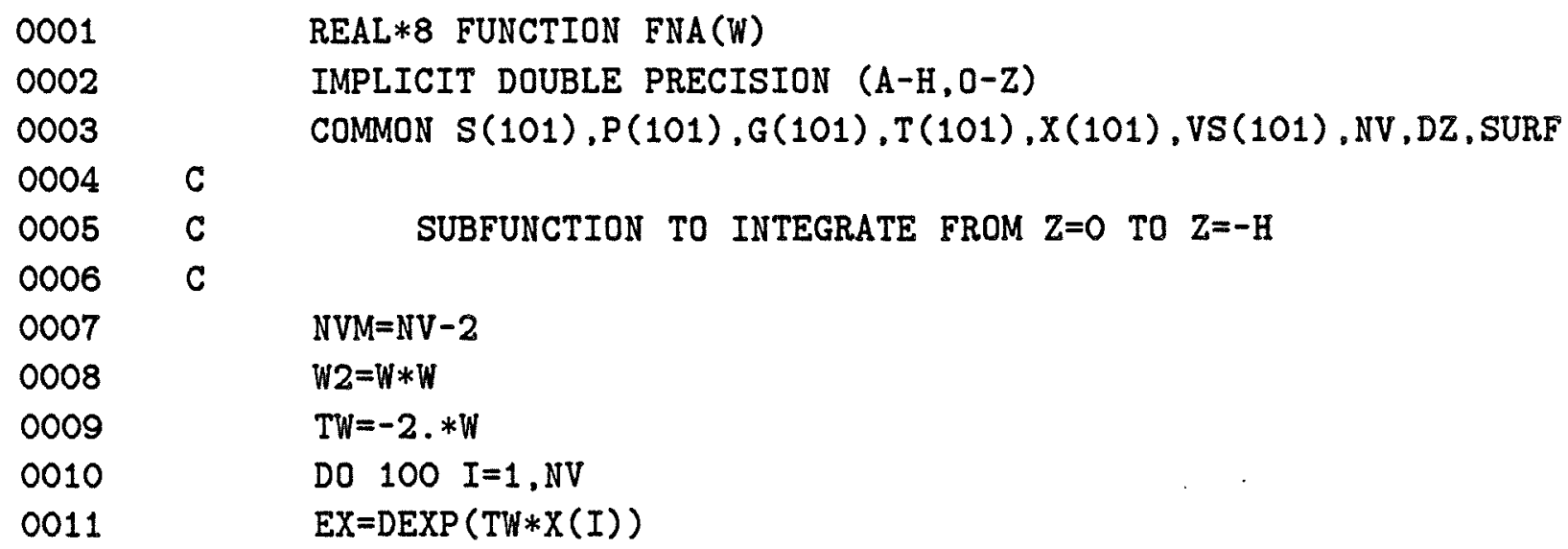


0012

0013

0014

0015

0016

0017

0018

0019

0020

0021

0022

0023

0024

0001

0002

0003

0004

0005

0006

0007

0008

0009

0010

0011

0012

0013

0014

0015

0016

0017

0018

0019

0020

0021

0022

0023

0024

0025

0026

0027

0028

0029

0030

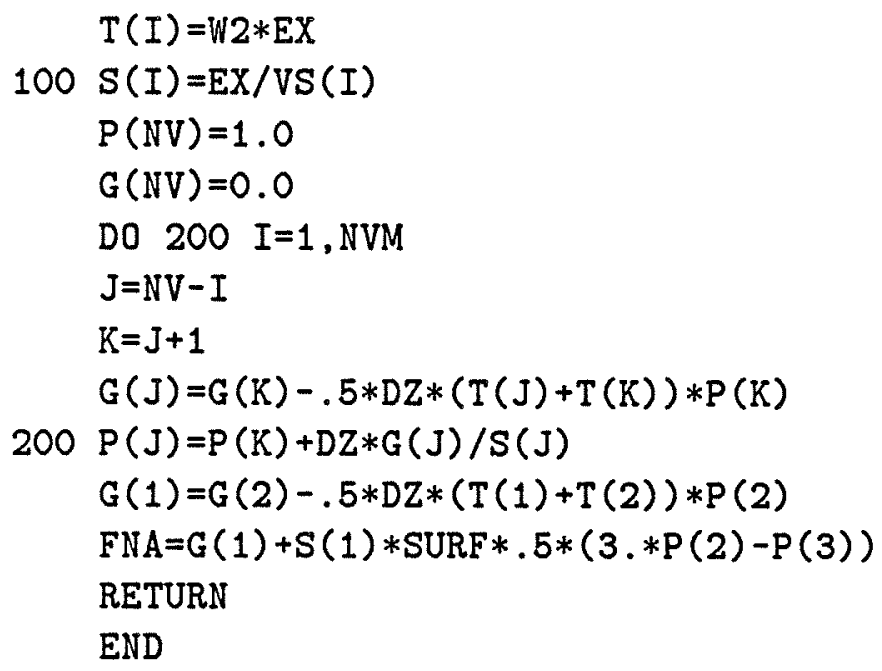

11 FORMAT $\left(/{ }^{\prime}\right.$ PROJECTION OUT OF INTERVAL:',D15.5//) 


$\begin{array}{ll}0031 & 200 \quad Y 3=F N A(X 3) \\ 0032 & \text { IF }(D A B S((X 3-X 2) / X 2) . L T .1 . E-7) \text { GO TO } 400 \\ 0033 & X 1=X 2 \\ 0034 & X 2=X 3 \\ 0035 & Y 1=Y 2 \\ 0036 & Y 2=Y 3 \\ 0037 & \text { GO TO } 420 \\ 0038 & 400 \text { RETURN } \\ 0039 & \text { END }\end{array}$




\section{Program BIGDRV2 Listing}

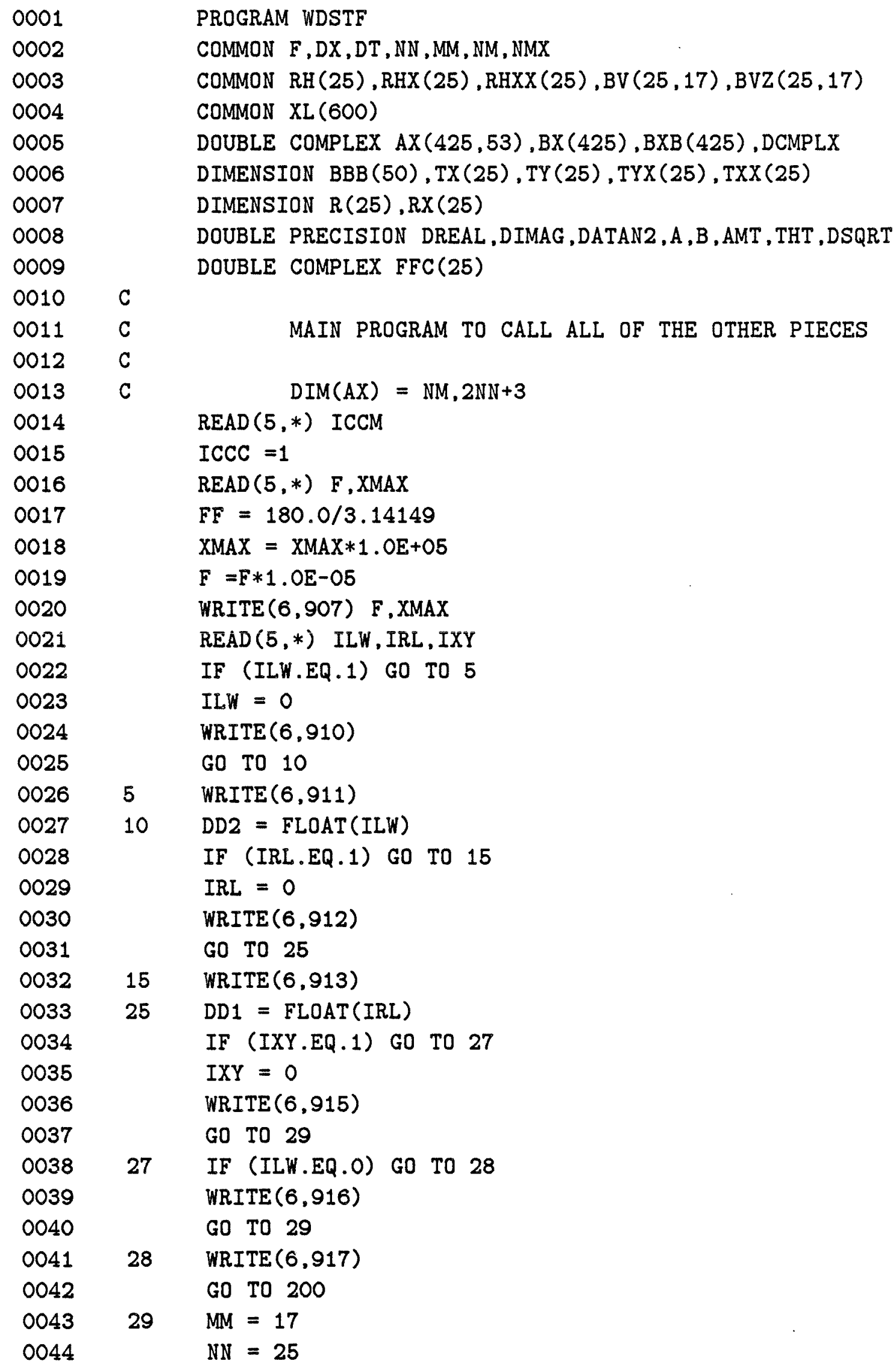




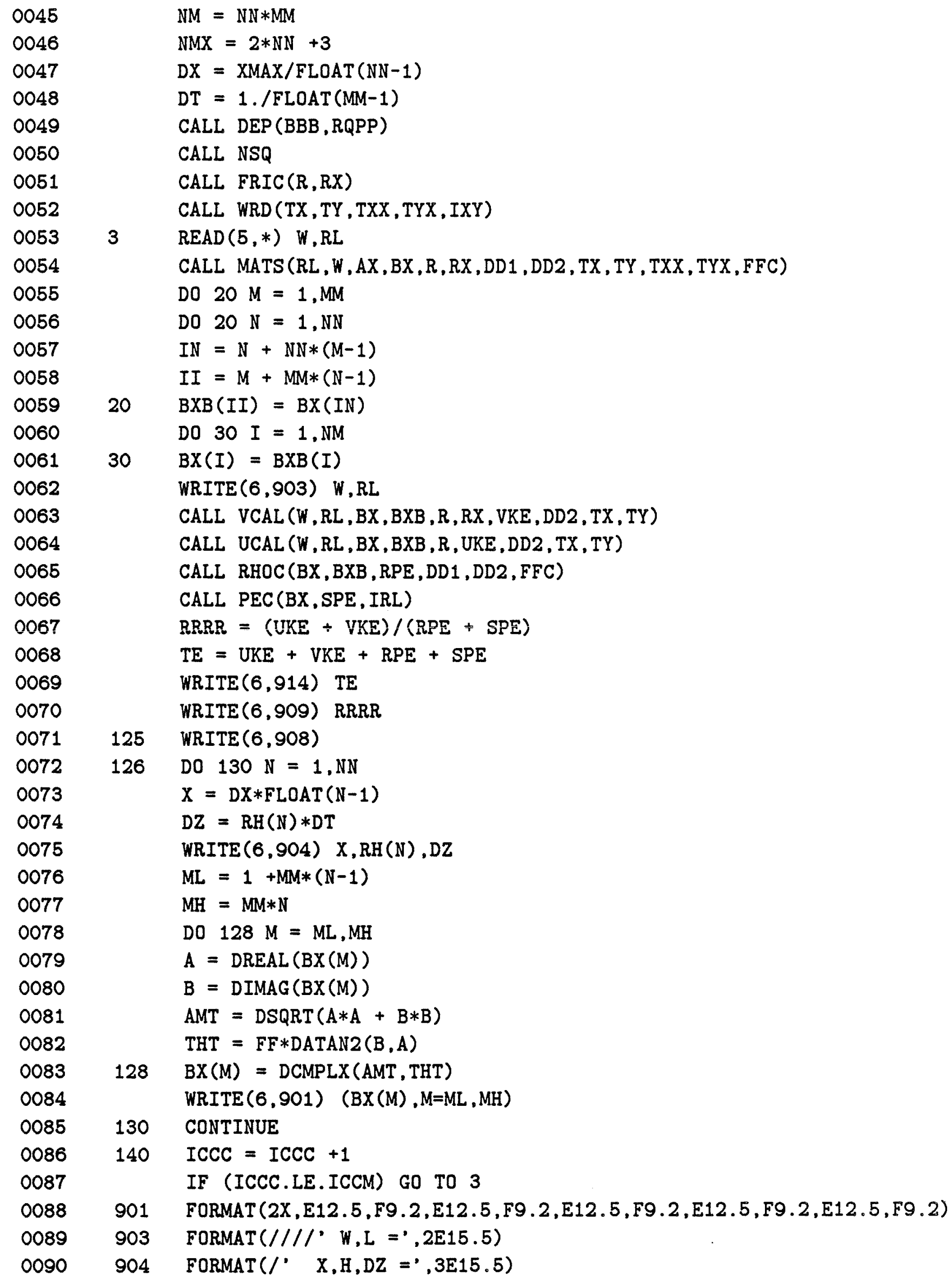




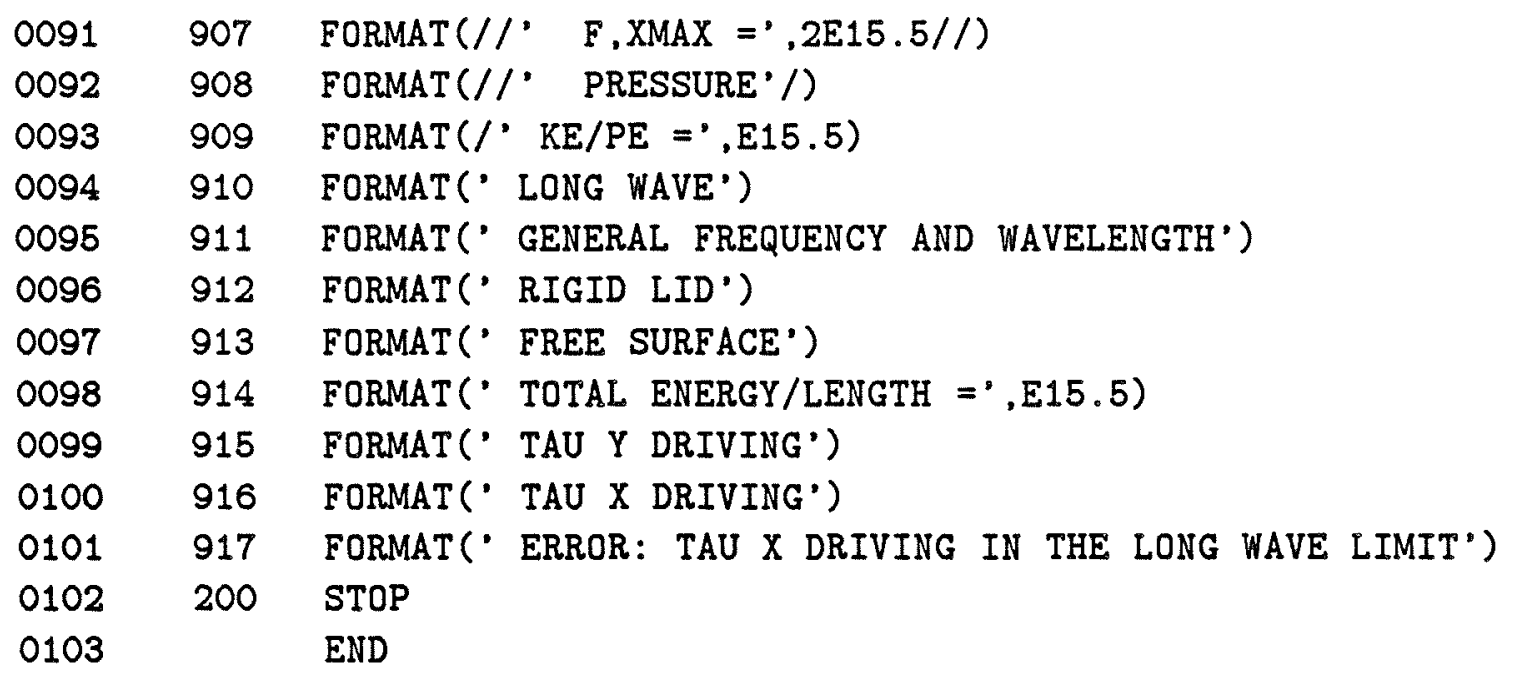

0001

0002

0003

SUBROUTINE NSQ COMMON F,DX,DT,NN,MM,NM,NMX

0004

0005

COMMON RH (25), RHX (25), $\operatorname{RHXX}(25), \operatorname{BV}(25,17), \operatorname{BVZ}(25,17)$

COMMON XL (600)

$0006 \quad C$

$0007 \mathrm{C}$

$0008 \quad \mathrm{C}$

$0009 \mathrm{C}$

$0010 \quad \mathrm{C}$

$0011 \mathrm{C}$

0012

0013

0014

0015

0016

0017

0018

0019

0020

0021

0022

0023

0024

0025

0026

0027

0028

0029

0030
PROGRAM TO READ AND INTERPOLATE BUOYANCY FREQUENCY SQUARED BV = BUOYANCY FREQUENCY SQUARED

$B V Z=Z$ DERIVATIVE OF $B V$

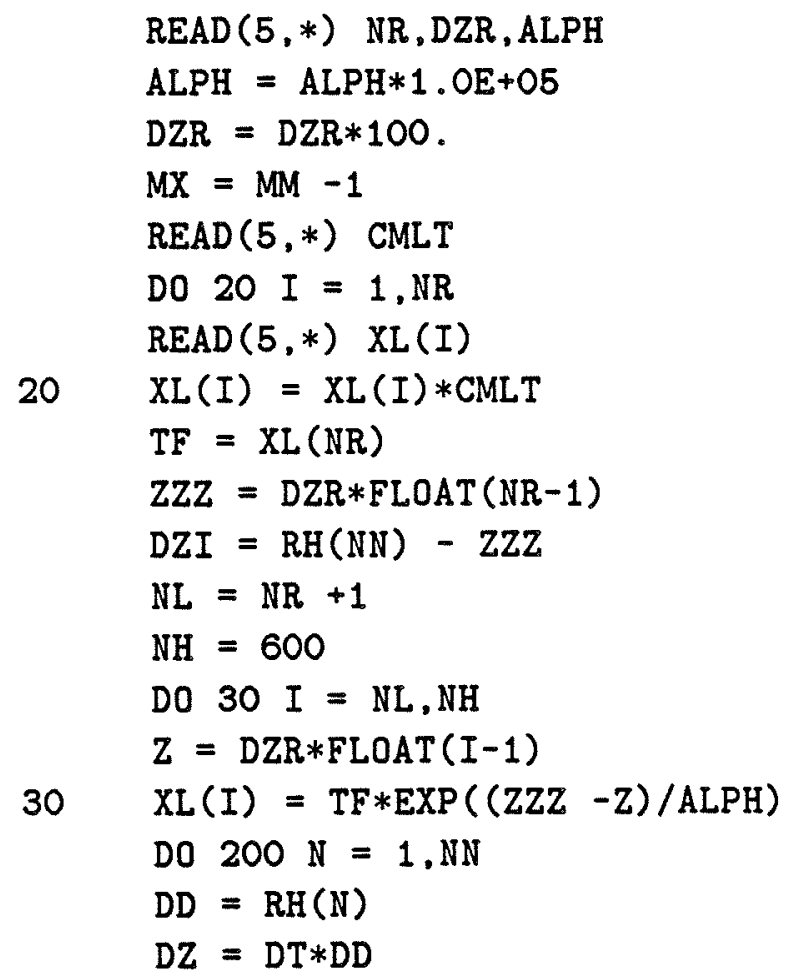




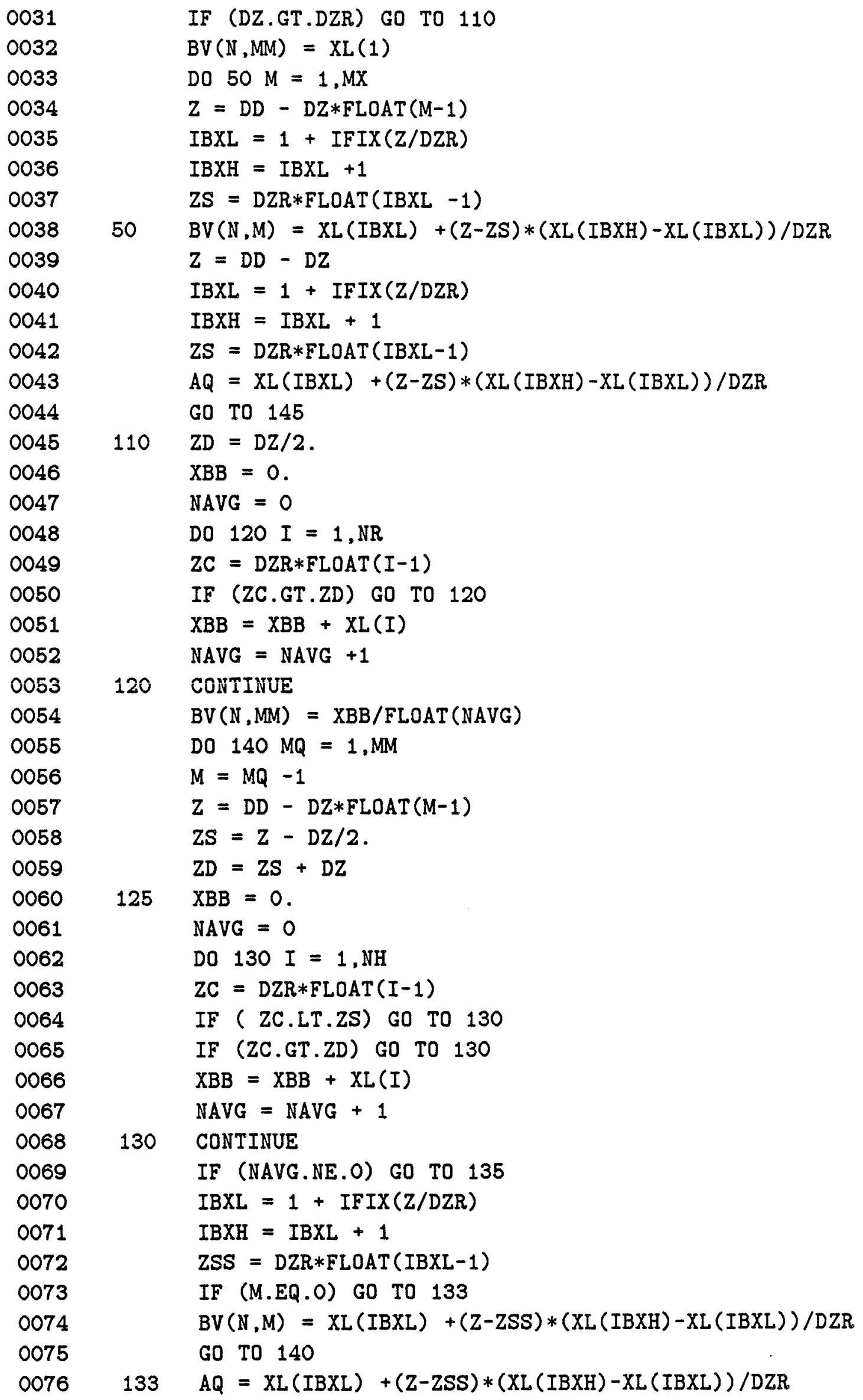




\begin{tabular}{|c|c|c|}
\hline 0077 & & GO TO 140 \\
\hline 0078 & 135 & IF (M.EQ.O) GO TO 138 \\
\hline 0079 & & $B V(N, M)=X B B / F L O A T(N A V G)$ \\
\hline 0080 & & GO TO 140 \\
\hline 0081 & 138 & $A Q=X B B / F L O A T$ (NAVG) \\
\hline 0082 & 140 & CONTINUE \\
\hline 0083 & 145 & DO $150 M=2, M X$ \\
\hline 0084 & & $I P=M+1$ \\
\hline 0085 & & $I M=M-1$ \\
\hline 0086 & 150 & $B V Z(N, M)=(B V(N, I P)-B V(N, I M)) /(2, * D Z)$ \\
\hline 0087 & & $B V Z(N, 1)=(B V(N, 2)-A Q) /(2.0 * D Z)$ \\
\hline 0088 & & $B V Z(N, M M)=(B V(N, M M)-B V(N, M X)) / D Z$ \\
\hline 0089 & 200 & CONTINUE \\
\hline 0090 & & $\operatorname{WRITE}(6,901)$ \\
\hline 0091 & & $\operatorname{WRITE}(6,902) \quad(B V(N N, J), J=1, M M)$ \\
\hline 0092 & 901 & FORMAT $(/ /, \quad$ NSQUARED AT XMAX $/ /)$ \\
\hline 0093 & 902 & FORMAT $(2 \mathrm{X}, 10 \mathrm{E} 12.5)$ \\
\hline 0094 & 250 & RETURN \\
\hline 0095 & & END \\
\hline
\end{tabular}

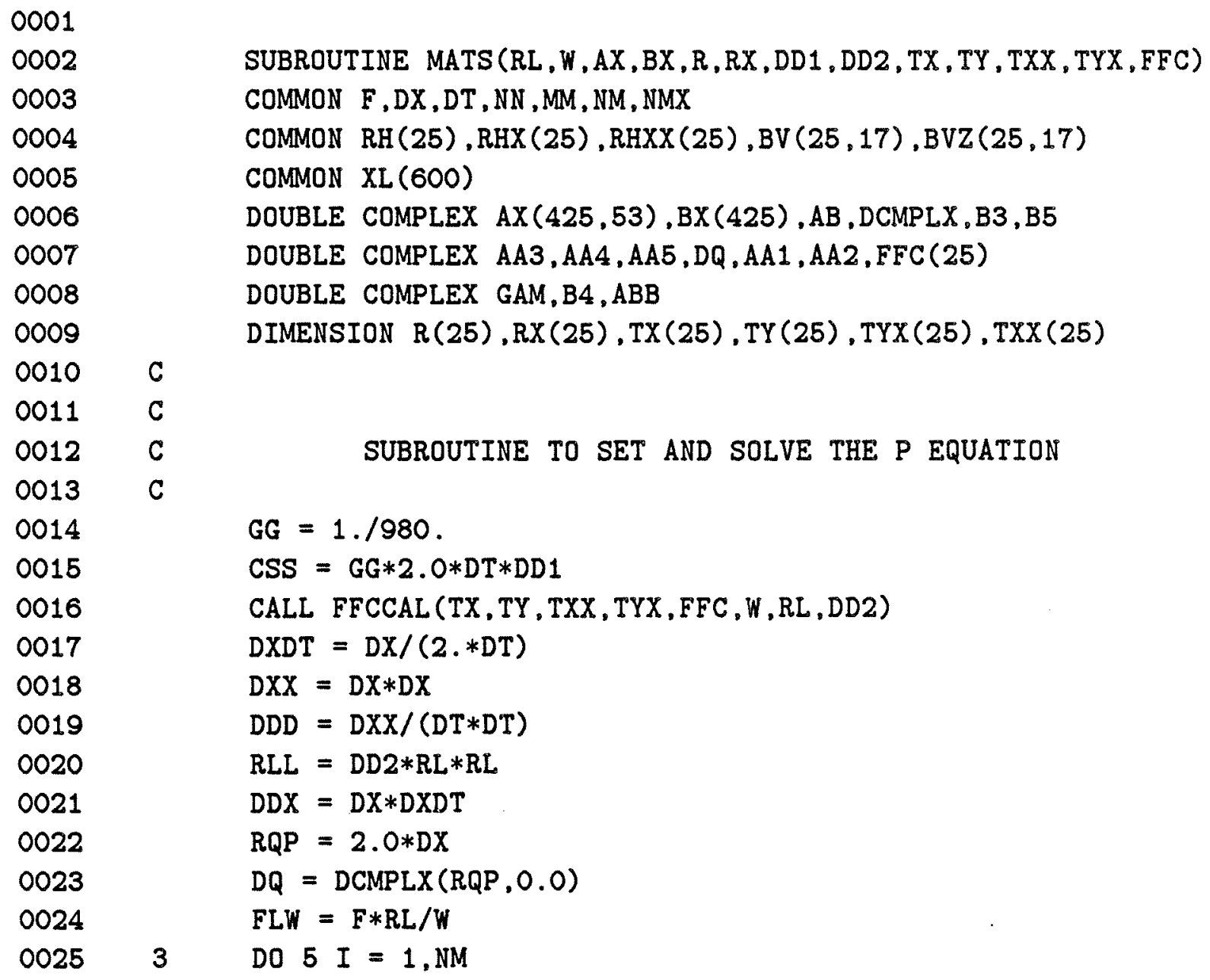




\begin{tabular}{|c|c|c|}
\hline 0026 & 5 & $\mathrm{BX}(I)=(0.0 .0 .0)$ \\
\hline 0027 & & DO $10 \mathrm{~J}=1, \mathrm{NMX}$ \\
\hline 0028 & & DO $10 I=1, \mathrm{NM}$ \\
\hline 0029 & 10 & $\operatorname{AX}(I, J)=(0.0,0.0)$ \\
\hline 0030 & & $\mathrm{~J}=\mathrm{NN}+2$ \\
\hline 0031 & & $I P 1=J+1$ \\
\hline 0032 & & $I M 1=J-1$ \\
\hline 0033 & & $I J J P=J+2$ \\
\hline 0034 & & $I J J M=J-2$ \\
\hline 0035 & & $I P M 1=2 * N N+1$ \\
\hline 0036 & & $I P M=2 * N N+2$ \\
\hline 0037 & & IPMM $=2 * N N+3$ \\
\hline 0038 & & DO $100 \mathrm{M}=1, \mathrm{MM}$ \\
\hline 0039 & & DO $90 \mathrm{~N}=1 . \mathrm{NN}$ \\
\hline 0040 & & $I=N+N N *(M-1)$ \\
\hline 0041 & & CALL AS (A1,A2,A3,W,N,M,C1,C2,C3,DD2) \\
\hline 0042 & & $\mathrm{RQP}=\mathrm{A} 2 * \mathrm{DXDT}$ \\
\hline 0043 & & $A B=D C M P L X(R Q P, 0.0)$ \\
\hline 0044 & & $\mathrm{AX}(I, 1)=\mathrm{AB}$ \\
\hline 0045 & & $A X(I, I P M 1)=-A B$ \\
\hline 0046 & & $A X(I, 3)=-A B$ \\
\hline 0047 & & $A X(I, I P M M)=A B$ \\
\hline 0048 & & $A X(I, I M 1)=(1.0 .0 .0)$ \\
\hline 0049 & & $\operatorname{AX}(I, I P 1)=(1.0,0.0)$ \\
\hline 0050 & & $R Q P=A 1 * D D D-A 3 * D D X$ \\
\hline 0051 & & $\operatorname{AX}(I, 2)=\operatorname{DCMPLX}(\mathrm{RQP}, 0.0)$ \\
\hline 0052 & & $\mathrm{RQP}=\mathrm{A} 1 * \mathrm{DDD}+\mathrm{A} 3 * \mathrm{DDX}$ \\
\hline 0053 & & $\operatorname{AX}(I, I P M)=\operatorname{DCMPLX}(R Q P, 0.0)$ \\
\hline 0054 & & $R Q P=-2.0-2.0 * A 1 * D D D-R L L * D X X$ \\
\hline 0055 & & $\operatorname{AX}(I, J)=\operatorname{DCMPLX}(\operatorname{RQP}, 0.0)$ \\
\hline 0056 & & IF (N.EQ.1) GO TO 20 \\
\hline 0057 & & IF (N.EQ.NN) GO TO 30 \\
\hline 0058 & & IF (M.EQ.1) GO TO 40 \\
\hline 0059 & & IF (M.EQ.MM) GO TO 50 \\
\hline 0060 & & GO TO 90 \\
\hline 0061 & 20 & $R Q P=2.0 * D X$ \\
\hline 0062 & & $F W=F * F-D D 2 * W * W$ \\
\hline 0063 & & $\mathrm{CHH}=\mathrm{RL} * \mathrm{~F} * \mathrm{RH}(\mathrm{N})$ \\
\hline 0064 & & $\mathrm{CH}=\mathrm{R}(\mathrm{N}) * \mathrm{DD} 2 * 2.0 * \mathrm{~F} * \mathrm{~W} * \mathrm{RL} / \mathrm{FW}$ \\
\hline 0065 & & $\mathrm{AA1}=\mathrm{DCMPLX}(\mathrm{CH}, \mathrm{CHH})$ \\
\hline 0066 & & $\mathrm{CH}=\mathrm{R}(\mathrm{N}) *(\mathrm{~F} * \mathrm{~F}+\mathrm{DD} 2 * W * W) / F W$ \\
\hline 0067 & & $\mathrm{CHH}=\mathrm{W} * \mathrm{RH}(\mathrm{N})$ \\
\hline 0068 & & $\mathrm{AA} 2=\mathrm{DCMPLX}(\mathrm{CH}, \mathrm{CHH})$ \\
\hline 0069 & & $\mathrm{CH}=\mathrm{F} * \mathrm{TY}(\mathrm{N})$ \\
\hline 0070 & & $\mathrm{CHH}=W * \mathrm{TX}(\mathrm{N}) * \mathrm{DD} 2$ \\
\hline 0071 & & $\mathrm{ABB}=\mathrm{DCMPLX}(\mathrm{CH}, \mathrm{CHH})$ \\
\hline
\end{tabular}




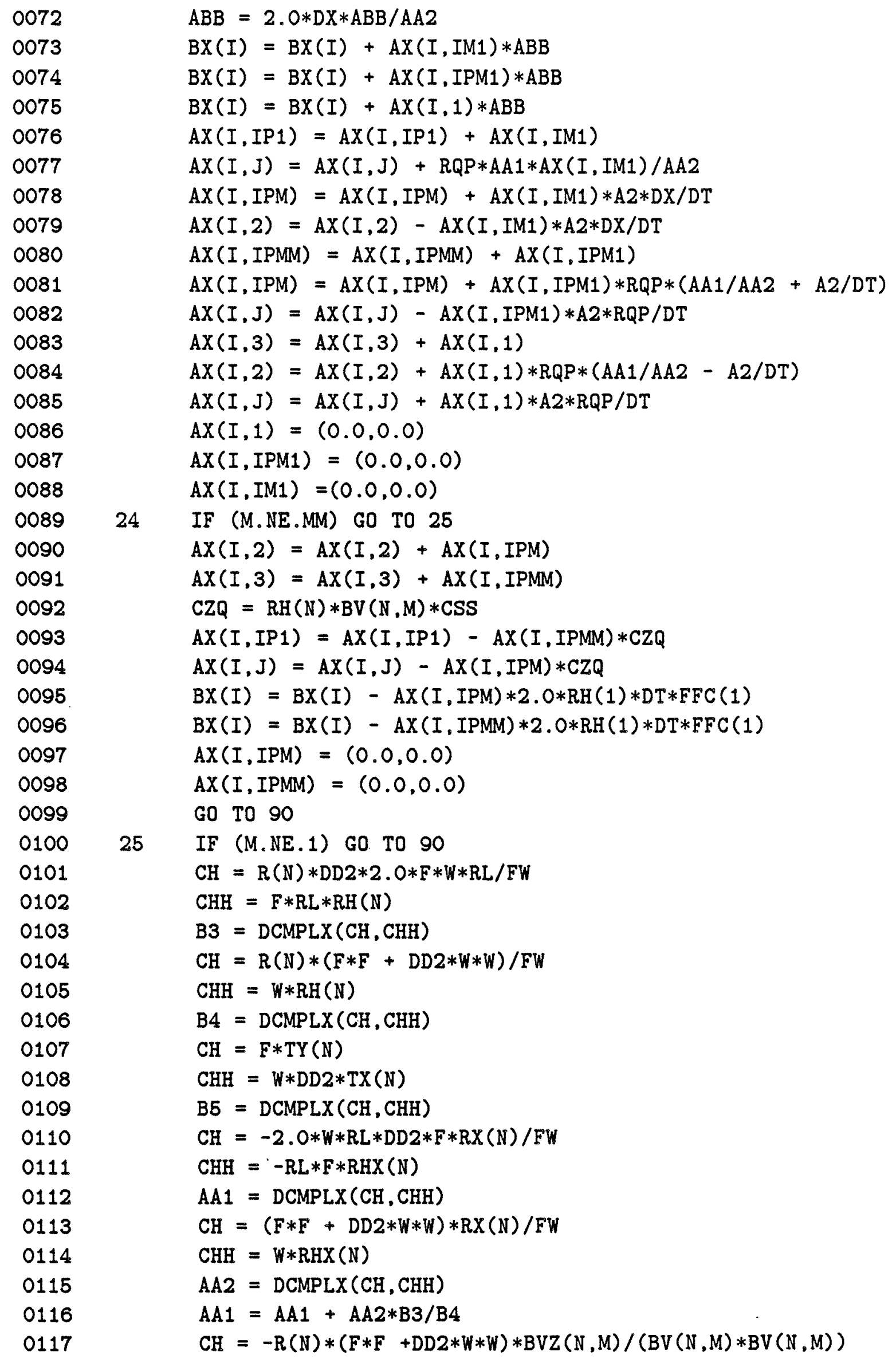




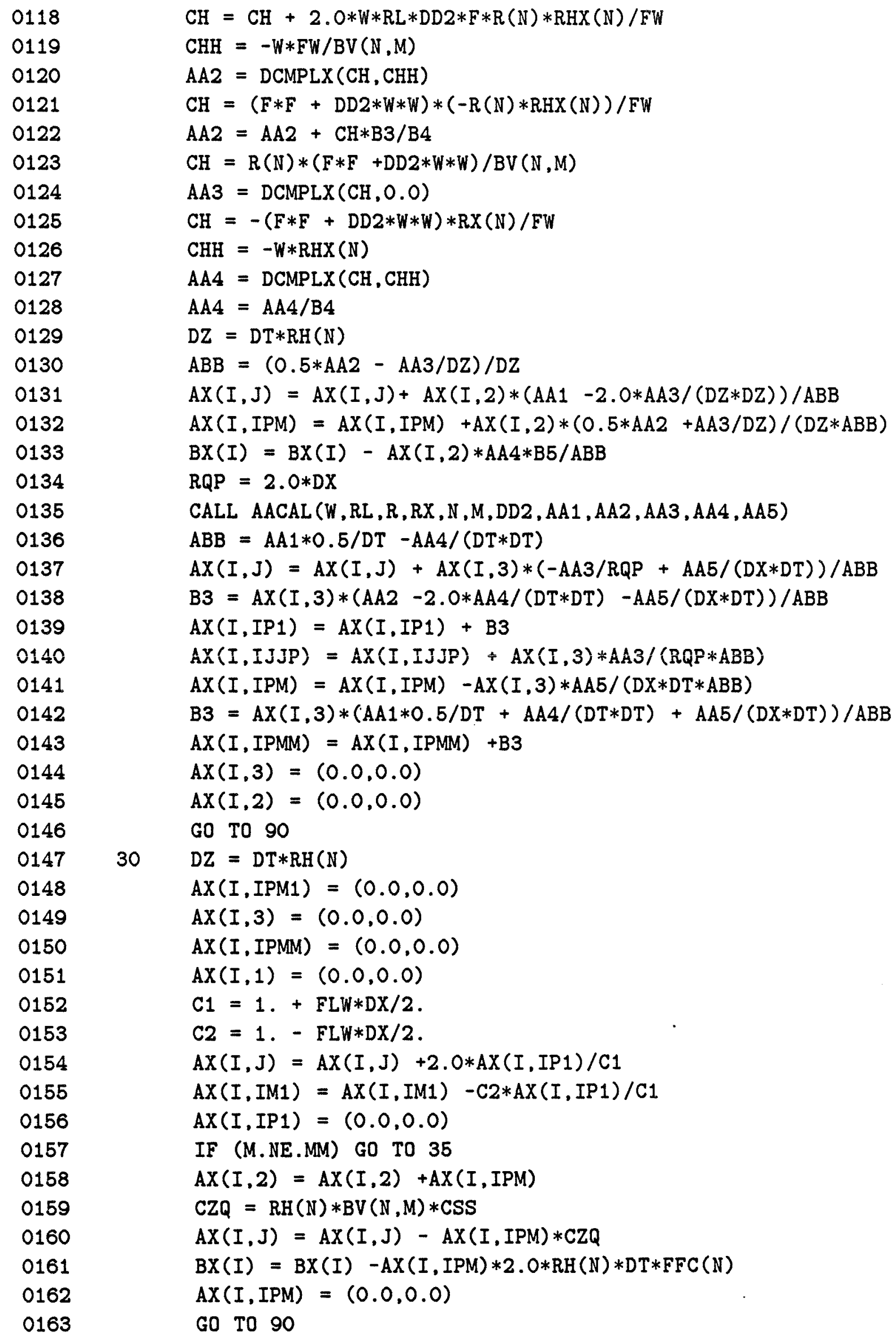




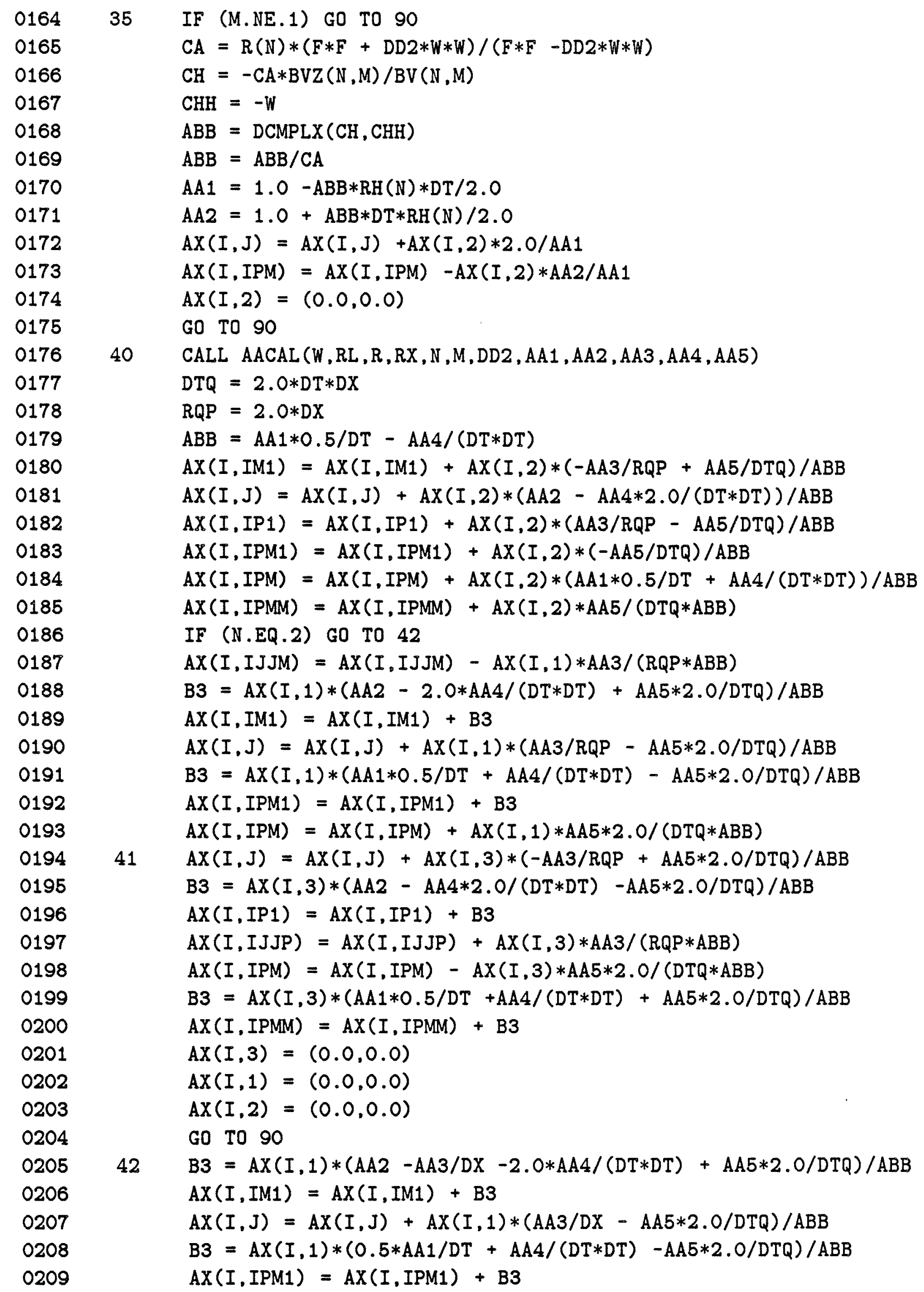




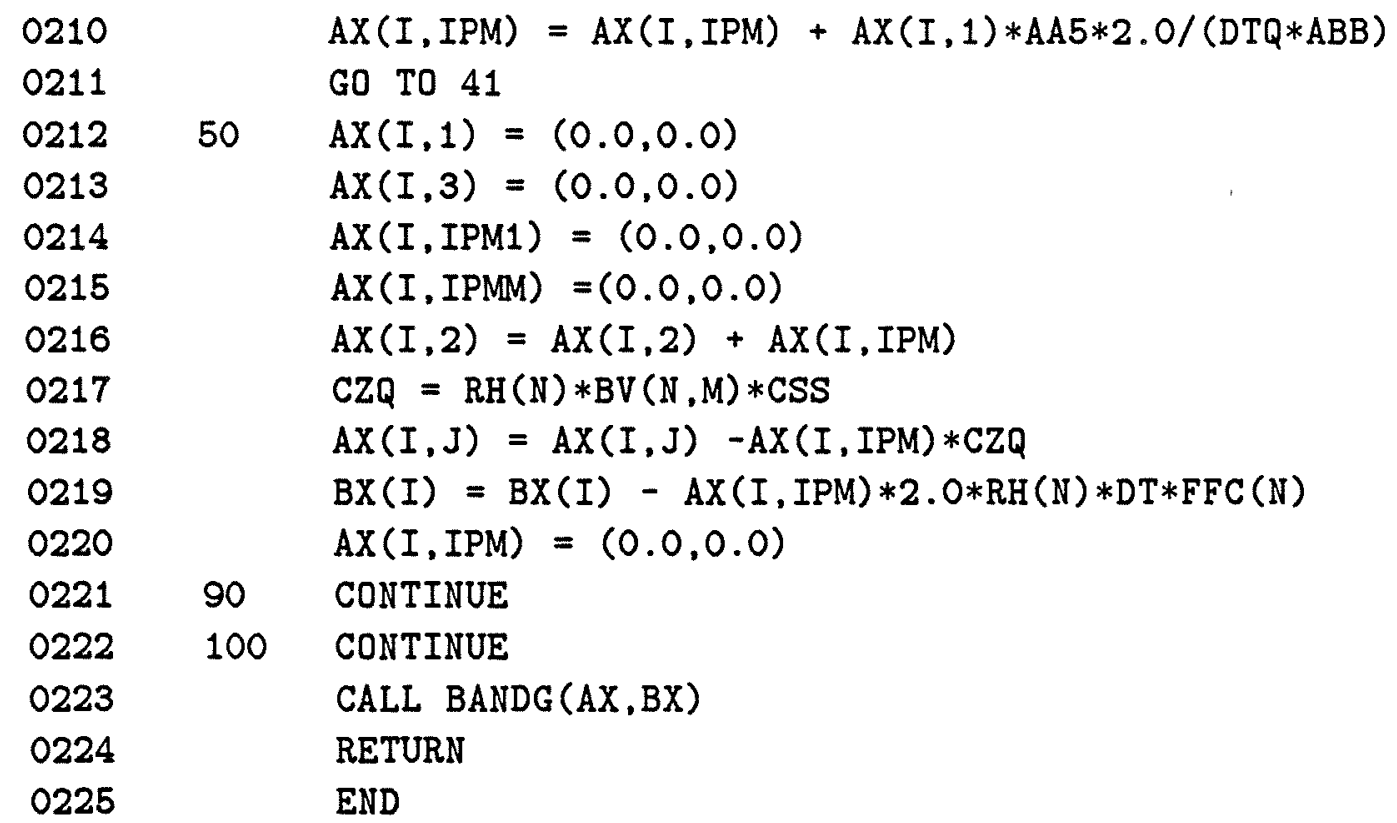




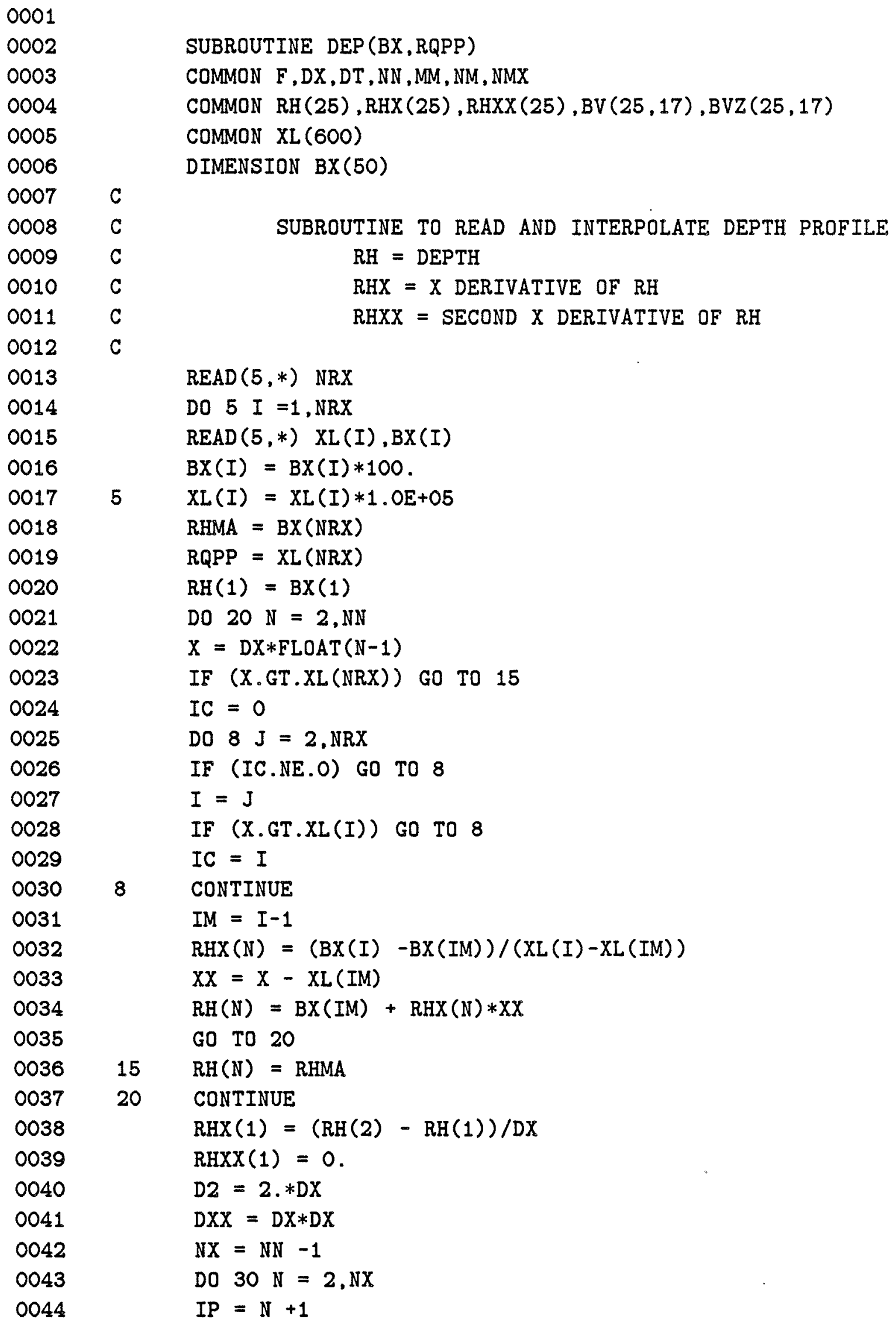




\begin{tabular}{|c|c|c|c|}
\hline 0045 & & $I M=N-1$ & \\
\hline 0046 & & $\operatorname{RHX}(\mathrm{N})=(\mathrm{RH}(\mathrm{IP})-$ & $\mathrm{RH}(\mathrm{IM})) / \mathrm{D} 2$ \\
\hline 0047 & 30 & $\operatorname{RHXX}(N)=(R H(I P)$ & $-2 . * \mathrm{RH}(\mathrm{N})+\mathrm{RH}(\mathrm{IM})) / \mathrm{DXX}$ \\
\hline 0048 & & $\operatorname{RHX}(N N)=0$ & \\
\hline 0049 & & $\operatorname{RHXX}(\mathrm{NN})=0$ & \\
\hline 0050 & & RETURN & \\
\hline 0051 & & END & \\
\hline
\end{tabular}

0001

0002

0003

SUBROUTINE VCAL(W,RL, BX, XL, R, RX, XINT , DD2, TX,TY)

COMMON F,DX,DT,NN,MM,NM, NMX

0004

0005

COMMON RH (25), $\operatorname{RHX}(25), \operatorname{RHXX}(25), \operatorname{BV}(25,17), \operatorname{BVZ}(25,17)$

COMMON XB(600)

0006

0007

0008

0009

0010

$0011 \quad C$

$0012 \quad C$

DOUBLE COMPLEX BX(425), XL (425), XPX, XPT, DCMPLX , RMU , T3 , B3 , B5, AA1 , AA2

DOUBLE COMPLEX GAM,B4,AA3,AA4,AA5

DOUBLE PRECISION DREAL,DIMAG,DATAN2,DSQRT, A,B

DIMENSION $\mathrm{R}(25), \mathrm{RX}(25), \mathrm{TX}(25), \mathrm{TY}(25)$

DOUBLE PRECISION XINT

$0013 \quad \mathrm{C}$

SUBROUTINE TO CALCULATE V FROM $P$

0014

0015

0016

0017

0018

0019

0020

0021

0022

0023

0024

0025

0026

0027

0028

0029

0030

0031

0032

0033

0034

0035

0036

0037

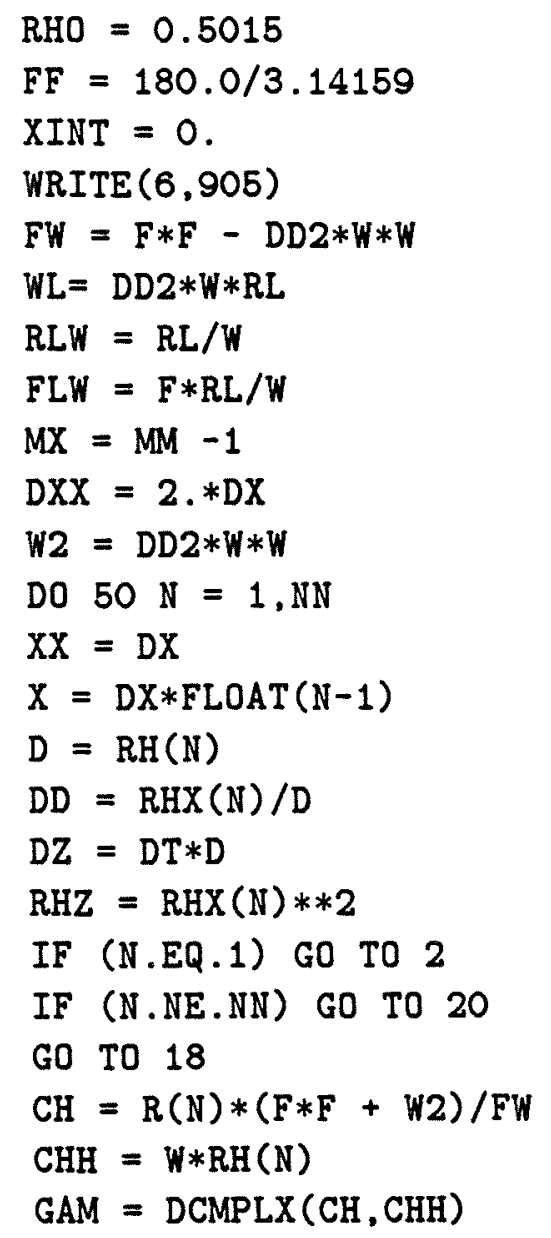




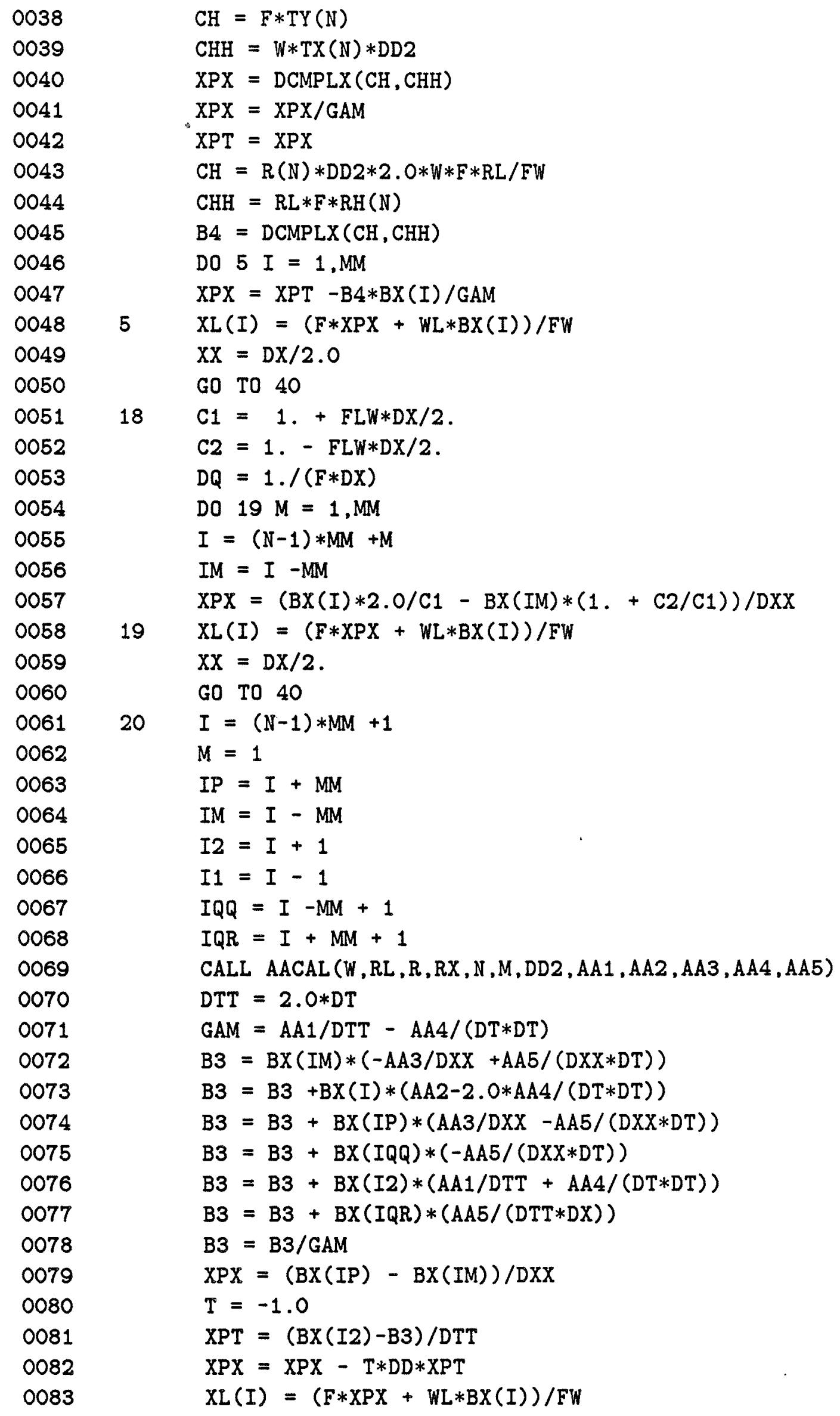




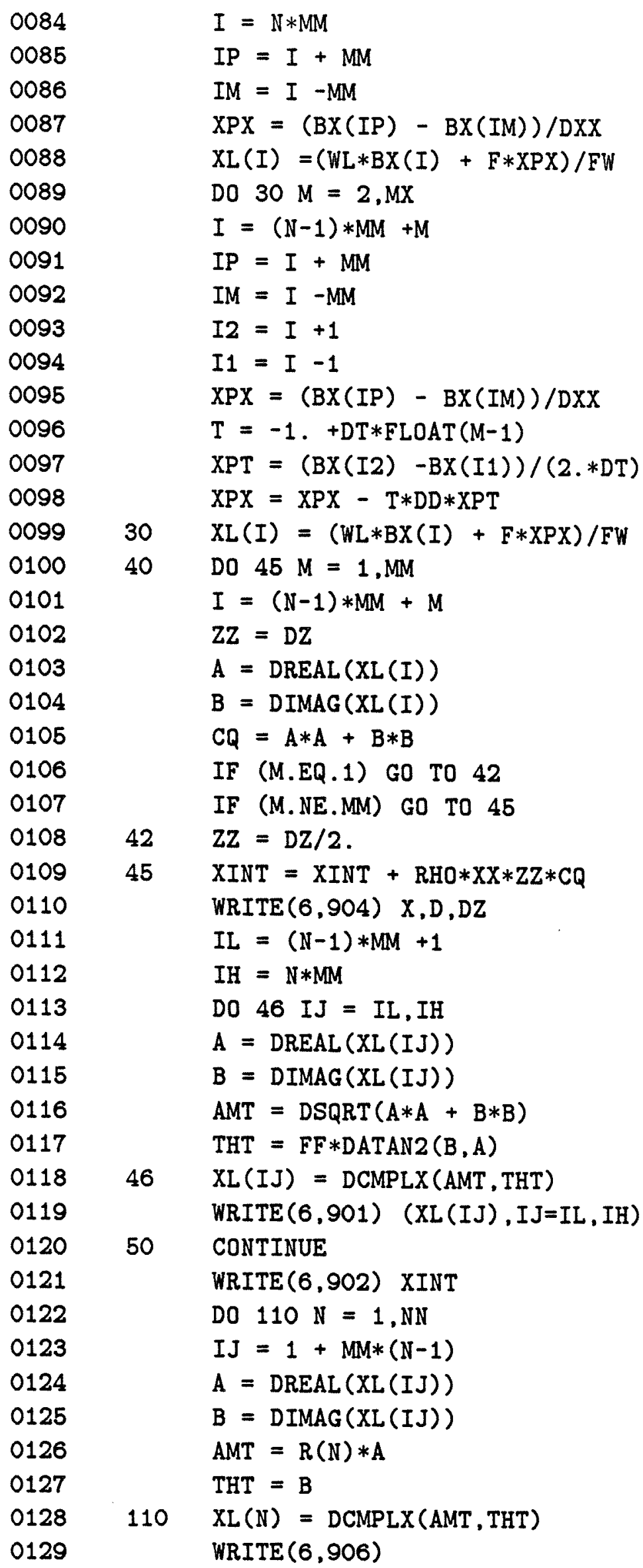




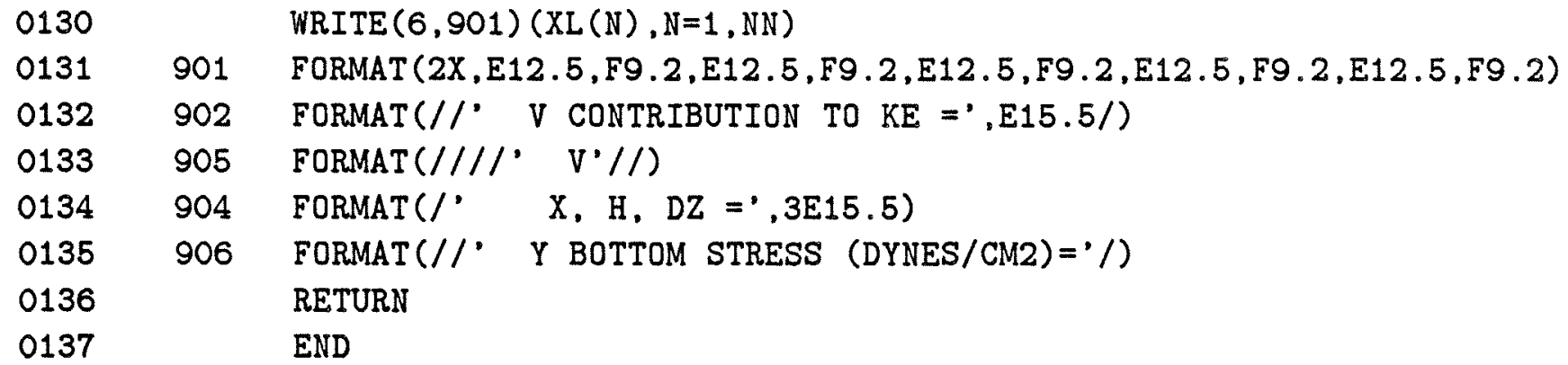

0001

0002

0003

0004

0005

0006

0007

0008

0009

0010

0011

0012

0013

0014

0015

0016

0017

0018

0019

0020

0021

0022

0023

0024

0025

0026

0027

0028

0029

0030

0031

0032

0033

0034

0035

SUBROUTINE RHOC(BX,XL,XINT,DD1,DD2,FFC)

COMMON $F, D X, D T, N N, M M, N M, N M X$

COMMON RH (25), RHX (25), $\operatorname{RHXX}(25), \operatorname{BV}(25,17), \operatorname{BVZ}(25,17)$

COMMON XQ(600)

DOUBLE COMPLEX BX(425), XL (425), DCMPLX, FFC (25)

DOUBLE PRECISION DREAL,DIMAG,DATAN2, DSQRT, A, B, CDABS

DOUBLE PRECISION XINT

SUBROUTINE TO CALCULATE DENSITY FROM P

$$
\begin{aligned}
& c \\
& c \\
& c
\end{aligned}
$$$$
\mathrm{G} 2=980 . * 980 \cdot / 2.06
$$$$
\mathrm{GRQ}=(1.0 / 980.0) * * 2
$$$$
F F=180.0 / 3.14159
$$$$
\mathrm{XINT}=0 \text {. }
$$$$
\text { WRITE }(6,903)
$$$$
G=980 \text {. }
$$$$
\text { DO } 50 \mathrm{~N}=1, \mathrm{NN}
$$$$
\mathrm{DXX}=\mathrm{DX}
$$$$
\text { IF (N.EQ.1) GO TO } 2
$$$$
\text { IF (N.NE.NN) GO TO } 5
$$$$
2 \mathrm{DXX}=\mathrm{DX} / 2 \text {. }
$$$$
5 \quad X=D X * F L O A T(N-1)
$$$$
\mathrm{DZ}=\mathrm{DT} * \mathrm{RH}(\mathrm{N})
$$$$
\mathrm{GDZ}=\mathrm{G} * \mathrm{DZ}
$$$$
\text { DO } 40 \mathrm{M}=1, \mathrm{MM}
$$$$
\mathrm{DZZ}=\mathrm{DZ}
$$$$
I=(N-1) * M M+M
$$$$
\text { IF (M.EQ.1) GO TO } 10
$$$$
\text { IF (M.NE.MM) GO TO } 20
$$$$
\mathrm{DZZ}=\mathrm{DZ} / 2 \text {. }
$$$$
\mathrm{XL}(\mathrm{M})=\mathrm{DD} 1 * \mathrm{BV}(\mathrm{N}, \mathrm{M}) * \mathrm{GRQ} * \mathrm{BX}(\mathrm{I})-\mathrm{FFC}(\mathrm{N}) / 980 \text {. }
$$$$
\text { GO TO } 35
$$$$
10 \quad \text { IP }=I+1
$$$$
\mathrm{DZZ}=\mathrm{DZ} / 2 \text {. }
$$ 


\begin{tabular}{|c|c|c|}
\hline 0018 & & WRITE $(6,903)$ \\
\hline 0019 & & DO $100 \mathrm{~N}=1, \mathrm{NN}$ \\
\hline 0020 & & $\mathrm{DXX}=\mathrm{DX}$ \\
\hline 0021 & & $X=D X * F L O A T(N-1)$ \\
\hline 0022 & & $\mathrm{DZ}=\mathrm{DT} * \mathrm{RH}(\mathrm{N})$ \\
\hline 0023 & & IF (N.EQ.1) GO TO 86 \\
\hline 0024 & & IF (N.EQ.NN) GO TO 110 \\
\hline 0025 & & $D D=R H X(N) / R H(N)$ \\
\hline 0026 & & DO $85 M=1, M M$ \\
\hline 0027 & & $I=(N-1) * M M+M$ \\
\hline 0028 & & $I P=I+M M$ \\
\hline 0029 & & $I M=I-M M$ \\
\hline 0030 & & $T=-1 .+D T * F L O A T(M-1)$ \\
\hline 0031 & & IF (M.EQ.1) GO TO 10 \\
\hline 0032 & & IF (M.EQ.MM) GO TO 15 \\
\hline 0033 & & GO TO 20 \\
\hline 0034 & 10 & $I 1=I+1$ \\
\hline 0035 & & $X P T=(B X(I 1)-B X(I)) / D T$ \\
\hline 0036 & & GO TO 25 \\
\hline 0037 & 15 & $\mathrm{XPT}=(0.0 .0 .0)$ \\
\hline 0038 & & GO TO 25 \\
\hline 0039 & 20 & $I 2=I+1$ \\
\hline 0040 & & $I 1=I-1$ \\
\hline 0041 & & $\mathrm{XPT}=(\mathrm{BX}(\mathrm{I} 2)-\mathrm{BX}(\mathrm{I} 1)) /(2 . * \mathrm{DT})$ \\
\hline 0042 & 25 & $X P X=(B X(I P)-B X(I M)) /(2 . * D X)$ \\
\hline 0043 & & $\mathrm{XPX}=\mathrm{XPX}-\mathrm{T} * \mathrm{DD} * \mathrm{XPT}$ \\
\hline 0044 & 85 & $X L(M)=-(0.0,1.0) *(W * X P X+F L * B X(I)) / F W$ \\
\hline 0045 & & GO TO 90 \\
\hline 0046 & 86 & $\mathrm{CH}=\mathrm{R}(\mathrm{N}) *(\mathrm{~F} * \mathrm{~F}+\mathrm{DD} 2 * \mathrm{~W} * \mathrm{~W}) / \mathrm{FW}$ \\
\hline 0047 & & $\mathrm{CHH}=\mathrm{W} * \mathrm{RH}(\mathrm{N})$ \\
\hline 0048 & & $\mathrm{GAM}=\mathrm{DCMPLX}(\mathrm{CH}, \mathrm{CHH})$ \\
\hline 0049 & & $\mathrm{CH}=\mathrm{F} * \mathrm{TY}(\mathrm{N})$ \\
\hline 0050 & & $\mathrm{CHH}=\mathrm{W} * \mathrm{TX}(\mathrm{N}) * \mathrm{DD} 2$ \\
\hline 0051 & & $\mathrm{XPX}=\mathrm{DCMPLX}(\mathrm{CH}, \mathrm{CHH})$ \\
\hline 0052 & & $\mathrm{XPX}=\mathrm{XPX} / \mathrm{GAM}$ \\
\hline 0053 & & $\mathrm{XPT}=\mathrm{XPX}$ \\
\hline 0054 & & $\mathrm{CH}=\mathrm{R}(\mathrm{N}) * \mathrm{DD} 2 * 2.0 * \mathrm{~W} * \mathrm{~F} * \mathrm{RL} / \mathrm{FW}$ \\
\hline 0055 & & $\mathrm{CHH}=\mathrm{RL} * \mathrm{~F} * \mathrm{RH}(\mathrm{N})$ \\
\hline 0056 & & $\mathrm{~B} 4=\mathrm{DCMPLX}(\mathrm{CH}, \mathrm{CHH})$ \\
\hline 0057 & & DO $87 \mathrm{M}=1 . \mathrm{MM}$ \\
\hline 0058 & & $\mathrm{XPX}=\mathrm{XPT}-\mathrm{B} 4 * \mathrm{BX}(\mathrm{M}) / \mathrm{GAM}$ \\
\hline 0059 & 87 & $X L(M)=-(0.0,1.0) *(F L * B X(M)+W * X P X) / F W$ \\
\hline 0060 & & $\mathrm{DXX}=\mathrm{DX} / 2.0$ \\
\hline 0061 & & GO TO 90 \\
\hline 0062 & 110 & $\mathrm{FLW}=0.5 * \mathrm{FL} / W$ \\
\hline 0063 & & $\mathrm{DXX}=\mathrm{DX} / 2$ \\
\hline
\end{tabular}




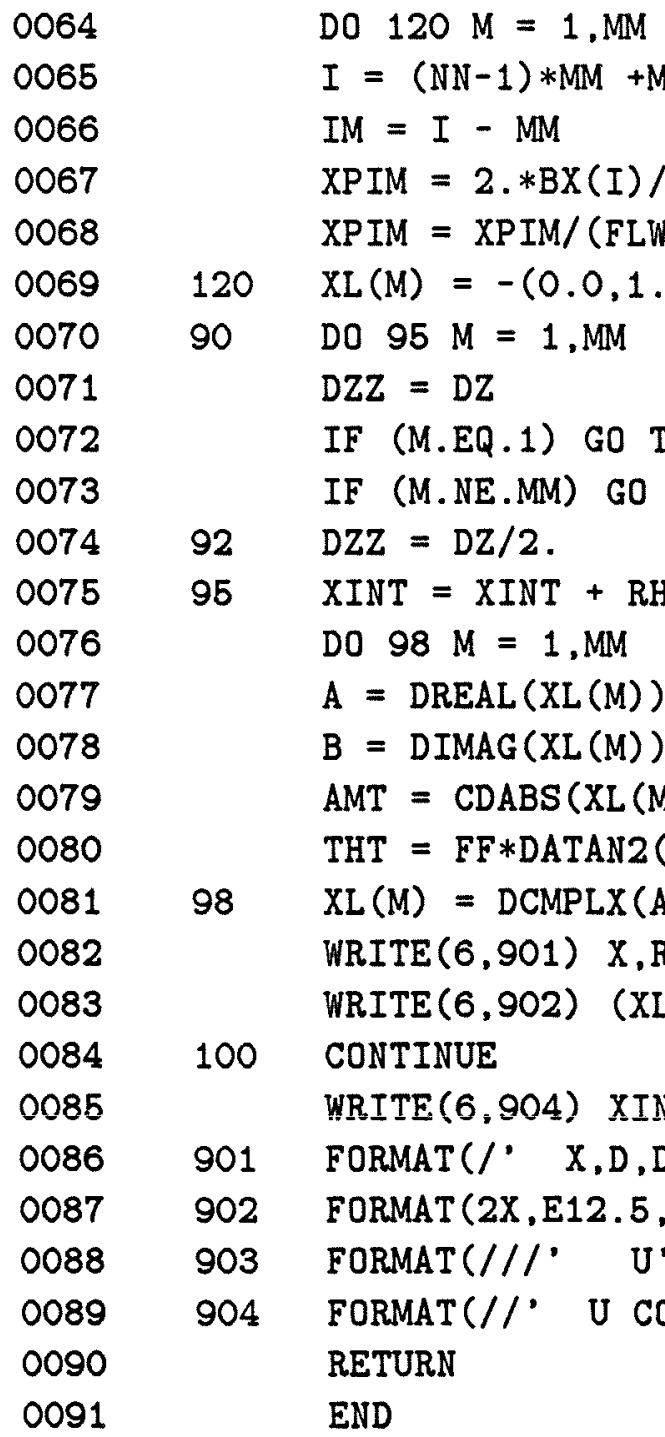




\begin{tabular}{|c|c|c|}
\hline 0017 & & $\mathrm{MH}=\mathrm{NM}$ \\
\hline 0018 & 5 & DO 50 IR $=I P, M H$ \\
\hline 0019 & & $I C D=M B W+N+1-I R$ \\
\hline 0020 & & $R=A(I R, I C D) / A(N, M D I A G)$ \\
\hline 0021 & & $B B(I R)=B B(I R)-R * B B(N)$ \\
\hline 0022 & & DO 50 IC $=$ IP, MH \\
\hline 0023 & & $I C D=M B W+I C+1-I R$ \\
\hline 0024 & & $I C B=M B W+I C+1-N$ \\
\hline 0025 & & $A(I R, I C D)=A(I R, I C D)-R * A(N, I C B)$ \\
\hline 0026 & 50 & CONTINUE \\
\hline 0027 & & DO $100 I=1, \mathrm{NH}$ \\
\hline 0028 & & $N=N M-I+1$ \\
\hline 0029 & & $\mathrm{BB}(\mathrm{N})=\mathrm{BB}(\mathrm{N}) / \mathrm{A}(\mathbb{N}, \mathrm{MDIAG})$ \\
\hline 0030 & & $I L=N-M B W$ \\
\hline 0031 & & $I H=N-1$ \\
\hline 0032 & & IF (IL.GE.1) GO TO 60 \\
\hline 0033 & & IL $=1$ \\
\hline 0034 & 60 & DO $100 \mathrm{IR}=\mathrm{IL}, \mathrm{IH}$ \\
\hline 0035 & & $I C D=M B W+N+1-I R$ \\
\hline 0036 & & $B B(I R)=B B(I R)-A(I R, I C D) * B B(N)$ \\
\hline 0037 & 100 & CONTINUE \\
\hline 0038 & & $\mathrm{BB}(1)=\mathrm{BB}(1) / \mathrm{A}(1, \mathrm{MDIAG})$ \\
\hline 0039 & & RETURN \\
\hline 0040 & & END \\
\hline
\end{tabular}

0001

0002

0003

0004

0005

$0006 \quad \mathrm{C}$

$0007 \quad \mathrm{C}$

$0008 \quad \mathrm{C}$

$0009 \quad \mathrm{C}$

$0010 \quad C$

$0011 \mathrm{C}$

SUBROUTINE FRIC (R,RX)

COMMON F,DX,DT,NN,MM,NM, NMX

COMMON RH (25), RHX (25), $\operatorname{RHXX}(25), \operatorname{BV}(25,17), \operatorname{BVZ}(25,17), \mathrm{XL}(600)$

DIMENSION $\mathrm{R}(25), \mathrm{RX}(25), \mathrm{A}(25)$

0012

0013

0014

0015

0016

0017

0018

SUBROUTINE TO READ AND INTERPOLATE BOTTOM RESISTANCE COEFFICIENT $R$

$\mathrm{RX}=\mathrm{X}$ DERIVATIVE OF $\mathrm{R}$

0019

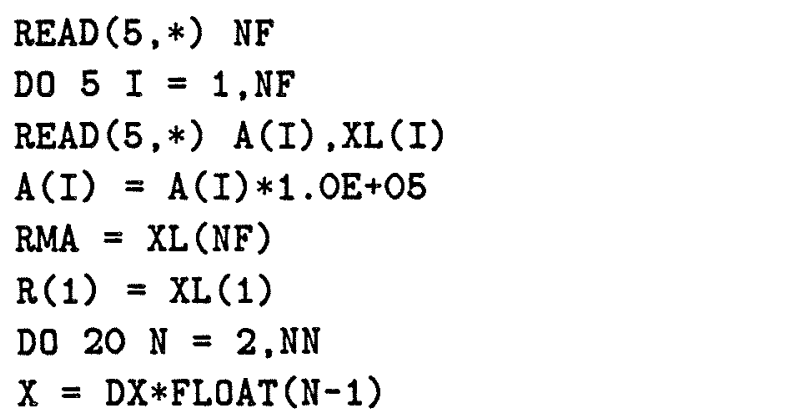




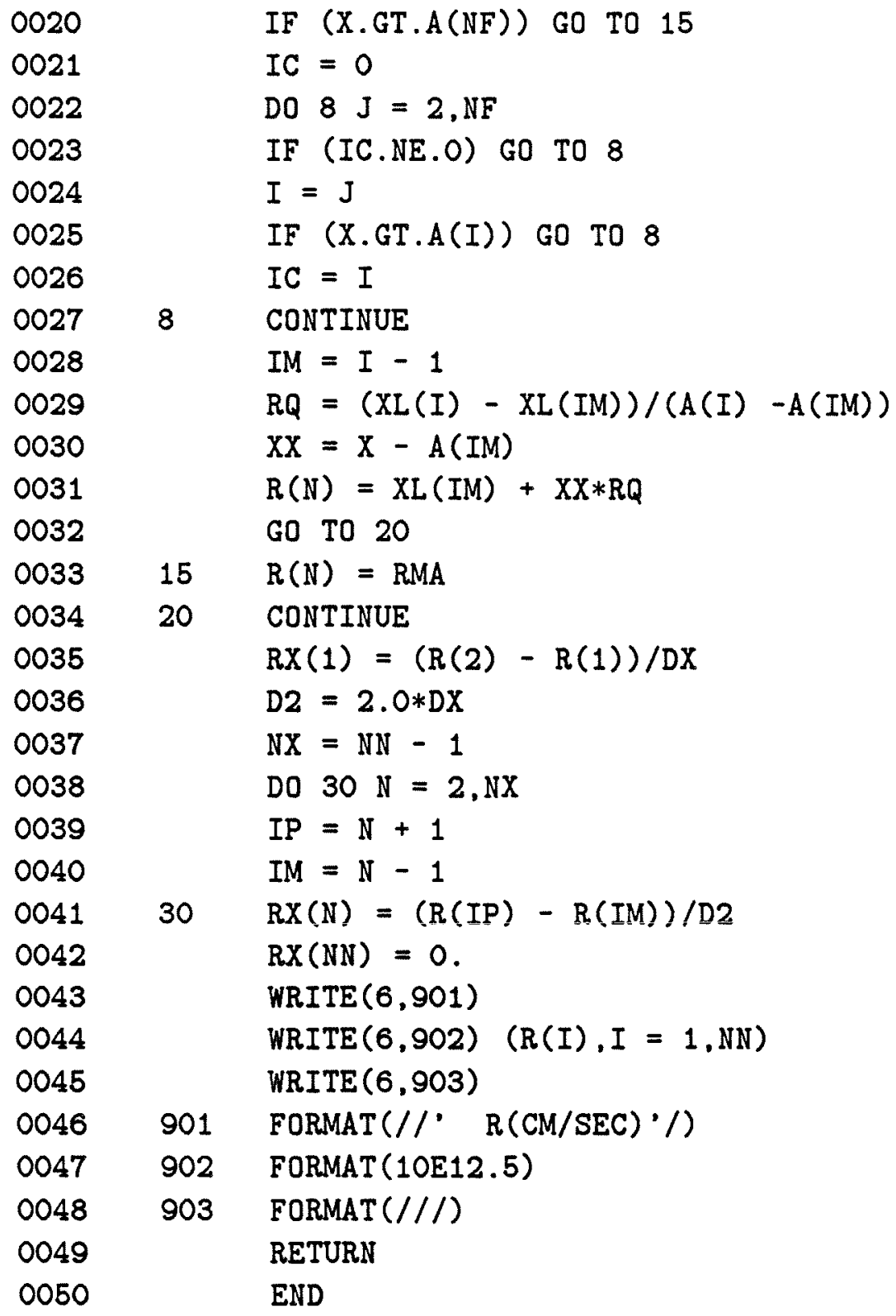




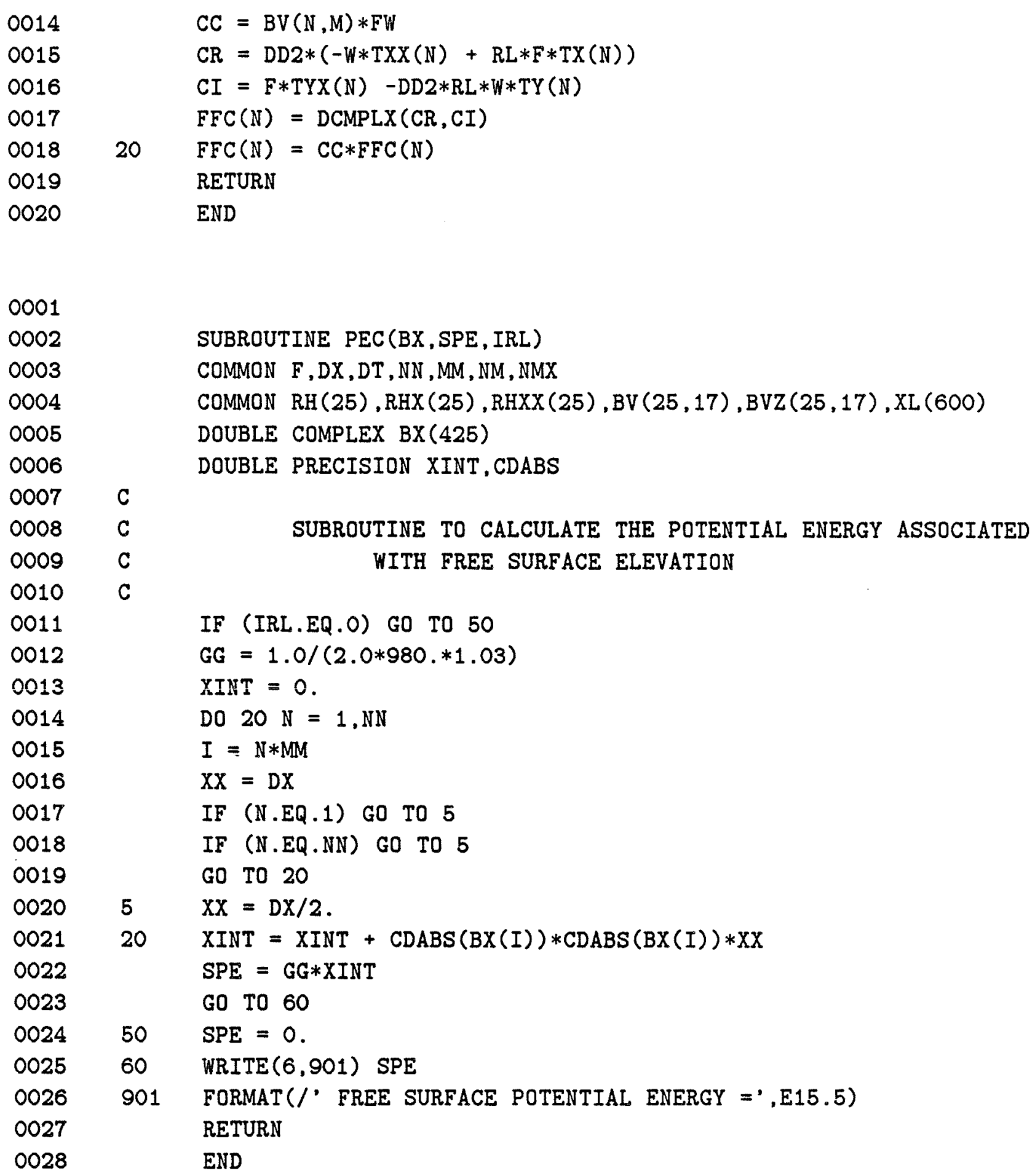




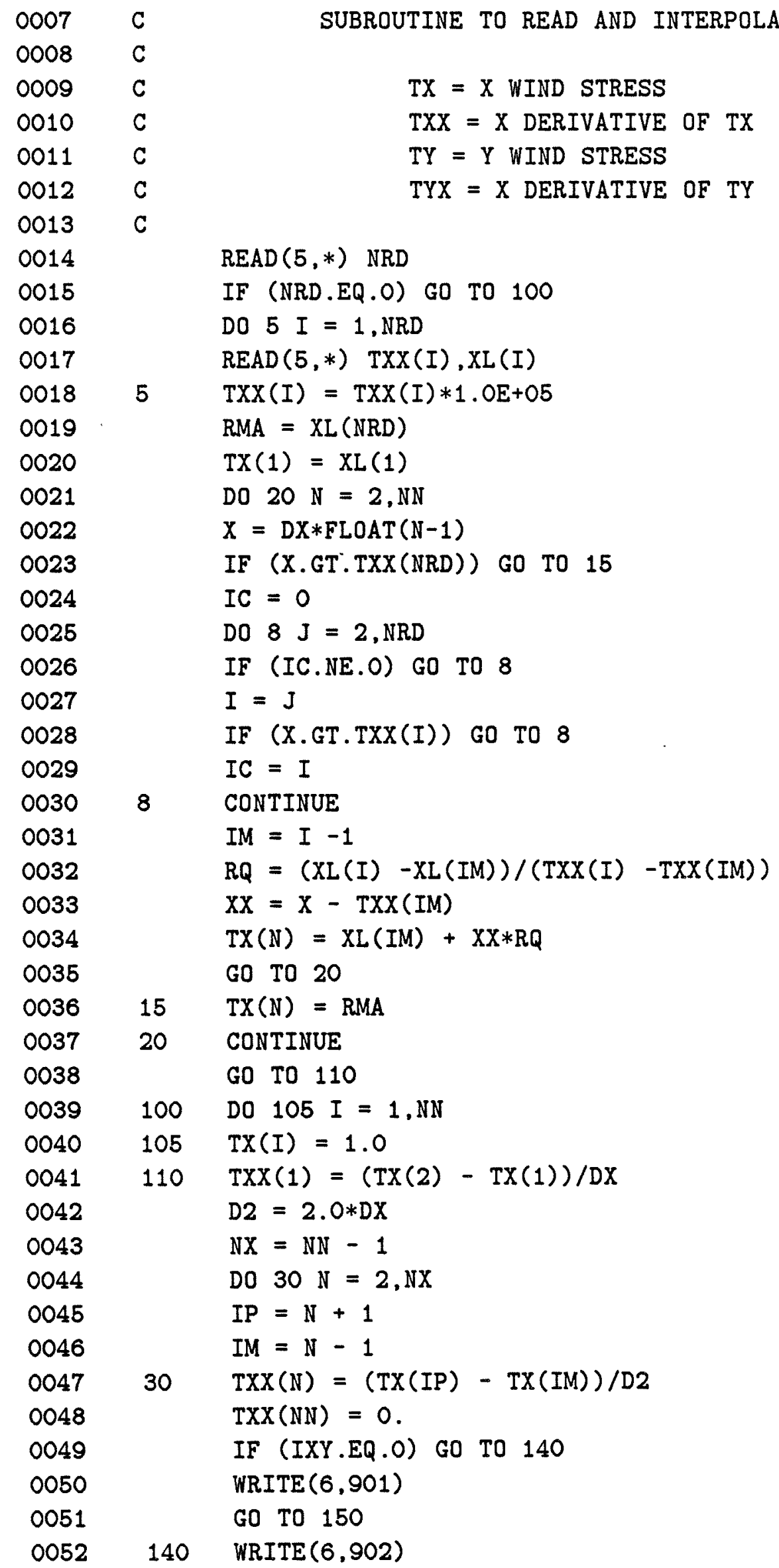




\begin{tabular}{|c|c|c|}
\hline 0053 & & DO $145 I=1, \mathrm{NN}$ \\
\hline 0054 & & $\operatorname{TY}(I)=\operatorname{TX}(I)$ \\
\hline 0055 & & $\operatorname{TYX}(I)=\operatorname{TXX}(I)$ \\
\hline 0056 & & $\mathrm{TX}(I)=0.0$ \\
\hline 0057 & 145 & $\operatorname{TXX}(I)=0$ \\
\hline 0058 & & $\operatorname{WRITE}(6,903) \quad(\mathrm{TY}(I), I=1, \mathrm{NN})$ \\
\hline 0059 & & GO TO 160 \\
\hline 0060 & 150 & DO $155 I=1, \mathrm{NN}$ \\
\hline 0061 & & $\operatorname{TY}(I)=0$ \\
\hline 0062 & 155 & $\operatorname{TYX}(I)=0$ \\
\hline 0063 & & $\operatorname{WRITE}(6,903) \quad(\operatorname{TX}(I), I=1, N N)$ \\
\hline 0064 & 901 & FORMAT $\left({ }^{\prime}\right.$ TAUX $($ DYNE/CM2)') \\
\hline 0065 & 902 & FORMAT (' TAUY $($ DYNE/CM2)') \\
\hline 0066 & 903 & FORMAT (1OE12.5) \\
\hline 0067 & 160 & RETURN \\
\hline 0068 & & END \\
\hline
\end{tabular}

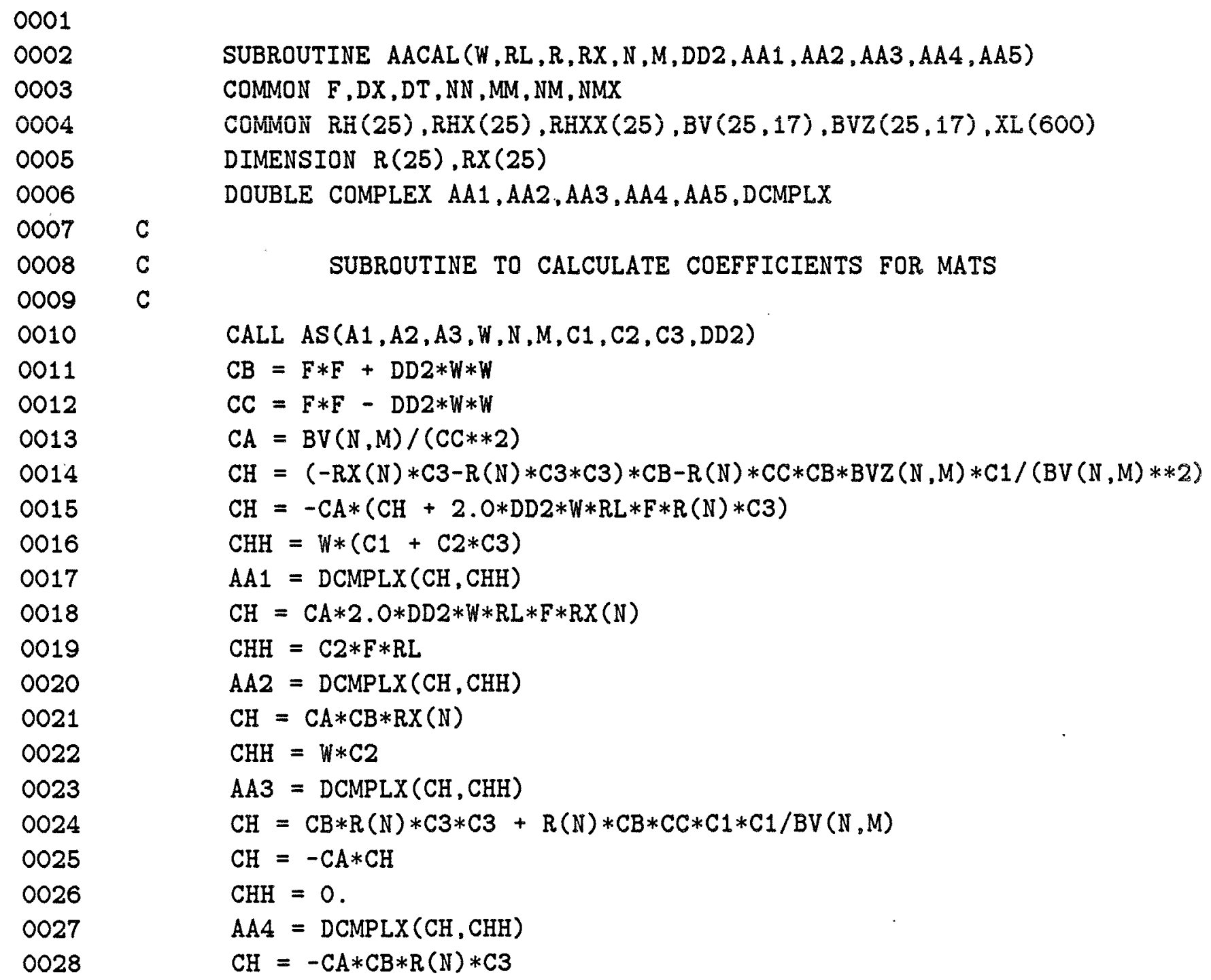


0029

0030

0031
$\mathrm{AA} 5=\mathrm{DCMPLX}(\mathrm{CH}, \mathrm{CHH})$

RETURN

END 



\section{I)OCUMENT LIBRARY}

November 21, 1986

\section{Distribution List for Technical Report Exchange}

Institute of Marine Sciences Library

University of Alaska

O'Neill Building

905 Koyukuk Ave., North

Fairbanks, AK

Attn: Stella Sanchez-Wade

Documents Section

Scripps Institution of Oceanography

Library, Mail Code C-075C

La Jolla, CA 92093

Hancock Library of Biology \& Oceanography

Alan Hancock Laboratory

University of Southern California

University Park

Los Angeles, CA 90089-0371

Gifts \& Exchanges

Library

Bedford Institute of Oceanography

P.O. Box 1006

Dartmouth, NS, B2Y 4A2, CANADA

Office of the International

Ice Patrol

c/o Coast Guard R \& D Center

Avery Point

Groton, CT 06340

Library

Physical Oceanographic Laboratory

Nova University

8000 N. Ocean Drive

Dania, FL 33304

NOAA/EDIS Miami Library Center 4301 Rickenbacker Causeway

Miami, FL 33149

Library

Skidaway Institute of Oceanography

P.O. Box 13687

Savannah, GA 31416

Institute of Geophysics

University of Hawaii

Library Room 252

2525 Correa Road

Honolulu, HI 96822

Library

Chesapeake Bay Institute

4800 Atwell Road

Shady Side, MD 20876
MIT Libraries

Serial Journal Room 14E-210

Cambridge, MA ()21:399

Director, Ralph M. Parsons Laboratory

Room 48-31 1

MIT

Cambridge, MA 02139

Marine Resources Information Center

Bldg. E38-320

MIT

Cambridge, MA 02139

Library

Lamont-Doherty Geological Observatory

Colombia University

Palisades, NY 10964

Library

Serials Department

Oregon State University

Corvallis, OR 97331

Pell Marine Science Library

University of Rhode Island

Narragansett Bay Campus

Narragansett, RI 02882

Working Collection

Texas A\&M University

Dept. of Oceanography

College Station, TX 77843

Library

Virginia Institute of Marine Science

Gloucester Point, VA 23062

Fisheries-Oceanography Library 151 Oceanography Teaching Bldg.

University of Washington

Seattle, WA 98195

Library

R.S.M.A.S.

University of Miami

4600 Rickenbacker Causeway

Miami, FL 33149

Maury Oceanographic Library

Naval Oceanographic Office

Bay St. Louis

NSTL, MS 39522-50)1

ATTN: Code 4601 


\begin{tabular}{|c|c|c|}
\hline $\begin{array}{l}\text { REPORT DOCUMENTATION } \\
\text { PAGE }\end{array}$ & $\begin{array}{l}\text { 1. REPORT NO. } \\
\text { WHOI-87-24 }\end{array}$ & 3. Recipient's Accession No. \\
\hline \multirow{2}{*}{\multicolumn{2}{|c|}{$\begin{array}{l}\text { 4. Title and Subtitle } \\
\text { Programs for Computing Properties of Coastal-Trapped Waves and } \\
\text { Wind-Driven Motions Over the Continental Shelf and Slope } \\
\text {-Second Edition- }\end{array}$}} & $\begin{array}{l}\text { 5. Report Date } \\
\text { June } 1987 \\
\end{array}$ \\
\hline & & 6. \\
\hline \multicolumn{2}{|c|}{$\begin{array}{l}\text { 7. Author(s) } \\
\text { Kenneth H. Brink, and David C. Chapman }\end{array}$} & $\begin{array}{l}\text { 8. Performing Organization Rept. No. } \\
\text { W HOI- } 87-24\end{array}$ \\
\hline \multirow{2}{*}{\multicolumn{2}{|c|}{$\begin{array}{l}\text { 9. Performing Organization Name and Address } \\
\text { Woods Hole Oceanographic Institution } \\
\text { Woods Hole, Massachusetts } 02543\end{array}$}} & 10. Project/Task/Work Unit No. \\
\hline & & $\begin{array}{l}\text { 11. Contract(C) or Grant(G) No. } \\
\text { (C) } \\
\text { (G) } \mathrm{OCE} 84-08563\end{array}$ \\
\hline \multirow{2}{*}{\multicolumn{2}{|c|}{$\begin{array}{l}\text { 12. Sponsoring Organization Name and Address } \\
\text { National Science Foundation }\end{array}$}} & $\begin{array}{l}\text { 13. Type of Report \& Period Covered } \\
\text { Technical }\end{array}$ \\
\hline & & 14. \\
\hline
\end{tabular}

\section{Suppiementary Notes}

This report should be cited as: Woods Hole Oceanog. Inst. Tech. Rept., WHOI-87-24.

16. Abstract (Limit: 200 words)

Documentation and listings are presented for a sequence of computer programs to be used for problems in continental shelf dynamics. Three of the programs are to be used for computing properties of free and forced coastal-trapped waves. A final program may be used to compute wind-driven fluctuations over the continental shelf and slope. This second edition includes several minor revisions and corrections in the computer code and the documentation.

17. Document Analysis a. Descriptors

1. coastal-trapped waves

2. wind-driven shelf currents

3. continental shelf

b. Identifiers/Open-Ended Terms

c. COSATI Field/Group

18. Availability Statemen:

Approved for publication; distribution unlimited.

19. Security Class (This Report)

-UNCLASSIFIED

20. Security Class (This Page)
21. No. of Pages 119

22. Price 
